\title{
Long-chain polyunsaturated fatty acids and child development
}

Citation for published version (APA):

Bakker, E. C. (2002). Long-chain polyunsaturated fatty acids and child development. [Doctoral Thesis, Maastricht University]. UM. https://doi.org/10.26481/dis.20020207eb

Document status and date:

Published: 01/01/2002

DOI:

10.26481/dis.20020207eb

Document Version:

Publisher's PDF, also known as Version of record

\section{Please check the document version of this publication:}

- A submitted manuscript is the version of the article upon submission and before peer-review. There can be important differences between the submitted version and the official published version of record.

People interested in the research are advised to contact the author for the final version of the publication, or visit the DOI to the publisher's website.

- The final author version and the galley proof are versions of the publication after peer review.

- The final published version features the final layout of the paper including the volume, issue and page numbers.

Link to publication

\footnotetext{
General rights rights.

- You may freely distribute the URL identifying the publication in the public portal. please follow below link for the End User Agreement:

www.umlib.nl/taverne-license

Take down policy

If you believe that this document breaches copyright please contact us at:

repository@maastrichtuniversity.nl

providing details and we will investigate your claim.
}

Copyright and moral rights for the publications made accessible in the public portal are retained by the authors and/or other copyright owners and it is a condition of accessing publications that users recognise and abide by the legal requirements associated with these

- Users may download and print one copy of any publication from the public portal for the purpose of private study or research.

- You may not further distribute the material or use it for any profit-making activity or commercial gain

If the publication is distributed under the terms of Article $25 \mathrm{fa}$ of the Dutch Copyright Act, indicated by the "Taverne" license above, 


\section{Long-chain polyunsaturated fatty acids and child development}


(c) Esther C. Bakker, Maastricht, 2002

Production: Datawyse/Universitaire Pers Mastricht ISBN 9052783357 


\title{
Long-chain polyunsaturated fatty acids and child development
}

\author{
PROEFSCHRIFT
}

ter verkrijging van de graad van doctor aan de Universiteit Maastricht, op gezag van de Rector Magnificus, Prof. Dr. A.C. Nieuwenhuizen Kruseman, volgens het besluit van het College van Decanen in het openbaar te verdedigen op donderdag 7 februari 2002 om 14.00 uur

door

\section{Esther Corina Bakker}

geboren te Hoorn op 19 juli 1973

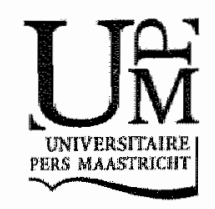




\section{Promotores:}

Prof. Dr. G. Homstra

Prof. Dr. C.E. Blanco

\section{Beoordelingscommissie:}

Prof. Dr. Ir. R.P. Mensink (voorzitter)

Prof. Dr. F. Hendrikse

Prof. Dr. J. Troost

Dr. P. Willatts (University of Dundee, UK)

Dr. H.A. Woltil (Rijksuniversiteit Groningen)
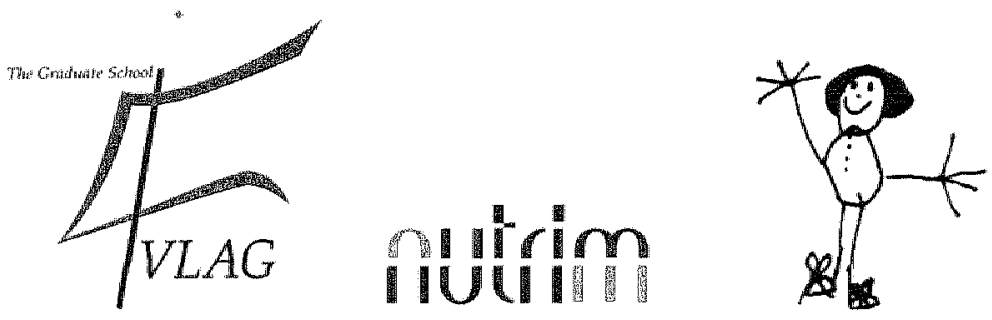

The studies presented in this thesis were part of the 'fatty acid follow-up study', performed at the Nutrition and Toxicology Research Institute Maastricht (NUTRIM), which participates in the graduate school VLAG (Food Technology, Agrobiotechnology, Nutrition and Health Sciences) accredited by the Royal Netherlands Academy of Arts and Sciences.

Studies of this thesis were supported by the University Hospital Maastricht (Profilerings Fonds: financial support) and Royal Numico, Wageningen, The Netherlands (blinded fatty acid analyses).

Financial support by the Stichting Dr. Meulemanfonds and the Dr. Ir. van de Laar Stichting for the publication of this thesis is gratefully acknowledged.

In addition, the author thanks Friesland Coberco Dairy Foods, Friesland Nutrition Research, Unilever Research Vlaardingen, Unilever Health Institute and Pie Medical Benelux B.V. for their financial support. 
Aan min ouders

Poom Roel en alle andere Kinderen 


\section{Contents}

Introduction 9

2 Long-chain polyunsaturated fatly acids at birth and cogninive function at 7 years of age

Infant breast or formula feeding and cognitive function at 7 years of age: the influence of docosahexaenoic acid status at birth

Long-chain polyunsaturated fatty acids at birth and motor function at 7 years of age term infants at 7 months of age

Long-chain polyunsaturated fatty acid status at term birth and visual function at 8 years of age

Summary

Samenvatting

Dankwoord 

1

\section{Introduction}


When talking about child development, the emphasis is often on the maturation of the central nervous system. Development of the human central nervous system already starts in the first embryonic weeks with the formation of the neural tube. The most rapid growth of nervous tissue takes place in the last intrauterine trimester and in the first year of life. However, its development goes on throughout hife. Nervous tissue, which originates from the neural tube, contains a high amount of lipids, up to $50 \%$ on a dry weight basis (about $10 \%$ of the fresh weight) $(1-3)$. These lipids can be classified into neutral hids (cholesterolesters and glycerides), glycolipids and phospholipids, and contain a wide variety of farty acids.

\section{Essential fatty acids and their long-chain polyunsaturated derivatives}

All fatty acids consist of a chain of carbon atoms with a methyl head group and a carboxyll tail group (COOH-). They differ from each other in length and structure of the carbon chain. Fatly acids can be saturated, monounsaturated or polyunsaturated, dependent on the number of double bonds between the carbon atoms $(0,1$ or more, respectively). More than one-third of brain fatty acids is polyunsaturated. There are various families of unsaturated fatty acids; the $n-6, n-3, n-9$ and $n-7$ families (also called $(\omega-6, \omega-3, \omega-9$ and $\omega-7$, respectively) are the most abundant ones. The number refers to the position of the first double bond counted from the methyl end of the molecule. A varicty of notations is avalable to indicate fatty acids. In this thesis, a system is used in which the first number refers to the number of C-atoms and the second number to the number of double bonds, followed by the family assignment. For example: arachidonic acid, written as 20:4n-6, contains 20 C-atoms and 4 double bonds, and belongs to the n-6 family (4). The n-9 and n-7 families can be synthesized de nowo. Mammals, however, lack the enzymes required to insert double bonds at n-6 or $n-3$ positions. Therefore, and regarding their role in the human body, fatty acids belonging to the n-6 family and the n-3 family are considered essential fatty acids and must be obtained through the diet. Linoleic acid ( $\mathrm{A}, 18: 2 n-6)$ is the parent $n-6$ fatty acid, while alpha-linolenic acid (ALA, 18:3n-3) is the parent fatty acid of the $n-3$ family. These parent fatty acids can be converted into longer-chain polyunsaturated fatty acids (LCPUFA) by chain elongation and desaturation*. Figure 1 shows the desaturation and elongation pathways in the synthesis of $n-6$ and n-3 LCPUFA, involving a series of desaturase and elongase enzymes. All fatty acid families utilize the same enzymes for desaturation, which results in competition between the fatty acid fimilies for the desaturase enzymes. The enzyme $\Delta 6$ desaturase, which inserts a double bond at the $6^{\text {th }}$ position from the carboxyl-end of the fatty acid, prefers to metabolize ALA above LA (5). However, substantial desaturation of latty acids of the m-6 family occurs, due to a relative abundance of $L A$. Only in case of $n-6$ and $n-3$ shotage, oleic acid (18:1n-9) will be converted to Mead acid (20:3n-9) and dihomoMend acid (22:3n-9). The presence of these derivatives thus indicates a relative deficiency of essential latty acids. Osbond acid $(22.5 n-6)$ is considered to be a marker of a not optimal n-3 status, since its production from $L A$ increases in case of $n-3$ shorage. Two LCPUPA, arachidonic acid (AA, 20:4n-6) and docosahexaenoic acid (OHA, 22:6n-3), are found in high amounts in the central nervous system (CNS) (2) and are thought to have an important role in CNS function.

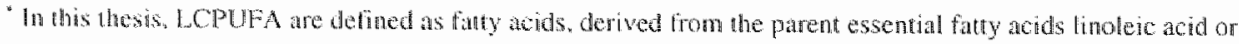
Alphin lnoknic wid, contaning alleast 20 carbon atoms and more double boumds than the parent essential fatty

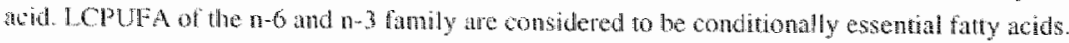


$n-6$ fomily

nus family

dilet

$18: 2 n-6$

$18: 3 n \cdots 3$

inoleic acid (LA)

atpha-linolenic acid (ALA)

delta 6 desaturation

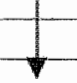

18:3n-6

gamma-linolenic acid

$18: 4 n-3$

stearidonic acid

elongation

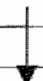

$20: 3 n-6$

$20: 4 n-3$

dihomo-gamma linolenic acid

\section{delta-5 desaturation}

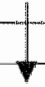

$20: 4 n-6$

arachidonic acid (AA)

$20 \cdot 5 n-3$

eicosapentaenoic acid (EPA)

\section{elongation}

$22: 4 n-6$

$22: 5 n-3$

adrenic acid

docosapentaenoic acic (DPA)

clongation

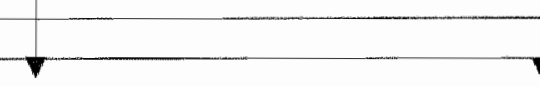

$24: 4 n-6$

$24: 5 n-3$

delta-6 desaturation

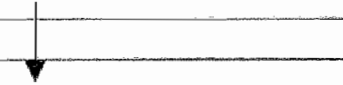

$24.5 n-6$

betaroxidation

$22: 5 \pi \cdots$

Osbond acid

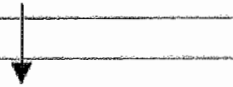

$24: 6 n-3$

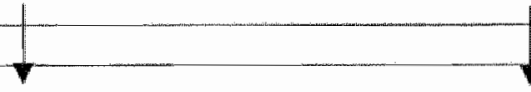

$22: 6 n-3$

docosahexacnoic acid (DHA)

Figure 1: The main pathways of $n-6$ and $n-3$ fatty acid conversion 
The parent fatly acid LA is found in most plant oils, whereas its derivative AA can be obtained from meat and has more recently been identified in some species of fungi. Dietary sources of ALA include green leaves and some seeds. The main source of DHA is fish (4).

\section{Essentiall fatty acid supply to the fetus}

The human fetus, like the adult, is unable to synthesize the essential fatty acids LA and ALA. Therefore, these essential fatty acids must be derived from the maternal circulation and, consequently, transferred across the placenta. The desaturation and elongation capacity of the human placenta itself is quite limited (6). The placental barrier is impermeable to phospholipids and triacylglycerols; fatty acids are transported from the maternal to the fetal circulation as free fatty acids $(7,8)$. Membrane-associated fatty acid binding proteins (FABP) most probably play a role in Whis transport by sequestration of matemal fatty acids in the placenta $(8,9)$.

The percentages of AA and DHA are higher in fetal blood compared with maternal blood, whereas the opposite is true for their precursors (10), which suggests the transfer of JCPUFA actoss the placenta to be selective (6). Evidence on the role of the placenta in the preferential accumulation of LCPUFA in fetal tissues has emerged from several studies $(8,11,12)$. Selective sequestration of matemal LCPUFA by placental FABP, located exclusively on the maternal-facing membranes of the placenta, may favor the unidirectional flow of these LCPUFA to the fetus (8). After cellular uptake, most of the DHA is esterified into triacylglycerol, whereas most of the AA is incorporated into phospholipid fractions (8). It is not known yet how and in what form DHA is released from the placenta into the fetal circulation.

The amount of fatly acids in the fetal blood is influenced by the maternal dietary fatty acid intake and, consequently, by the maternal blood values. Al et al. (13-15) found that the neonatal essential fatty acid status is strongly related to the maternal essential fatty acid status. They observed significant positive correlations between maternal and umbilical plasma levels for almost all $n-6$ and $n-3$ fatty acids. These and other results suggest that the fatty acid composition of the maternal dief can have an effect on the fatty acid delivery to the fetus $(12,15)$.

\section{Essential fatty acid supply to the neonate}

During the first postnatal months, human milk or artificial formulas are the only sources of mutrients and energy for the infant. Half of the total calories in both human milk and artificial formulas are provided by fat. The fatty acid composition differs considerably between these two types of infant nutrition (4).

The essential fatty acid composition of human milk varies with gestational age at parturition and stage of lactation, among others $(3,16,17)$. The LA percentage of mature breast milk lipids from well nourished mothers can vary from $4-16 \%$ (percentage of the total amount of fatty acids). Furthemore, human milk contains between 0.5-1 \% ALA and about $1 \%$ n-6 LCPUFA and $1 \%$ n-3 LCPUFA (3). Maternal dietary fatty acid intake influences these percentages. Breast milk from vegetarian women, for instance, contains significantly more LA than breast milk from omnivorous women (18). The levels of eicosapentaenoic acid (EPA, 20:5n-3) and DHA in human milk can be readily increased by maternal supplementation with fish oils or by diets containing marine lipids $(3,16)$.

The fatty acid composition of different infant formulas varies according the source of tat used: soybean oil, salflower or corm oil, among others. Most oils provide large 
amounts of $\mathbb{L A}$, but no $\mathrm{n}-6$ and $\mathrm{n}-3$ LCPUFA, in contrast with human milk (3). The most commonly used formulas for term infants in The Netherlands (Nutrilon Premium, Numico and Frisolac, Friesche Vlag) contain between 11.20 and $13.50 \mathrm{~g}$ LA and between 1.35 and $2.20 \mathrm{~g}$ ALA per $100 \mathrm{~g}$ total fatly acids. These amounts are somewhat higher than those found in human mik. However, the commonly used Dutch formulas do not contain n-6 and n-3 LCPUFA. Hence, intants fed exclusively with formulas have to synthesize all the LCPUFA needed for new membranes from the LA and ALA provided in the formula. It is not known, however, whether the fatty acid desaturation capacity of infants is high enough to meet their LCPUFA requirements.

LCPUFA in the infant diet clearly contribute to the fatty acid composition of the intant's plasma and red blood cell (RBC) phospholipids. Different studies (19-23) show that infants fed formula without LCPUFA have significantly lower levels of AA and DHA in plasma and RBC phospholipids than inlants led human milk. The influence of dietary LCPUFA on the lissue fatty acid composition will be discussed later in this chapter.

\section{Essential fatty acids in the central nervous system}

The high rate of central nervous system (CNS) growth in early development is known as the CNS growth spurt. The human CNS growth spurt extends from the beginning of the third trimester of gestation and continues for about 18 months after birth. At birth, the brain weighs aboul; $300-350 \mathrm{~g}$ and it increases to $1250-1500 \mathrm{~g}$ in adults. Most of this growth occurs during the first year, when the weight increases from $350 \mathrm{~g}$ to about $1000 \mathrm{~g}(24)$. A disruption of the CNS growil process can lead to structural changes in the CNS, which are often irreversible and can result in functional deficits. Nutritional factors, like fatty acid supply, may interfere with developmental processes during this critical period $(25)(3,4)$.

LCPUFA, especially AA and DHA, are found in high concentrations in structural lipids of the central nervous system. The highest concentrations of AA and DHA are found in the synapse membranes and in the phospholipids of the retina (3). During the third trimester of fetal development, rapid accretion of these LCPUFA occurs, and this continues after birth (26-28). The absolute accretion rates of the $n-3$ fatly acids are greater in the prenatal period compared with the postnatal period, whereas for the other fatty acids the postnatal accretion rates exceeds the prenatal rates $(26,27)$.

The central nervous system can derive its fatty acids in two ways. First, LCPUFA can be synthesized by the nervous system itself, through desaturation and elongation of LA and ALA lrom plasma. However, the degree to which the human fetus and newborn are able to desaturate and elongate these parent essential fatly acids to their respective LCPUFA is presently unclear. Second, LCPUFA, which are symthesized by other tissues or derived from the diet, can be transported from plasma to the brain. Both LA, ALA and the n-6 and n-3 LCPUFA can pass the blood-brain barrien as free fatty acids. The uptake of LCPUFA by the brain is higher than the uptake of LA and ALA. This suggests that the developing central nervous system prefers 10 obtain preformed $\mathbb{L C P U F A}(4)$.

As discussed, prenatal fally acid accretion in the CNS requires transport of these fatty acids via the placenta and the fetal circulation to the developing nervous tissue. The sources of postnatal fatty acid supply are human milk or artificial formula. The next paragraph discusses the association between pre-and postnatal fatty acid supply and the fatty acid concentrations of the developing brain. 


\section{Effect of dict on fatty acid composition of the brain}

Although the brain is generally considered resistant to structural changes induced by endogenous or exogenous factors, research has shown that nutritionally adequate diets with different compositions of dietary fats can influence the fatty acid composition of structural lipids in brain membranes and a wide variety of rnembrane functions (29).

Animal studies have repeatedly shown that brain phospholipid fatty acid composition can be influenced by diet. With increasing dietary LA/ALA ratios or decreasing n-3 fatty acid intakes, the level of DHA declines, while the level of Osbond acid rises (30-32). In humans, few studies have looked at the influence of dietary fatty acids on the fatty acid composition of membrane phospholipids in the brain. Farquharson et al. (33) determined the phospholipid fatty acid composition of cerebral parietal cortex gray matter of 20 term and 2 preterm infants who had died of "sudden infant death syndrome" and related the results to the milk diet the infants had received. Breastfed infants had greater weight percentages of: DHA in their cerebral cortex phospholipids than infants fed different formulas $(9.7 \%$ compared with $6.6-7.6$ $\%$, respectively). In formula-fed infants, the relatively low levels of DHA were "compensaled' for by significantly higher incorporation of $\mathrm{n}-6$ fatty acids, namely, AA, adrenic acid (22:4n-6) and Osbond acid (22:5n-6), compared with the breastfed group (33). Further analysis of individual phospholipid classes (phosphatidylethonolamine (PE), phosphatidylserine (PS) and phosphatidylcholine $(\mathrm{PC})$ in cerebral cortex of 16 infants again revealed lower DHA values in infants fed different formulas (PE: 11.6-13.4\%; PS: 14.4-19.3\%, PC < 0.6\%) than in breastfed infants (PE: $17.7 \%$, PS: $23.5 \%, \mathrm{PC}<0.6 \%$ ) with the difference again made up by $n-$ $6 \operatorname{LCPUFA}(24,34)$

Makrides et al. (22) dettected higher percentages of DHA in frontal cortex total lipids of breastfed term infants $(8.5 \%$ ) as compared with that of formula-fed infants (7.5\%). The length of breastfeeding was a major factor influencing the proportion of cortex DHA up to 48 weeks postnatal age. In addition to brain fatty acid composition, they also determined the fatty acid composition of red blood cells (RBC). Breastfed infants had at greater percentage of DHA in their RBC $(4.3 \%)$ relative to those fed formulas $(3.0 \%)$. Both age at death and RBC-DHA were significantly associated with the percentage of cortex DHA (22).

Studies on the influence of maternal dietary fatty acid intake on human fetal brain fatty acid composition have not been reported, but since good correlations are found between blood and brain values (22) and since the amount of fatty acids in the fetal blood is influenced by the maternal dietary fatty acid intake (15), it seems likely that fetal brain fatty acid accretion can be influenced by maternal dietary fatty acid supply. In rats the level of DHA in brain PE and PS of fetuses from dams fed fish oil was higher than in fecuses from control group dams at 19 and 21 days of gestation, whereas levels of AA were lower in the fish oil group (35). Thus, it seems likely that maternal dietary fatly acid intake influences fetal brain fatty acid composition.

\section{Brain function in relation to LCPUFA supply}

It can be concluded that phospholipid fatty acid composition of the developing CNS, which is very rich in LCPUFA, is likely to be influenced by the diet. The lunctional implications of these changes in brain structural lipids are still uncertain. Both in premature (36-47) and term (48-56) infants, dietary LCPUFA have been shown to improve some aspects of the function of the cerebral cortex and retina. 
However, other studies failed to show an effect $(57-60)$. One study even found a negative effect of LCPUFA-supplementation (61). Moreover, some benefits of LCPUFA seem to be transient (62-64), though the long-term effects of LCPUPA supply on cognitive and visual performance in children still have to be investigated. Indirect arguments for a role of mutritional factors, like LCPUPA, in the long-tem functional development of the central nervous system come from studies showing long-term $1 Q$ differences between children fed either artificial formulas without LCPUFA or human milk, which contains LCPUFA (65-75).

All mentioned studies investigated the influence of postnatal fatty acid supply. Since the absolute accretion rates of the n-3 fatty acids are even greater in the prenatal period compared with the postnatal period $(26,27)$, it can be hypothesized that prenatal LCPUFA supply might also be important for CNS development. This prenatal supply takes place via transport through the placenta, and may, therefore, be influenced by the maternal dietary fatty acid intake. The fatty acid intake of pregnant women varies and this is rellected in the neonatal farty acid status (13-15).

\section{Aim of the study and outline of thesis}

The ain of the studies described in this thesis was to investigate the relation between early LCPUFA avalability and later cognitive, motor and visual function. The association between these aspects of development and the prenatal LCPUFA avalability was investigated by a follow-up measurement at 7 or 8 years of age (Chapter 2, 3, 4 and 7). Umbilical venous plasma LCPUFA percentages were taken as indicators for the prenatal availability of these fatty acids. The potential influence of postnatal dietary LCPUFA supply on later development was studied by comparing the performance of children fed standard artificial formulas without LCPUFA with that of children fed human milk, which contains LCPUFA. Furthermore, the relation between LCPUFA availability in plasma at 7 years of age and developmental outcomes at 7 or 8 years of age was also investigated.

The relation between the cognitive performance at 7 years of age, including the school achievement scores, and the LCPUFA percentages at birth is described in Chapter 2. Due to the long period between birth and follow-up, variables like socioeconomic status and parental skills, among others, may potentially confound this relation. Therefore, they were included in our statistical andyses. In this study, we also looked at the relation belween LCPUFA availability in plasma at 7 years of age and the cognitive outcomes at 7 years of age. In Chapter 3 we compared the cognitive performance at 7 years of age of children red exclusively with standard artificial formulas in infancy with that of breastfed children. The non-random design of this study again obliged us to correct for many potential confounders. Furthemone. the influence of the initial DHA status at birth on the relation between infant feeding type and cognitive performance was studied. Chapter 4 focuses on the motor development in relation to LCPUFA status at birth and at 7 years of age. Two aspects of motor development were studied: the ability of the child to perform movements and the quality of the movements. Chapter 5 gives a review of the literature on the association between dietary DHA and infant visual function and serves as an introduction 10 the next two chapters. Chapter 6 addresses the relation between visual acuity of term infants at 7 months of age and the LCPUFA percentages in plasma and red blood cell phospholipids at this age. Furthermore, the viswal acuity and fatty acid status of formula-fed infants was compared with that of breastfed infants. The visual function at 8 years of age is the subject of Chapter 7 . Several aspects of visual 
function are addressed in this chapter, and they are all studied in relation to LCPUFA siatus at birth and at 7 years of age, and to the type of infant feeding. Finally, in Chapter 8 the results of the sudies reported in this thesis and their possible consequences are discussed.

\section{Literature}

1. O'Brien JS. Fillerup DL, Mead JF. Quantification and fatty acid and fatty aldehyde composition of thanolumine, choline, and serine glycerophosphatides in human cerebral grey and white matter. J Lipid Res 1964;5:329-38.

2. Sastry PS. Lipids of nervous nissue: composition and metabolism. Prog Lipid Res 1985:24:69. 176.

3. Innis SM. Essential fatly acids in growth and development. Prog Lipid Res 1991;30:39-103.

4. Jumpsen $J$, Clandinin MT. Brain development: Retationship to dietary lipid and lipid metabolism. Champaign, Illinois: AOCS Press: 1995.

5. Holman R'T Nutritionall and metabolic interrelationships between fatty acids. Fed Proc $1964 ; 23: 1062-7$.

6. Kuhn DC, Crawford M. Placental essential faty acid transport and prostaglandin synthesis. Prog Lipid Res $1986 ; 25: 345-53$.

7. Robertson AF, Sprecher H. A review of human placental lipid metabolism and transport. Acta Paediatr Scand 1968:183:S3-18.

8. Dutla-Roy AK. Transport mechanisms for long-chain polyunsaturated fatty acids in the human placenta. Am J Clin Nutr 2000;71:S315-22.

9. Stremmel W, Kleinert H, Fitscher BA, Gunawan J, Klasssen-Schluter C, Moller K. Wegener M. Mechanism of cellular fatty acid uptake. Biochem Soc Trans 1992;20:814-7.

10. Crawford MA. Hassam $A G$, Williams $G$. Essential fatty acids and fetal brain growth. Lancet $1976: 1: 452-3$.

11. Haggarly P. Page $K$, Abramowich DR. Ashton J, Brown D. Long-chain polyunsaturated fatty acid transport across the perfused human placenta. Placenta 1997;18:635-42.

12. Haggarty P. Ashton J, Joynson M, Abramovich DR, Page K. Effect of matemal polyunsaturated fatty acid concentration on transport by the human placenta. Biol Neonate 1999:75:350-9.

13. Al MD, Hornstra G, van der Schouw YT, Bulstra Ramakers MT, Huisjes HJ. Blochemical EFA status of mothers and their neonates after normal pregnancy. Early Hum Dev 1990:24:239-48.

14. AI MDM. Houwelingen ACv, Kester ADM. Hastart RHM, Jong EAPd. Hornstra G. Maternil essential fatty acid pattern during normal pregnancy and their relationship to neonatal essential fally acid status. Br J Nutr 1995:74:55-68.

15. Al MD. Badan Smook A, von Houwelingen AC, Hasaart TH. Homstra G. Fat inake of women during nomal pregnamey: relationship with maternal and neonatal escential fatty acid status. I Am Coll Nutr 1996:15:49-55.

16. Miakricles M. Neumann MA, Gibson RA. Effect of maternal docosahexaenoic acid (DHA) supplkmentation on breast milk composition. Eur J Clin Nutr 1996:50:352-7.

17. Bitman J. Wood L, Hamosh M. Hamosh P. Mehta NR. Comparison of the lipid composition of breast milk from mothers of term and preterm infants. Am J Clin Nutr 1983;38:300-12.

18. Sanders TA, Reddy $S$. The influence of a vegetarian diet on the fatty acid composition of human milk and the essential fatty acid status of the infant. J Pediatr 1992;120:571-7.

19. Bakker EC, van Houwelingen AC, Hornstra G. Early nutrition, essential faty acid status and visual acuity of term infants at 7 months of age. Eur J Clin Nutr 1999;53:872-9.

20. Innis SM. Plasma and red blood cell fatty acid values as indexes of essential fatty acids in the developing organs of infants fed with milk or formulas. J Pediatr 1992;120:S78-86. 
21. Imnis SM. Akrabawi SS. Diersen Schade DA. Dobson MV, Guy DG. Visual acuty and blood lipids in term infants fed humarn milk or formulae. Lipids 1997:32:63-72.

22. Makrides M. Neumann MA, Byard RW. Simmer R. Gibson RA. Faty acid composition of brain, retina, and erythrocytes in breast-and formula-fed infants. Am J Clin Nutr 1994:60:189. 94.

23. Makrides M. Neumann MA, Smmer K, Gibson RA. Erythrocyte faty acids of tem infants fed either breast milk, standard formula, or formulit supplemented with long-chain polyunsantates. Lipids $1995 ; 30,941-8$

24. Farqubarson J. Infant cerebral cortex and dietary faty acids. Eur J Clin Nutr 1994:48:S24-6.

25. Reisbick S. Neural Development. In: Carlson S, Netringer M. Reisbick S, editors. Assessment of infant visual and cognitive function in relation to long chan polyunsaturated fatty acids. Basel: Editiones Roche; 1996. p. 10-8.

26. Clandinin MT, Chappell JE, Leong S, Heim T, Swyer PR, Chance GW. Intraterine fatty acid accretion rates in human brain: implications for faty acid requirements. Early Hum Dev $1.980 ; 4: 121-9$.

27. Clandinin MT, Chappell JE, Leong S, Heim $\mathbb{T}$, Swyer PR, Chance GW, Extraterine fanty acid accretion in infant brain: implications for fatty acid requirements. Early Hum Dev 1980;4:1318.

28. Martinez M. Tissne levels of polyunsalurated fatty acids during early human development, Pediatr 1992;120:5129-38.

29. Clandinin MT, Jumpsen J, Suh M. Relationship between fatty acid accretion. membrane composition, and biologic functions. J Pediatr 1994:125:S25-32.

30. Carlson SE, Carver JD, Honse SG. High fat diets varying in ratios of polyunsaturated to saturated faty acid and linoleic to linolenic acid: a comparison of rat neural and red cell niembrane phospholipids. J Nutr 1986;116:718-25.

31. Neuringer M, Connor WE, Lin DS, Barstad L, Luck S. Biochenical and functional effects of prenatal and postnatal omega 3 fatty acid deficiency on retina and brain in rhesus monkeys. Proc Natl Acad Sci U S A 1986;83:4021-5.

32. Bourre JM, Bonneil M, Dumont O, Piciotti M, Nalbone G. Lafont H. High dietary fish oil alters the brain polyunsaturated fatty acid composition. Biochim Biophys Acta 1988;960:458-61.

33. Farquharson J, Cockburn F. Patrick WA, Jamieson EC, Logan RW. Infant cerebral cortex phospholipid fatty acid composition and diet. Lancet 1992,340:810-3.

34. Farquharson J. Jamieson EC. Abbasi KA. Patrick WJ, Logan RW, Cockburn F. Effect of dius on the faty acid composition of the major phospholipids of infant cerebral cortex. Arch Dis Child 199:5;72:198-203.

35. Yonekubo A. Honda S, Okano M, Takathashi K. Yamamoto Y. Dietary fish oil alters rat milk composition and liver and brain fatty acid composition of fetal and neonatal rats. I Nutr $1993: 123: 1703-8$.

36. Uaty RD, Birch DG, Birch EE, Tyson JE, Hoffman DR. Effect of dietary omega-3 fanty acids on retinal function of very-low - birth-weight neonates. Pediat Res 1990;28:485-92.

37. Bjerve KS. Thoresen L. Bonaa K, Vik T, Johnsen H. Brubakk AM. Clinical studies with at phalinolenic acid and long-chain n-3 fatty acids. Nutrition 1992:8:130-2.

38. Birch EE, Birch DG. Hoffman DR. Uauy R. Dietary essental fatly acid supply and visual acuity dewelopment. Invest Ophthalmol Vis Sci 1992:33:3242-53.

39. Birch DG. Birch EE. Hofman DR, Uauy RD. Retimat development in very-low-bith-weight infants fed diets differing in omega-3 faty acids. Invest Ophualmot Vis Sci 1992,33:2365-76.

40. Bjerve KS, Brubakk AM. Fougner KJ, Johnsen H. Midthjell K. Vik T. Omega-3 fally acids: essential fatty acids with important biological effects, and serum phospholipid fatly acids as markers of dietary onega 3-fatty acid intake. Am J Clin Nutr 1993;57:S801 -5. 
41. Carlson SE. Werkman SH. Rhodes PG. Tolley EA. Visual-acuity development in healthy preterm infants: effect of marine-oil supplementation. Am J Clin Nutr 1993;58:35-42.

42. Carlson SE. Werkman SH, Peeples IM. Wilson WM. Growth and development of premature in lants in relation to omega 3 and omega 6 fatty acid status. World Rev Nuts Diet 1994;75:639.

43. Carlson SE, Werkman SH. Peeples MM. Wison WM. Long-chan fatty acids and early visual and cognitive development of preterm infants. Eur J Clin Nutr 1994;48:527-30

44. Carlson SE, Werkman SF. A randomized trial of visual attention of preterm infants fed docosahexaenotic acid until wo months. Lipids 1996;31:85-90.

45. Carlson SE. Werkman SH, Tolley EA. Effect of long chain a 3 fatty acid supplementation on visual acuity and growth of preterm infants with and without bronchopulmonary dysplasia. Am JClin Nutr 1996;63:687-97.

46. Werkmath $\mathrm{SH}$, Carlson $\mathrm{SE}$. A tandomized trial of visual attention of preterm infants fed docosahexaenoic acid until nine months. Lipids 1996;31:91-7.

47. OConnor DL, Hatl R, Adamkin D. Auestad N. Casillo MI, Connor WE, Connor SL Fitzgerald K, Groh-Wargo S. Hartmann EE, Jacobs J, Janowsky J. Lucas A. Margeson D, Mena P. Neuringer M. Nesin M. Singer L, Stephenson T, Szabo J, Zemon V. Growth and development in preterm infants fed long-chain polyunsaturated fatty acids: a prospective, randomized controlled trial. Pediatrics 2001:108:359-71.

48. Agostoni C. Trojan S, Bellu R, Riva E, Giovanmini M. Neurodevelopmental quotient of healthy term infants at 4 months and feeding practice: the role of long-chain polyunsaturated fatty acids. Pediatr Res 1995;38:262-6.

49. Makrides M, Neumann M, Simmer K, Pater J, Gibson R. Are long-chain polyunsaturated fatty acids essential mutrients in infarcy? Lancet 1995;345:1463.8.

50. Carlson SE, Ford AJ, Werkman SH, Peeples WM, Koo WW. Visual acuity and fatty acid status of term infants fed human milk and formulas with and without docosalexaemoatte and anchidonate from egg yolk lecithin. Pediatr Res 1996;39:882-8.

51. Carlson S. LCPUFA and functional development of preterm and term infants. In: Bindels JG, Goedhart AC, Visser HKA, editors. Recent developments in infant nutrition. Dordrecht: Kluwer Academic Publishers; 1996. p. 218.24.

52. Birch EE, Hof frman DR, Uaty $R$, Birch DG, Prestidge $C$. Visual acuity and the essentiality of docosahexaenoic acid and arachidonic acid in the diet of term infants. Pediatr Res 1998:44:2019.

53. Willats P. Forsyth IS, DiModugno MK. Varma S. Colvin M. Eftect of long-chain polyunsaturated fattly acids in infant fomula on problem solving at 10 months of age. Lancet $1998: 352: 688.91$.

54. Willats $P$, Forsyth IS, DiModugno $M K$, Varma $S$, Colvin $M$. Influence of long-chain polynusantuated fatty acids on infant cognitive function. Lipids 1998;33:973-80.

55. Birch EE, Gatield S. Hofman DR. Uauy R. Birch DG. A randomized controlled trial of early dietary supply of long chatin polyunsaturated fatty acids and mental development in term infunts. Dev Med Child Neurol 2000:42:174-81.

56. Makrides M, Neumann MA. Simmer K, Gibson RA. A criticasl appraisal of the role of dietary long-chain polyunsaturated fatty acids on neural indices of term infants: a randomized. controlled trial. Pediatrics 2000; 105:32-8.

57. Auestad N, Montalto MB, Hall RT, Fitzgerald KM. Wheeler RE, Connor WE, Neuringer M, Connor SL. Taylor JA. Harmann EE. Visual acuily, erythrocyte fatty acid composition, and growth in tem infants fed formulas with long chain polyunsaturated fatty acids for one year. Pediatr Res 1997; $+1: 1-10$. 
58. Lucas A. Stafford M, Morley R. Abbot R, Stephenson T, Mac Fadyen U. Elias-Jones A. Clements H. Efficacy and safety of long-chain polyunsaturated farty acid supplementation of infant-formulla milk: a randonised trial. Lancet 1999;354:1948-54.

59. Makrides M. Neumann MA. Jeftrey B. Lien Ell. Gibson RA. A randonized trial of different ratios of linoleic to alpha-linolenic acid in the diet of term infants: effects on visual function and growth. Am I Clin Nutr 2000:71:120-9.

60. Auestad N, Halter R, Hall RT, Blater M. Bogle ML, Burks W, Erickson JR, Fingrerald KM. Dobsan V, Innis SM. Singer LT, Montalto MB, Jacobs JR, Qiu W. Bornstein MH. Growth and development in term infants fed long-chain polyunsaturated fatly acids: a double-masked. randomized, parallel, prospective, multivariate study. Pediatrics 2001:108:372-81.

61. Scon DT, Janowsky JS, Caroll RE. Taylor JA, Auestad N, Montalto MB. Formula supplementation with long chain polyunsaturated fatty acids: are there developmental benefits? Pediatrics 1998; 102:E59.

62. Gibson RA. Neumann MA. Makrides M. Effect of increasing breast milk docosahexaenoic acid on plasma and erythrocyte phospholipid faty acids and neural indices of exclusively breast fed infants. Eur J Clim Nutr 1997,51:578-84.

63. Agostoni C, Trojan S, Bellu R, Riva E, Bruzzese MG, Giovanmini M. Developmental quotient at 24 months and fatty acid composition of diet in early infancy: a follow up study. Arch Dis Child 1997;76:421-4.

64. Agostoni C, Marangoni F, Giovannini M, Riva E, Galli C. Long-chain polyunsaturated fatly acids, infant formula, and breastfeeding. Lancet 1998;352:1703-4.

65. Rodgers B. Feeding in infancy and later ability and attaiment: a longitudinal study. Dev Med Child Neurol 1978;20:421-6.

66. Lucas A. Morley R, Cole TJ, Lister G, Leeson-Payne C. Breast milk and subsequent intelligence quotient in children born pretern. Lancet 1992;339:261-4.

67. Morley R, Lucas A. Influence of early diet on outcome in preterm infants. Acta Paediatr Suppl 1994:405:123-6.

68. Rogan WJ, Gladen BC. Breast-feeding and cognitive development, Early Hum Dev 1993;31:181-93.

69. Taylor B. Wadsworth I. Breast feeding and child development at fuve years. Dew Med Child Neurol 1984;26:73-80.

70. Morley R, Cole TJ, Powell R, Lucas A. Mother's choice 10 provide breast milk and developmental oncome. Arch Dis Child 1988;63:1382-5.

71. Fergusson DM, Beautrais AL. Silva PA. Breast-feeding and cognitive development in the first seven years of life. Soc Sci Med 1982:16:1705-8.

72. Morrow-Tiucak M, Hade RH. Enhard CB. Breastfeeding and cognitive development in the first 2 years of life. Soc Sci Med 1988;26:635\%9.

73. Pollock II. Long-term associations with infant feeding in a clinically advantaged population of babies. Dev Med Child Neurol 1994;36:429.40.

74. Temboury MC. Otero A, Polanco I. Arribas $\mathrm{E}$. Influence of breast-feeding on the infant's intellectual development. I Pediatr Gastroenterol Nutr 1994:18:32-6.

75. Forey CD. Leech AM. Blackhall A. Infant feeding and mental and motor dewelopment at 18 months of age in firs born singletons. Int J Epidemiol 1995:24:521-6. 


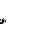




\section{2}

\section{Long-chain polyunsaturated fatty}

acids at birth and cognitive function at 7 years of age

Esther C. Bakker

Alex J.A. Ghys

Arnold D.M. Kester

Johan S.H. Vles

Judith S. Dubas

Carlos E. Blanco

Gerard Hornstra 


\begin{abstract}
During the central nervous system (CNS) growth spurt, rapid accretion of long chain polyunsaturated fatry acids (LCPUFA) takes place. This particularly concerns docosahexamoic acid (DHA: 22:6n-3) and arachidonic acid (A: 20:4n-6), which are thought to play important roles in CNS development and function. The aim of this study was to investigate the relation between cognitive performance at 7 years of age and LCPUF A levels in umbilical venous plasma phospholipids, representing the prenatal fatty acid availability, and in plasma phospholipids sampled at 7 years.

As part of a follow-up study, the cognitive performance of 306 children, borm at term, was assessed at 7 years of age with the Kaufman-Assessment Battery for Children. In addition the school achievement scores were obtained. Backward stepwise regression analysis was used to study the relation between the outcomes and LCPUFA status. Social class, maternal intelligence and parenting skills were included as covariables, among others.

Results show no significant association with either DHA or AA at birth and the cognitive performance at 7 years of age. The relations between the school achievement scores and umbilical plasma LCPUFA were not consistent. Only two significant negative relation were observed: umbilical plasma $A A$ was negatively associated with spelling, whereas umbilical plasma DHA was negatively associated with school arithmetic scores, but not with the arithmetic scores as measured with the Kaufman-Assessment Battery for Children. The LCPUFA levels at 7 years were not clearly associated with cognitive performance of school achievements either. Consistent with the literature, significant relations were found between cognitive outcome measures and maternal education, maternal intelligence and the child's birthweight.
\end{abstract}

In conclusion, our results do not provide evidence for a positive association between cognitive performance at 7 years and LCPUFA status at birth or at 7 years of age. 


\section{Introduction}

Two fatty acid families, the $n-3$ family and the $n-6$ family, are essential in humans. because they are necessary as constituents of membrane phospholipids and cannot be synthesized by the human body. The parent faty acids of these families, alphalinolenic acid and linoleic acid, respectively, have, therefore, to be supplied for by nutrition. Two of their long-chain, highly unsaturated derivatives, docosahexaenoic acid (DHA) and arachidonic acid (AA), account for up to $50 \%$ of the total fatly acids in the gray matter of the brain (1). DHA and AA accumulation mainly occurs during the last intrauterine trimester and continues in the first months after birth (2-4).

Indications for the functional importance of these long-chain polyunsaturated fatly acids (LCPUFA) in central nervous system (CNS) development came from studies comparing cognitive functions of children fed either artificial formulas or human milk. Human milk generally contains DHA and AA, whereas standard artificial formulas do not contain these LCPUFA. This difference in fatly acid composition may contribute to the known differences in cognitive function between formula and breasted children (5). This idea is supported by studies showing a lower brain DHA in infants fed artificial formulas as compared with human milk-fed infants (6-9).

Some randomized supplementation studies, comparing term infants fed either ICPUFA-enriched formulas or standard artificial formulas, showed beneficial effects of LCPUFA supplementation on visual or cognitive development (10-17). Other studies, however, did not confurm this $(18-22)$. One study even found lower language developmental scores in infants receiving LCPUFA-supplementation (23). In summary, resullts of these postnatal supplementation studies are not consistent.

Since the absolute accretion rates of the n-3 fatty acids are even greater in the prenatal period compared with the postnatal period $(2,3)$, it can be hypothesized that prenatal LCPUFA supply might also be important for later cognitive function. We, therefore, investigated the relation between cognitive function and school achevement at 7 years of age and the DHA and A levels in umbilical venous plasma, representing prenatal LCPUFA availability. In addition, we studied the association between cognitive performance and LCPUFA status at 7 years, as a measure of LCPUFA supply in later life.

\section{Methods}

Study population

The study described in this chapter is part of a prospective follow-up study investigating the relationship beween essential fatty acid status at birth and cognitue, visual and motor function at 7-8 years of age. The eligible study population consisted of 750 Caucasian children of 7 years old, born between December 1990 and January 1994 in the course of an earlier study on maternal and neonatal LCPUFA status and pregnancy outcome (24). Of these children we traced $728(97.1 \%)$, of which $3(0.4 \%)$ were deceased, and $34(4.5 \%)$ had emigrated. Eventually 691 (92.1\%) children were invited to participate in this study. In spite of several letters and repeated phone-calls, we did not receive any response from the parents of 133 children. The parents of 231 children did not give consent. The main reasons were lack of time and the concern of the parents that this study would burden their child too much. Writuen informed consent was obtained from 327 parents of the 691 invited children. During the study, 21 children dropped out, because they repeatedly did not show up for the appointmenis. Therefore, the ultimate follow-up study population consisted of 300 children. 
The sudy was approved by the Ethics Committee of the Unversity Hospital Maastrichuniversiteil Maastricht.

\section{Measurements of cognitive function and achievement}

Cognitive function was assessed with the Kaufman Assessment Battery for Children (K-ABC)(25), a standardized measure of intelligence and achievement. This multi-subtest battery consists of two scales, each measuring a different type of information processing: the "Sequential processing" scale and the 'Simultaneous processing" scale. Together, these scalles form the total score for cognitive performance: the 'Mental Processing Composite'. The K-ABC also measures different aspects of achievement. We only administered the subtest 'Arithmetic', because the other subtests were not appropriate for use in the Dutch population. The K-ABC was administered by a single well-trained tester (ECB) in a quiet room with blinded windows.

School achievement scores were obtained for reading, spelling and arithmetic according to the standard Dutch Cito-system (Central institute of test development, (26)). Achievements obtained in the child's first year of actual reading and arithmetic education were divided in quartiles, based on scores in a normative group of children: A (very good, highest quartile in normative group of children), B (good), C (moderate), D (weak, lowest quartile).

\section{Analyical procedurez and measurements}

Fatty acid profiles of umbilical venous plasma phospholipids were determined as described by Al et al (24). Analysis of the venous plasma samples taken at 7 years of age was slightly different, using the lipid extraction method of Bligh and Dyer (27) and a CP-sil 88 column (Chrompack ${ }^{6}, 50 \mathrm{~m} \times 0.25 \mathrm{~mm}$, film thickness $0.2 \mu \mathrm{m}$ ) with $5.0 \mathrm{He}$ as carrier gas (flow rate $0.7 \mathrm{ml} / \mathrm{min}$ ). The injection temperature was $250^{\circ} \mathrm{C}$ and the detection temperature $300^{\circ} \mathrm{C}$. The starting temperature of the column was $160^{\circ} \mathrm{C}$. After 10 minutes, the temperature increased up $10190^{\circ} \mathrm{C}$ with a rate of $3.2^{\circ} \mathrm{C} /$ minute and finally to $230^{\circ} \mathrm{C}$ with a rate of $5^{\circ} \mathrm{C} /$ minute. The split ratio was $5: 1$. Fatty acid data are presented as relative levels (\% of total fatty acids, wt/wt).

\section{Measurements of covariables}

The following lactors. which are important deteminants of intellectual development, were included as covariables in the analyses: social class (28), maternal intelligence $(29,30)$, parenting skills $(28,30)$, maternal smoking (31) and drinking habits during pregnancy (32), breasteeding duration (5) and the child's sex (33), birth order (34) and birthweight (35). Most of these data were collected by a questionnaire and an interview with the mother at follow-up. A three level classification of maternal cducation was used as an indicator for the variable social class, as has been done before in the Netherlands (36). In the statistical analyses two dummy variables (maternal education "high" and maternal education 'low', with maternal education "middlle" as reference) for maternal education were used. Maternal intelligence was tested with Raven's Siandard Progressive Matrices (37). Parenting skills were assessed using mothers" and fathers' self-report about the degree of attachment, responsiveness, affection, induction, conformity demands and punishment in the parent-child relation (38). Two parenting dimensions, derived by factor analysis on the six scales, were used in the statistical analyses: parental warmth and parental restrichve control. 
Table 1: Climical characteristics of the sudy population ( $\mathrm{a}=306$ )

\begin{tabular}{|c|c|c|}
\hline Variable & value & $\mathrm{n}$ \\
\hline \multicolumn{3}{|l|}{ parental characteristics } \\
\hline maternal age at delivery (yrs) & $29.8(4.1)$ & 306 \\
\hline maternal weight $(\mathrm{kg})$ & $65.5(11.2)$ & 289 \\
\hline maternal intelligence (correct answers on SPM out of 60 ) & $45.6(7.7)$ & 290 \\
\hline smoking during pregnancy (yes/no, o) & $30 / 70$ & 301 \\
\hline alcohol use during pregnancy $($ yes/mo, $\%)$ & $23 / 77$ & 300 \\
\hline maternal education (high/middle/low, \%) & $60 / 36 / 4$ & 289 \\
\hline paternall education (high/swiddle/low, 咆) & $61 / 36 / 3$ & 280 \\
\hline \multicolumn{3}{|l|}{ delivery } \\
\hline 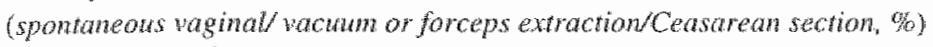 & $75 / 19 / 6$ & 306 \\
\hline parental warmeh & $0.0(0.84)$ & 223 \\
\hline parental restrictive control & $0.0(1.0)$ & 223 \\
\hline \multicolumn{3}{|l|}{ child characteristics } \\
\hline age at measurement. & $7.3(0.3)$ & 306 \\
\hline gender (boys/girls, os) & $56 / 44$ & 306 \\
\hline gestational age (weeks) & $39.8(1.6)$ & 305 \\
\hline birth order (first childother, of) & $66 / 34$ & 304 \\
\hline birth weight $(g)$ & $3304(5 \| 1)$ & 304 \\
\hline birth length (cm) & $49.9(2.4)$ & 280 \\
\hline head circumference at birch $(\mathrm{cm})$ & $34.3(1.7)$ & 256 \\
\hline Apgar score after 5 minutes & $96(0,9)$ & 302 \\
\hline infant feeding habits (human milkformular, \%) & $47 / 53$ & 305 \\
\hline
\end{tabular}

4 values are either mean (SD) or percentages of study population

† Standard Progressive Matrices of Raven (37)

$\ddagger$ Results of factor analyses, expressed in SD-anits

\section{Statistical analyses}

All data are expressed as means (SD). The relation between cognitive function of the children at 7 years of age and their fatty acid status at birth and at 7 years was investigated with backward stepwise multiple linear regression analyses, thereby identifying other significant predictors as well. The scores on the K-ABC (total Mental Processing Composite Standard Score, Simultaneous processing score and Sequential processing score) were the dependent variables and docosahexaenoic acid and arachidonic acid the (separate) independent variables. Social class (maternal education), maternal intelligence, parenting skills, maternal smoking and drinking habits during pregnancy, duration of breastfeeding, and the child's birth order, gestational age, birthweight, and gender were included as covariables in the initial model. In each step of the analyses the least significant covariable was removed from the regression model (after checking confounding), except for the fatty acid variable (either DHA or AA), which was always retained. This procedure resulted in a final regression model containing only the fatty acid variable and the significant predicting variables. To study the relation between school achievement scores and the fatty acid status, polytomous ordinal logistic regression analyses were used, again in a backward stepwise procedure. In the statistical analyses a $\mathrm{p}$-value of $<0.05$ was considered significant, unless mentioned otherwise. The statistical analyses were performed using the statistical computer programs StatView version 5.0 (SAS Institute Inc., Cary, NC) 
and SPSS version 10.0 .5 (SPSS Inc, only for the aralyses of school achievements). No studies on this subject have been published before, but power calculations indicate that our sample size of more than 300 children was sufficient to get a $90 \%$ chance of a significant result when the true correlation coefficient equals 0.20 . This chance would be $70 \%$ with a sample size of 150 children (in case of the school achievements scores).

\section{Results}

\section{Study population}

The study population consisted of 306 children, 170 boys and 136 girls, with a mean age of 7.3 years (range 6.6-8.1 years). The neurological function, as measured with a standard neurological examination, performed in 262 of the children by the child neurologist (JSHV), was within the normal range. Table 1 shows the clinical characteristics (mean $\pm S D$ ) of the participating children. There were no differences in baseline clinical characteristics between the participants and non-participants. However, a small difference in umbillcal plasma arachidonic acid percentages was found (16.6\% versus $16.9 \%$ for the paricipants and the non-participants, nespectively). This difference, although statistically significant, is considered clinically irrelevant. We were permitted to take a venous blood sample at follow-up of 261 of the 306 children. The essential fatty acid status at birth (in umbilical plasma phospholipids) and at 7 years of age (in venous plasma phospholipids) are given in Table 2. At 7 years of age the fatty acid values were comparable to adult values.

Table 2: Fatty acid composition of phospholipids of umbilical plasma and of venous plasma at?

\begin{tabular}{|c|c|c|}
\hline $\begin{array}{l}\text { Fatty acid" } \\
\text { (Fwitwt of total FA) }\end{array}$ & $\begin{array}{c}\text { umbilical plasma PL } \\
\text { mean (SD), } n=306\end{array}$ & $\begin{array}{c}\text { plasma PL at } 7 \text { years } \\
\text { mean }(\mathrm{SD}), \mathrm{n}=261\end{array}$ \\
\hline Total FA (mg/L) & $592.4(120.7)$ & $1060.3(147.8)$ \\
\hline $18: 2 n-6$ & $7.7(1.3)$ & $23.2(2.3)$ \\
\hline $20: 4 n-6$ & $16.6(1.6)$ & $9.2(1.2)$ \\
\hline $22: 5 n-6$ & $0.83(0.27)$ & $0.32(0.08)$ \\
\hline En-0 UCPUFA & $23.4(1.5)$ & $12.9(1.3)$ \\
\hline $18: 3 n-3$ & trace & $0.19(0.07)$ \\
\hline $20: 5 \mathrm{n}-3$ & $0.23(0.11)$ & $0.51(0.22)$ \\
\hline $22: 6 n-3$ & $0.1(0.14)$ & $2.8(0.7)$ \\
\hline EM-3 LCPUFA & $6.8(1.6)$ & $4.2(0.9)$ \\
\hline
\end{tabular}

* 18:2n-6=linoleic acid, 20:4n-6=atrachidonic acid. 22:5n-6=0sbond acid, $2 n-6$ LCPUFA =sum of the n-6 Long-chain Polyunsaturated faty acids $(20: 3,20: 4,22: 4,22: 5), 18: 3 n-3=a$ alpha-linolenic acid. $20: 5 n-3=$ eicosapentaenoic acid, 22:6n-3=docosahexaenoic acid, $\sum n-3$ LCPUFA=sum of the $n-3$ LCPUFA $(20: 5,22: 5,22: 6)$. PL $=$ phospholipids, FA=fatly acids.

\section{Cognitive function}

Total scores on the Kaufman.Assessment Battery for Children, the Mental Processing Composite, were available for 304 children; 2 boys refused to co-operate. The cognitive outcomes of all children, shown in Table 3 , were normally distributed. Figure I shows the total scores on the Kaufman-ABC, according to quartiles of umbilical plasma DHA or AA percentage, repectively. 
Talle 3: Cogrtive perfomance and achicuement soores

\begin{tabular}{|c|c|c|c|}
\hline Test & & Score* & n \\
\hline \multicolumn{4}{|c|}{ Cognitine Performance (Kawfonan-ABC) } \\
\hline & Mental Processing Composite & $107.3(11.9)$ & 304 \\
\hline & Sequential Processing & $101.9(12.3)$ & 304 \\
\hline & Simultaneous Processing & $109.4(11.8)$ & 304 \\
\hline & arithmetic & $113.1(10.8)$ & 235 \\
\hline \multicolumn{4}{|c|}{ School Acherenent Scores } \\
\hline & reading $(A / B / C / D$, ow $)$ & $39 / 27 / 2816$ & 148 \\
\hline & spelling $(A / B / C / D, W)$ & $60 / 20113 / 7$ & 159 \\
\hline & arithmetic $(A B / C D, \%)$ & $52 / 29114 / 5$ & 155 \\
\hline
\end{tabular}

* Mean (SD), except for the school achievement scores, where percentages of children are reported for the following categories: A, B, C and D, with A being the best score.

Backward stepwise multiple regression analyses for Mental Processing Composite, with either DHA or AA in umbilical plasma as independent variable (rotained in the model in each step) and social class (matemal education), maternal intelligence. parenting skills, maternal smoking and drinking habits during pregnancy, duration of breasteeding, and the child's birth order, gestational age, birthweight and gender as covariables in the initial model, resulted in a model with "maternal education" and "maternal intelligence" as the only significant predictors (see Table 4). In the model with DHA, "birthweight" was a significant predictor as well. The (corrected) associations between DHA or AA and the cognitive outcomes were not signilicant (partial $p=0.29$ and 0.60 respectively).

The same analyses with the subscalle "Sequential processing" resulted in models with "parental warmth" as significant covariable, in addition to the other significant predictors 'maternal education' and 'maternal intelligence' (see Table 5). Umbilical plasma DHA and AA, forced to remain in the model, were not related to Sequential processing at all (partial $p=0.90$ and 0.94 , respectively).

The regression models found for the subscale 'Simultaneous processing' after backward stepwise muliple regression analyses are shown in Table 6. Umbilical plasma DHA and AA did not correlate significantly with this outcome (partial $p=0,21$ for DHA, with "maternal education", "maternal intelligence' and 'birthweight" as significant covariables, and $\mathrm{p}=0.4 \|$ for $\mathrm{A} A$, with "maternal education" and "maternal intelligence' as significant covariables).

Comparable regression models, with the same significant predictors, were found for the two LCPUFA at 7 years of age (see Tables 4,5 and 6 , respectively). Again, DHA and $A A$ were not associated with the total score on the Kaulman-Assessment Battery for Children (partial $p=0.88$ and 0.82 , respectively). Similar analyses with the subscales 'Simullaneous processing" and "Sequential processing' also resulted in no significant associations between DHA and AA at 7 years and these outcomes (partial $p=0.62$ and 0.58 , respectively for Sequental processing and 0.48 and 0.71 , respectively for Simultaneous processingt. 

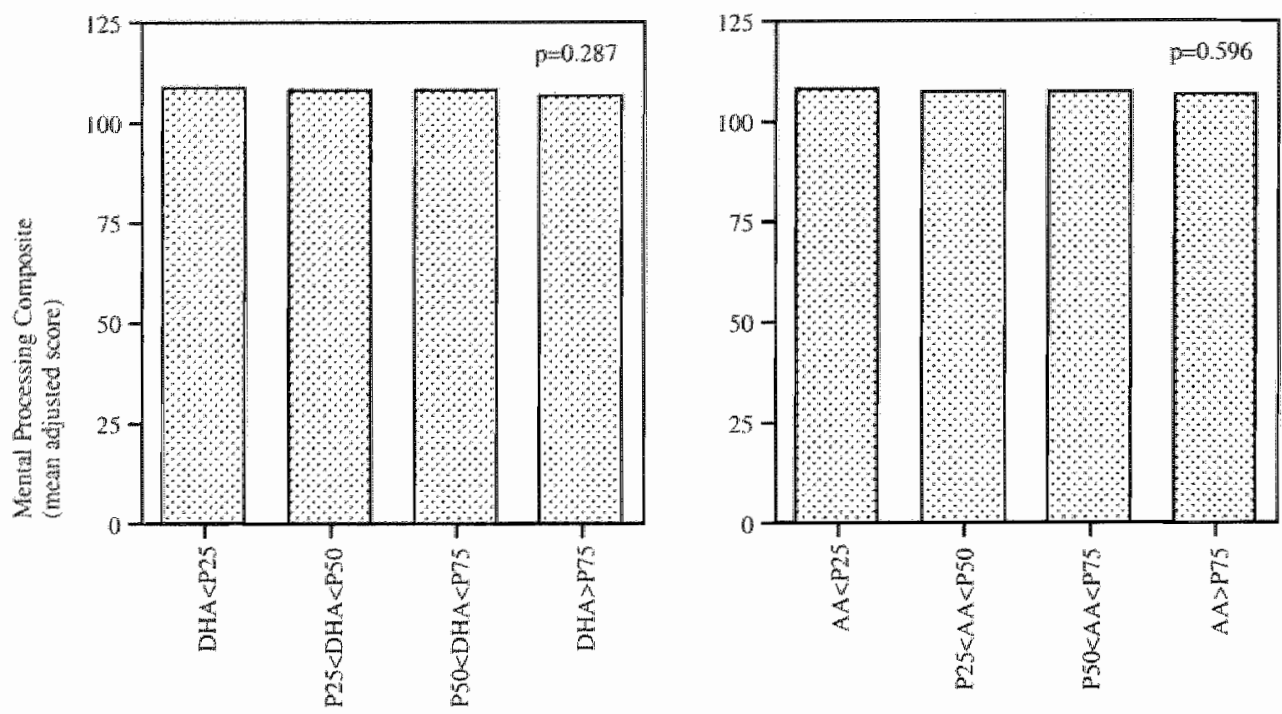

Figure 1: Mental Processing Composite scores at 7 years of age $(n=304)$, according to quartiles of umbilical plasma DHA or AA percentage, adjusted for maternal education, maternat intelligence and birthweight (ontly for DHA).

Talkle 4: Regression coefficients for the relation between LCPUFA status and Mental Processing Composite, corrected for covariables.

\begin{tabular}{|c|c|c|c|c|c|c|}
\hline \multirow{2}{*}{ Wariables in model } & \multicolumn{3}{|c|}{ umbilical plasna } & \multicolumn{3}{|c|}{ plasma at 7 years of age } \\
\hline & $B(S D)$ & Beta & p-value & $B(S D)$ & Beta & p-value \\
\hline DHA & $-0.517(0.48)$ & -0.06 & 0.287 & $-0.156(1.06)$ & -0.009 & 0.882 \\
\hline education (high) & $5.765(1.56)$ & 0,22 & 0.0003 & $5.814(1.73)$ & 0.22 & 0.0009 \\
\hline educution (low) & $-4.125(1.79)$ & -0.14 & 0.022 & $-3.710(1.96)$ & .0 .12 & 0.060 \\
\hline matern. intelligence & $0.283(0.09)$ & 0.18 & 0.002 & $0.285(0.10)$ & 0.19 & 0.005 \\
\hline bintrweight & $0.00(0.001)$ & 0.13 & 0.029 & & & \\
\hline AM & $-0.223(0.42)$ & -0.03 & 0.596 & $-0.136(0.58)$ & -0.01 & 0.815 \\
\hline educution (high) & $5.794(1.59)$ & 0.22 & 0.0003 & $5.738(1.72)$ & 0.22 & 0.001 \\
\hline education (low) & $-4.371(1.81)$ & -0.15 & 0.016 & $-3.684(1.95)$ & -0.12 & 0.060 \\
\hline matern. intelligence & $0.31 .40 .09)$ & 0.20 & 0.0008 & $0.288(0.10)$ & 0.19 & 0.004 \\
\hline
\end{tabular}

* results of backward stepwise multiple regression analyses, the initial models included 1.3 variables (docosahexaenoic acid status (DHA) or arachidonic acid status (AA, wht wt), two dummy variables for maternal education, maternal intelligence, parental warmtla, parental restrictive control, matemal smoking and drinking habits daring pregnancy, duration of breastfeeding, and the child's birth order, gestational age, birthweighi, and gender). B=regression coefficient. Beta=standardized regression coefficient. 
Table 5: Regression coefficients for the relation beiween LCPUFA status and Sequential Processing. corrected for covariables*.

\begin{tabular}{|c|c|c|c|c|c|c|}
\hline \multirow{2}{*}{ Variables in model } & \multicolumn{3}{|c|}{ umbilical plasma } & \multicolumn{3}{|c|}{ Mlasma at 7 years of age } \\
\hline & $\mathrm{B}(\mathrm{SD})$ & Beta & $\beta$-value & $\mathrm{B}(\mathrm{SD})$ & Beta & p-value \\
\hline DHA & $-0.072(0.52)$ & -0.008 & 0.891 & $0.584(1.17)$ & 0.03 & 0.617 \\
\hline education (high) & $5.357(1.74)$ & 0.19 & 0.002 & $5.686(1.90)$ & 0.20 & 0.003 \\
\hline education (low) & $-2.776(2.01)$ & -0.09 & 0.168 & $-1.617(2.17)$ & -0.05 & 0.457 \\
\hline matern. intelligence & $0.287(0.10)$ & 0.18 & 0.005 & $0.258(0 . \| 1)$ & 0.16 & 0.021 \\
\hline parental warmih & $2.516(0.88)$ & 0.17 & 0.005 & $2.412(0.95)$ & 0.16 & 0.012 \\
\hline $\mathrm{AA}$ & $0.035(0.47)$ & 0.004 & 0.940 & $0.356(0.64)$ & 0.04 & 0.578 \\
\hline education (high) & $5.388(1.76)$ & 0.19 & 0.002 & $5.879(1.90)$ & 0.21 & 0.002 \\
\hline education (low) & $-2.743(2.00)$ & -0.09 & 0.171 & $-1.688(2.16)$ & -0.05 & 0.434 \\
\hline matem intelligence & $0.288(0.102)$ & 0.18 & 0.005 & $0.249(0.11)$ & 0.16 & 0.023 \\
\hline parental warmtl & $2.530(0.89)$ & 0.17 & 0.005 & $2.494(0.94)$ & 0.17 & 0.009 \\
\hline
\end{tabular}

see table 4 for legend

Table 6: Regression coefficients for the relation between LCPUFA status and Simulaneous processing, corrected for covariables.

\begin{tabular}{|c|c|c|c|c|c|c|}
\hline \multirow{2}{*}{ Variables in model } & \multicolumn{3}{|c|}{ umbilical plasma } & \multicolumn{3}{|c|}{ plasma a 7 years of age } \\
\hline & $\mathrm{B}(\mathrm{SD})$ & Beta & p-value & $B(S D)$ & Betat & p-value \\
\hline DHA & $-0.610(0.48)$ & -0.07 & 0.206 & $-0.727(1.03)$ & -0.04 & 0.483 \\
\hline education (high) & $4.849(1.55)$ & 0.19 & 0.002 & $4.770(1.69)$ & 0.19 & 0.005 \\
\hline education (low) & $-3.853(1.77)$ & -0.13 & 0.031 & $-3.879(1.92)$ & -0.13 & 0.045 \\
\hline mutern. intelligence & $0.245(0.09)$ & 0.16 & 0.008 & $0.261(0.10)$ & 0.18 & 0.009 \\
\hline birthweiglat & $0.003(0.001)$ & 0.13 & 0.033 & & & \\
\hline AA & $0.340(0.41)$ & -0.05 & 0.413 & $-0.210(0.57)$ & -0.02 & 0.714 \\
\hline edication (high) & $4.978(1.57)$ & 0.19 & 0.002 & $4.559(1.69)$ & 0.18 & 0,008 \\
\hline education (low) & $-4.132(1.78)$ & -0.14 & 0.021 & $-3.728(1.9 \pi)$ & .0 .13 & 0.052 \\
\hline mutern. intelligence & $0.280(0.09)$ & 0.19 & 0.002 & $0.273(0.10)$ & 0.18 & 0.005 \\
\hline
\end{tabular}

see table 4 for legend

\section{Achievement scores:}

School achievement scores for reading, spelling and arithmetic were avalable from 148,154 and 158 children respectively. Not all schools administered these tos ts. Other schools administered the lest at another moment (c.g. after 2 years of reading education), or did repeatedly not respond to our call. Therefore, the school achievement scores of about half of the children were missing. Unfortunately, these children thad a lower intelligence (mean K-ABC score $=105 \pm 12$ ) than the children whose school achievement scores were known (mean $\mathrm{K}-\mathrm{ABC}$ score $=109 \pm 12$. $p=0.0035$ ). Maternal intelligence also differed between both groups (correct answers on the Standard Progressive Matrices of RAVEN: 44 versus $47, p=0.006$ ). Table 3 shows the frequency of the available school achievement scores (A through D) in the study population.

With polytomous ordinal logistic regression analyses, again used in a backward stepwise procedure, the relation between school achievement and DHA and AA at 
birth and at 7 years was analysed. The inital model contained the same covariables as mentioned earlier (social chass (matemal education), matemal intelligence, parenting skills, maternal smoking and drinking habits during pregnancy, duration of breastfeeding, and the child's birth order, gestational age, birthweight and gender). The analyses for reading resulted in final regression models with no significant contribution of umbilical plasma DHA or $\mathrm{AA}$ (partial $\mathrm{p}=0.40$ and 0.74 , respectively, with "matemal smoking habits during pregnancy' as significant negatively associated covariable and "maternal education" as significant positively associated covariables). The relation between DHA at 7 years of age and reading scores, corrected for the significant covariables 'maternal smoking habits during pregnancy' and 'maternal education', was positive and significant (partial $p=0.023$ ). There was no association between $A A$ at 7 years and reading ability (partial $p=0.21$, with 'matemal smoking habits as significant negative covariable).

Similar analyses for spelling yielded no significant association with umbilical plasma DHA (partial $p=0.554$, with 'matemal smoking habits during pregnancy" as significant negative covariable) and a negative association with umbilical plasma $A A$ $(p=0.021)$. The percentages of these two LCPUFA at 7 years showed no association with spelling at this age $(p=0.27$ for DHA and 0.11 for $A A)$.

The arithmetic scores achieved at school showed a negative relation with umbilical plasma DHA (partial $p=0.005$ ), corrected for the only covariable that appeared a significant (negative) predictor: "maternal smoking habits during pregnancy". Umbilical plasma arachidonic acid did not show an association with arithmetic scores (partial $p=0.77$, with "maternal education" as significant (positive) covariable). The same holds for DHA at 7 years (partial $p=0.32$, with 'maternal smoking habits' as significant negative covariable). Arachidonic acid at 7 years showed a negative relation with arithmetic (partial $p=0.02$ ), when corrected for the significant covariables "maternal smoking habits during pregnancy" (negative) and "maternal education" (positive).

Arithmetic was also measured with the Kaufman-Assessment Battery for Children. The scores on this measurement were neither related to the umbilical plasma DHA $(p=0.21)$ or AA values $(p=0.11)$, nor to DHA or AA values at 7 years of age $(p=0.60$ and 0.49 , respectively). Other significant predictors in these models, resulting from backward stepwise regression analyses, were "maternal education" and "alcohol consurmplion during prognancy", as well as 'birth weight' in the model with umbilical plasma DHA.

\section{Discussion}

The main aim of this study was to investigate the relation between cognitive function and achievement at 7 years of age and the DHA and AA levels in umbilical. venous plasma phospholipids, representing the prenatal LCPUFA availability. For this purpose we measured the cognitive function of 304 children at 7 years of age using the Katman-Assessment Battery for Children; school achievement scores were obtained from 159 children. Because of the large number of outcome variables and, conseguently, the large number of statistical analyses, the chance of a type I error is relatively lange. This implies that any significant relation could have been observed by chance and should, therefore, be interpreted with care.

The results showed no relation between umbilical plasma DHA or AA and cognitive performance as measured by the Kaufman-Assessment Battery for Children. The significant relations between this cognitive outcome measure and maternal 
ducation, maternal intelligence and the child's birthweight llustrates that we were able to find the same significant results with our methods as described in the literature $(28,29,35)$. School achievement scores for reading, spelling and arthmotic were analysed as well. Reading showed no significant relations with umbilical plasma LCPUFA. However, spelling showed a negative relation with umbilical plasma AA and school arithmetic scores a negative relation with umbilical plasma DHA. The arithmetic scores measured with the Kaufman-Assessment Battery for Children comelated significantly ( $p>0,0001$ ) with the school arithmetic scores, but did not show any correlation with umbilical plasma DHA values. Therefore, the negative correlation between umbilical plasma DHA values and school arithmetic scores may be chance finding, resulting from a type 1 error. As an additional argument for this, the significant relation between umbilical plasma DHA and school arithmetic scores seems to be the result of the high number of "low achievers" in the group of children with the highest DHA quartile (15 children scored a 'D') as compared with this number in the other DHA quartiles (on average, less than 2 children scored a " $D$ ' in the other quartiles).

As far as we know, publications about the relation between prenatal LCPUFA availability (measured by proxy) and cognitive performance in childhood are not available yet. The influence of postnatal LCPUFA supply on cognitive function in term infants has been investigated in several supplementation shdies $(10,11,15.19$, 21-23). Some randomized controlled LCPUFA trials in term infants younger than 12 months show a positive influence of dietary LCPUFA on cognitive function, as measured with different methods $(10,16,17)$. At 12 months of age, an influence of dietary LCPUFA on cognitive function was not observed $(15,18,22,23,39)$. Only one study reported an influence of LCPLFA in infant nutrition on the Mental Development Index (MDI, Bayley Scales of Infant Development) at 18 months of age (11). Other studies at 6 or 12 months (22), 18 months (19) or 24 months of age $(18,21)$ did not find differences in cognitive function between dietary groups with or without LCPUFA. This summary of the literature suggests that the influence of dietary LCPUFA on cognitive function might be transient. Nonetheless, as stated by Lucas et al (19), it is possible that other effects of early LCPUFA supply can be found in later life.

In long-term development, LCPUFA supply during later life can also play a role. Dietary LCPUFA may be associated to the LCPUFA concentrations in membrane phospholipids. Therefore, we also investigated the association between LCPUFA status at 7 years, as a measure of LCPUFA supply in later life, and cognitive performance at this age. With respect to the scores on the Kaulman-Assessment Battery for Children there was no significant contribution of DHA or AA at 7 years of age. These results are in line with the findings of Birch et al (11), reporting no conrelation between DHA at 12 months and developmental outcomes at 18 months. The associations we observed between the LCPUFA levels at 7 years of age and the school achievement scores at that age were not consistent. The only posilive correlation was between DHA and reading scores. A A showed a negative association with arithmetic, which was not present in the direct measurement of arithmetic with the Kaufman test.

In conclusion, our results do not provide evidence for a positive association between cognitive performance at 7 years and LCPUFA status either at birth or at 7 years of age. Because of the long period between measurement of the LCPUFA sLatus at birth and measurement of the cognitive outcomes, it can be assumed that other 
factors, not included in this study, exert an influence on childhood cognifive function. Since there are indications for a transient influence of dietary LCPUFA on cognitive function, there may be an association between prenatal LCPUFA avalability and cognitive performance at an earlier age. Moreover, other domains of development, e.g. visual or motor development, may possibly be associated with prenatal LCPUFA avallability.

\section{Literature}

1. OBrien JS, Fillenp DL. Mead JF. Quantification and fatry acid and fatty aldehyde composition of ethanolamine, choline, and serine glycerophosphatides in human cerebral grey and white matter. J Lipid Res 1964;5:329-38.

2. Clandinin MT, Chappell JE, Leong S. Heim T, Swyer PR, Chance GW. Intrauterine fatty acid accretion rates in human brain: implications for fatly acid requirements. Early Hum Dev $1980 ; 4: 121-9$.

3. Clandinin MT, Chappell JE, Leong S, Heim T, Swyer PR, Chance GW. Extrauterine fatty acid accretion in infant brain: implications for fatty acid requirements. Early Hum Dev 1980:4:1318 .

4. Martinez M, Mougan I. Fatty acid composition of human brain phospholipids during normal development. J Neurochem 1998,71:2528-33.

5. Anderson JW, Johnstone BM, Remley DT. Breast-feeding and cognitive development: a metaanalysis. Am J Clin Nutr 1999; 70:525 35.

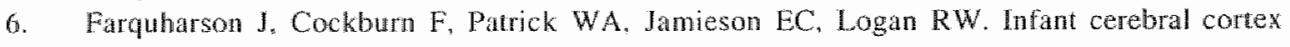
phospholipid fatty-acid composition and diet. Lancet 1992;340:810-3.

7. Farquharson J. Infant cerebral contex and dietary fatty acids. Eur J Clin Nutr 1994;48:524-6.

8. Farquharson J, Jamieson EC, Abbasi KA, Patrick WJ, Logan RW, Cockburn F. Effect of diet

* on the fatty acid composition of the major phospholipids of infant cerebral cortex. Arch Dis Child 1995;72:198-203.

9. Makrides M. Neumann MA, Byard RW, Simmer K. Gibson RA. Fatty acid composition of brain, retina, and erythrocytes in breast- and formulawed infants. An J Clin Nutr 1994;60:18994.

10. Agostoni C, Trojan S, Bellu R, Riva E, Giovannimi M. Neurodevelopmental quotient of healthy term infants at 4 months and feeding practice: the role of long-chain polyunsaturated fatty acids. Pediatr Res 1995;38:262-6.

11. Birch EE, Garficld S, Hofman DR, Uany R, Bitch DG. A randomized controlled trial of early dietary supply of long-chain polyunsaturated fatly acids and mental development in term infants. Dev Med Child Neurol 2000;42:174-81.

12. Makrides M. Neumann M, Simmer K, Pater J, Gilyson R. Are long-chain polyunsaturated fatty acids essentiat mutrents in infancy" Lancet 1995;345:1463-8.

13. Carlson SE. Ford AI, Werkman SH. Peeples JM. Koo WW. Visual acuity and fatty acid status of lerm infants fed human milk and formulas with and without docosahexaenoate and mrachidonate from egg yolk lecithin. Pediatr Res 1996:39:882-8.

14. Birch EE, Hofman DR, Uay $\mathbb{R}$, Birch DG, Prestidge $C$. Visual acuity and the essentiality of docosathexaenoic acid and arachidonic acid in the diet of term infants. Pediatr Res 1998;44:2019.

15. Carlson S. LCPUFA and functional development of preterm and term infants. In: Bindels JG, Goedhart AC. Visser HKA, editors. Recent developments in infant nutrition. Dordrecht: Kluwer Academic Publishers: 1996. p. 218-24. 
16. Willatts $P$. Forsyth IS, DiModugno MK, Varma S. Colvin M. Effect of long-chain polyunsamated fatty acids in infant formula on problem solving at 10 months of age. Lancet 1998:352:688-91.

17. Willats P. Forsyth IS. DiModugno MK, Warma S, Colwin M. Influence of long-chain polyunsaturated faty acids on infant cognitive function. Lipids $1998,337973-80$.

18. Makrides M, Neumann MA. Simmer K. Gibson RA. A critical appraisal of the role of dietary long-chain polyunsaturated fatty acids on neural indices of term infants: a randomized. controlled trial. Pediatrics 2000: 105:32-8.

19. Lucas A, Stafford M, Morley $\mathbb{R}$, Abbott R, Stephenson T, MacFadyen U. Elias-Jones A. Clements H. Efficacy and safety of long-chain polyunsaturated fatly acid supplementation of infant-formula milk: a randomised trial. Lancet 1999:354:1948-54.

20. Auesiad N, Montalto MB. Hall RT, Fitzgerald KM. Wheeler RE, Connor WE, Neuringer M. Connor SL, Taylor JA. Hartmann EE. Visual acuity, eryuhrocyte fatty acid composition, and growth in term infants fed formulas with long chain polyunsaturated fatty acids for one year. Pediatr Res 1997:41:11 10.

21. Agostoni C, Trojan S. Bellu R, Riva E, Bruzzese MG, Giovannini M. Developmental quotient at 24 months and fatty acid composition of diet in early infancy: a follow up study. Arch Dis Child $\sqrt{9} 997,76: 421-4$.

22. Auestad N, Halter R, Hall RT, Blatter M, Bogle ML. Burks W, Erickson JR, Fitzgerald KM. Dobson V. Innis SM, Singer LT, Montalto MB, Jacobs JR, Qiu W, Bornstein MH. Growth and development in tem infants fed long-chain polyunsaturated faty acids: a double-masked. randomized, parallel, prospective, multivariate study. Pedatrics 2001;108:372-81.

23. Scott DT, Janowsky IS, Carroll RE. Taylor JA, Auestad N, Montalto MB. Formulat supplementation with long-chain polyunsaturated fatty acids: are there developmental benefits? Pediatrics 1998;102:E59.

24. Al MDM, Houwelingen ACV, Kester ADM, Hasaart RHM, Jong EAPd, Homstra G. Matemal essential fatty acid pattern during normal pregnancy and their relationship to neonatal essential fatty acid status. BrJ Nutr 1995:74:55-68.

25. Kaufman AS, Kaufman NL. Kaufman Assessment Battery for Children. Circle Pines. Minnesota: American Guidance Serwice; 1983.

26. Cito. Cito Group Amhem [World Wide Web]. Central Institute for Test Development; 2001. Avalilable: htep:/www.cito.n1

27. Bligh ED, Dyer WJ. A rapid method for total lipid extraction and purification. Can J Biochem Physiol 1959:37:911-7.

28. Andersson HW. Sommerfeli K. Somander K. Ahlsten G. Matemal child-rearing attitudes, TQ and socioeconomic status as related to cognitive abilities of five-yearold children. Psychol Rep $1996 ; 79: 3-14$.

29. Bacharach VR, Baumeister AA. Effects of maternall intelligence, marital status, income, and home environment on cognitive development of low birthweight infants. J Pediatr Psychol $1998: 23: 197-205$.

30. Jacobson SW. Assessment of long-chain polyunsaturated fatty acid nutritional supplementitlion on infant neurobehawional development and visual acuily, Lipids 1999:34:151-60.

31. Mac Arthur C. Knox EG. Simons KJ. Breastfeeding and untelligence. Lancet 1992;339:612-3.

32. Larroque B. Kaminski M. Dehaene P. Subtil D. Delfosse MJ, Querleu D. Moderate prenatal alcohol exposure and psychomotor development at preschool age. Am J Public Health 1995:85:1654-61

33. Andersson HW Sonmander K, Sommerfelt K. Gender and its contribution to the prediction of cognitive abilities at 5 years. Scand J Psychol 1998;39:267-74. 
34. Rogan WJ. Gladen BC. Breast-feeding and cognitive development. Early Hum Dew $1993 ; 31: 181-93$.

35. Richards $M$, Hardy $R$, Kuh $D$. Wadsworth ME. Birth weight and cognitive function in the British 1946 bith cohort: longitudinal population based study. BMJ 2001:322:199-203.

36. Hengreen WP, Reerink JD, Noord wan-Zandstra BM. Verloove-Vanhorick SP. Ruys JH. Connections between socio-economic status and differences in care during pregnancy, delivery and lying-in period (in Dutch), Ned Tijdschr Geneeskd 1993;137:1007-12.

37. Raven J, Court J, Raven J. Standard Progressive Matrices. Oxford: Oxford Psychologists Press; 1996.

38. Vermats IRR, As NCMV, Gerris JRM. Between nutrition and parenting: a proposal for a method to measure family and parenting characteristics in parents and children of 7 years old (in Dutch). Nijmegen: Institute of Family Studies, Katholieke Universiteit Nijmegen; 1999.

39. Agostoni C, Trojan S, Bellu R. Riva E, Luott D, Giovanni M. LCPUFA status and developmental quotient in term infants fed different dietary sources of lipids in the first months of life. In: Bindels JG, Goedhart AC. Visser HKA, editors. Recent developments in infant nutrition. Dordrecht: Kluwer Academic Publishers; 1996. p. 212-7. 
Infant breast or formula feeding and cognitive function at 7 years of age: the influence of docosahexaenoic acid status at birth

Esther C. Bakker Alex J.A. Ghys Jan R.M. Gerris Carlos E. Blanco Gerard Hornstra 


\begin{abstract}
Significantly lower scores on tests of cognitive function seem to be present in formula-fed children as compared with breasted children, although this difference not always persists after adjustment for potential confounders. The initial fatty acid status at birth may have an influence on the association between infant feeding type and cognitive function. The aims of this study were to find out whether cognitive function at 7 years of age differs between breasted and formula-fed term children, with or without adjustment for potential confounders, and to investigate the influence of the docosahexaenoic acid (DHA) status at birth on the relationship between infant nutrition and cognitive developrnent.

Cognitive function was assessed with the Kaufman-Assessment Battery for Children in 306 children at 7 years of age with a known LCPUFA status at birth. Regression analyses were used to study the relation between the test outcomes and type of infant feeding, both uncorrected and corrected for potential confounders. The influence of the intial DHA status on this relation was investigated with an interaction term for infant feeding by umbilical plasma DHA percentage".

A significant difference in cognitive function was found between formula and breastfed children, in favour of the breastfed children (105.6 versus 109.0, respectively, $\mathrm{p}=0.01 \mathrm{l}$, which disappeared after adjustment for several covariables (106.0 versus 107.0 , respectively, $\mathrm{p}=0.5$ ). The difference in cognitive function between the two feeding groups seemed to be more pronounced in children with low initial DHA values compared to that of children with high DHA values at birth. However, this interaction was not statistically significant.

The findings of this study do not provide evidence for a relation between cognitive performance at 7 years of age and type of infant nutrition, nor for a role of the DHA status at birth in this relation.
\end{abstract}




\section{Introduction}

The results of many clinical studies suggest that formula-fed children have lower scores on tests of cognitive function than do breastfed children (1-11). The duration of breastfeeding was also found to be positively associated with cognitive performance $(4,5,8,12,13)$. Although this correlation did not always perstst after adjustment for potential contounders $(14,15)$, a meta-analysis of most available sudies shows that significantly lower scores on tests of cognitive function are present in formula-ted children as compared with breastfed children, even after adjustment for covariates (13).

One of the factors mentioned to explain this difference between breastfed and fomula-fed children is the difference in fatly acid composition between standard artificial formulas and human milk (16, 17). The long-chain polyunsaturated fatty acids (LCPUFA) docosahexaenoic acid (DHA) and arachidonic acid (AA) are found in high proportions in the central nervous system $(18,19)$ and seem to play a functional role. Human milk generally contains DHA and AA; standard artificial formulas do not contain these LCPUFA. This difterence results in lower DHA concentrations in the cerebral cortex of children fed standard artificial formula as compared with breastfed children (20-23). This may provide an explanation for the relationship between infant nutrition and cognitive function. Indeed, several randomized clinical trials have shown a difference in cognitive function between infants receiving standard artificial formula and infants receiving formulas supplemented with LCPUFA, especially DHA (24-27). However, others did not show an effect of LCPUFA supplementation on cognitive outcomes in term infants (28-30) or even found lower developmental scores in infants receiving LCPUFAsupplementation (31). Several explanations for these inconsistencies in the literature have been mentioned, including the use of different methods, different compositions. of the formulas, different study populations and different test ages. Variations in initial fatty acid concentrations at birth could provide an alternative explanation. It can be hypothesized that the difference in cognitive function between children fed artificial formulas or human milk is larger within the group of children who had low initial LCPUFA values as compared with the group of children with high LCPUFA values at birth. The aims of the present study were to determine whether cognitive function at 7 years of age differs between breasted and formula-fed children born at term, with or without adjustment for potential confounders, and to investigate the influence of the DHA status at birth, as measured in umbilical venous plasma, on the relationship between inlant nutrition and cognitive development at 7 years of age in children born at term.

\section{Methods}

\section{Suludy population}

The study described in this chapter is part of a follow-up study investigating the relationship between essential fatty acid status at birth and cognitive, visual and motor function at 7-8 years of age. The eligible study population consisted of 750 Caucasian children of 7 years old, born between December 1990 and January 1994 in the course of an earlier study on maternal and neonatal L.CPUFA status and pregnancy outcome (32). As described in Chapter 2, 306 of these children eventually participated in the follow-up study, 144 breastfed and 161 formula-fed children. The mother's report al follow-up was used to define these groups. The breastfeeding group included all children who received human milk, even if it was for a very short period. Formula-fed 
children were cuclusively fed arlificial formula without LCPUFA. Written consent was obtaned from the parents of each participant. The study was approved by the Ethics Committee of the University Hospital Maastricht/niversiteit Maastricht.

\section{Measurement of cognitue function, covariables and fatty acid status at birth}

Data were collected as described in Chapter 2. Briefly, cognitive function of all participating children was assessed at 7 years of age using the Kaufman Assessment Battery for Children (33), which consists of two scales, each measuring a different type of information processing: the 'Sequential processing' scale and the 'Simultaneous processing' scale. Together, these scales form the total score for cognitive performance: the 'Mental Processing Composite'. The following covariables were included in the analyses: social class (reflected by two dummy variables for matemal educational level), matemal intelligence (tested with Raven's Standard Progressive Matrices (34), parenting skills, maternal smoking and drinking habits during pregnancy, and the child's sex, birth order, gestational age, birthweight and umbilical plasma DHA status. Fatty acid profiles of umbilical venous plasma phospholipids (presented in \% of totall faty acids, wt/wt) were determined as reported by Al el al (32).

\section{Siatistical analyses}

All data are expressed as means (SD). The differences in clinical characteristics between breastfed and formula-fed children were tested with unpaired t-tests. To test the differences in cognitive function beween both groups, linear regression analyses were done, both with and without correction for the mentioned covariables. From the results of these analyses, unadjusted and adjusted means for cognitive function were calsulated for the total population and for children with low or high umbilical plasma DHA percentages separately. The latter two groups were defined on the basis of the median umbilical plasma DHA percentage (median DHA $=6.0 \%$ of total fatty acids): "low' means DHA below median, whereas median or higher DHA is defined as 'high'. Furthermore, an interaction term for 'infant feeding by umbilical plasma DHA percentage' was added to both (uncorrected and corrected) regression analyses to test the statistical significance of our hypothesis. The same analyses (simple and multiple regression analyses, both with and whout interaction term) were done with 'duration of breasteeding" as an independent variable instead of "inflant feeding type". In all statistical analyses a p-value of $<0.05$ was considered significant. The statistical analyses were performed using the statistical computer program StatView version 5,0 (SAS Institute Inc, Cary, NC). Sample size calculations (35) indicated that we needed at least 212 infants, preferably 106 children in each group, to achieve a power of 0.80 at an overall-alpha of 0.05 , to pick up a 5 -point difference in cognitive performance (based on expected group means of 108.5 (SD 12.9) for breastfed children and 103.7 (SD 12.0) for lormula-fed children (36)). Consequently, our sample size of 306 children (144 breastfed and 16.1 formula-fed) was adequate.

\section{Results}

Study population

Table I shows the clinical characteristics (mean $\#$ SD) of the 144 children who received human milk and the 161 bottle-fed children. Of the breastfed children, 52 were breastfed less than 3 months, 48 between 3 and 6 months and 43 children 6 months or longer. The mean duration of breastleeding was 4.6 months $( \pm 4.6$ months, 
range $<1$ month-40 months). Parental education, maternal intelligence and matemal smoking habits during pregnancy were significantly different between the artificial formula group and the human milk group $(p<0.0005,0.0125$ and 0.0005 , respectively).

Table 1: Clinical characteristics of the study population

\begin{tabular}{|c|c|c|}
\hline Variable* & $\begin{array}{l}\text { Human milk group } \\
(\mathrm{n}=144)\end{array}$ & $\begin{array}{l}\text { Artificial formula group } \\
(n=161)\end{array}$ \\
\hline \multicolumn{3}{|l|}{ parental characteristics } \\
\hline maternal age at delivery (yrs) & $30.8(4.3)$ & $30.0(3.7)$ \\
\hline maternal weight $(\mathrm{kg})$ & $65.1(9.9)$ & $65.9(12.2)$ \\
\hline \multicolumn{3}{|l|}{ maternal intelligence } \\
\hline (correct answers on SPM ${ }^{*}$ out of 60 ) & $46.8(7.7)$ & $44.5(7.6)^{\dagger}$ \\
\hline smoking during pregnancy (yes/no, $\%$ ) & $20 / 80$ & $39 / 61^{+}$ \\
\hline alcohol use during pregnancy $($ yes/no, $\%)$ & $24 / 76$ & $23 / 77$ \\
\hline maternal education (high/middle/tow, \%) & $73 / 24 / 3$ & $48 / 47 / 5^{t}$ \\
\hline paternal education (high/middle/low, $\%$ ) & $75 / 23 / 2$ & $49 / 48 / 3^{\dagger}$ \\
\hline \multicolumn{3}{|l|}{ delivery (spontaneous vaginalnacum or } \\
\hline forceps extraction (Ceasarean section, $\%$ ) & $74 / 20 / 6$ & $77 / 17 / 6$ \\
\hline parental warmth ${ }^{5}$ & $0.0(0.83)$ & $0.0(0.85)$ \\
\hline parental restrictive control & $-0.1(1.04)$ & $0.1(0.96)$ \\
\hline \multicolumn{3}{|l|}{ child characteristics } \\
\hline age at measurement (yrs) & $7.3(0.2)$ & $7.3(0.3)$ \\
\hline gender $($ boys/gils,$\%)$ & $58 / 42$ & $53 / 47$ \\
\hline gestational age (weeks) & $40.0(1.6)$ & $39.9(1.7)$ \\
\hline birth order (first child/orher, $\%$ ) & $71 / 29$ & $73 / 27$ \\
\hline birth weight $(\mathrm{g})$ & $3395(472)$ & $3225(533)$ \\
\hline birth length $(\mathrm{cm})$ & $50.3(2.2)$ & $49.6(2.5)$ \\
\hline head circumference at birth (cm) & $34.6(1.8)$ & $34.1(11.5)$ \\
\hline Apgan 8 cone-5 & $9.6(1.1)$ & $9.6(0.7)$ \\
\hline Umbilical plasma DHA $(\% \text { of lotal } F A)^{*}$ & $6.2(1.5)$ & $0.0(1.3)$ \\
\hline Umbilical plasma AA (\% of total FA) & $16.5(1.6)$ & $16.7(1.6)$ \\
\hline
\end{tabular}

values are either mean (SD) or percentages of study population

It significantly different from human milk group ( $\mathrm{P}<0.05)$

\$ SPM = Standard Progressive Matrices of Raven (34). FA=fatty acids

\& Results of factor analyses, expressed in $\mathrm{SD}$-units

\section{Cognitive performance}

The assessment of cognitive performance on the Kaufman-Assessment Battery resulted in a total score for cognitive function (Mental Processing Composite), which was composed of the scores on two subscales: the scales for 'Sequential processing' and 'Simultaneous processing'. These scores were available for 304 children, 2 boys refused to co-operate. 


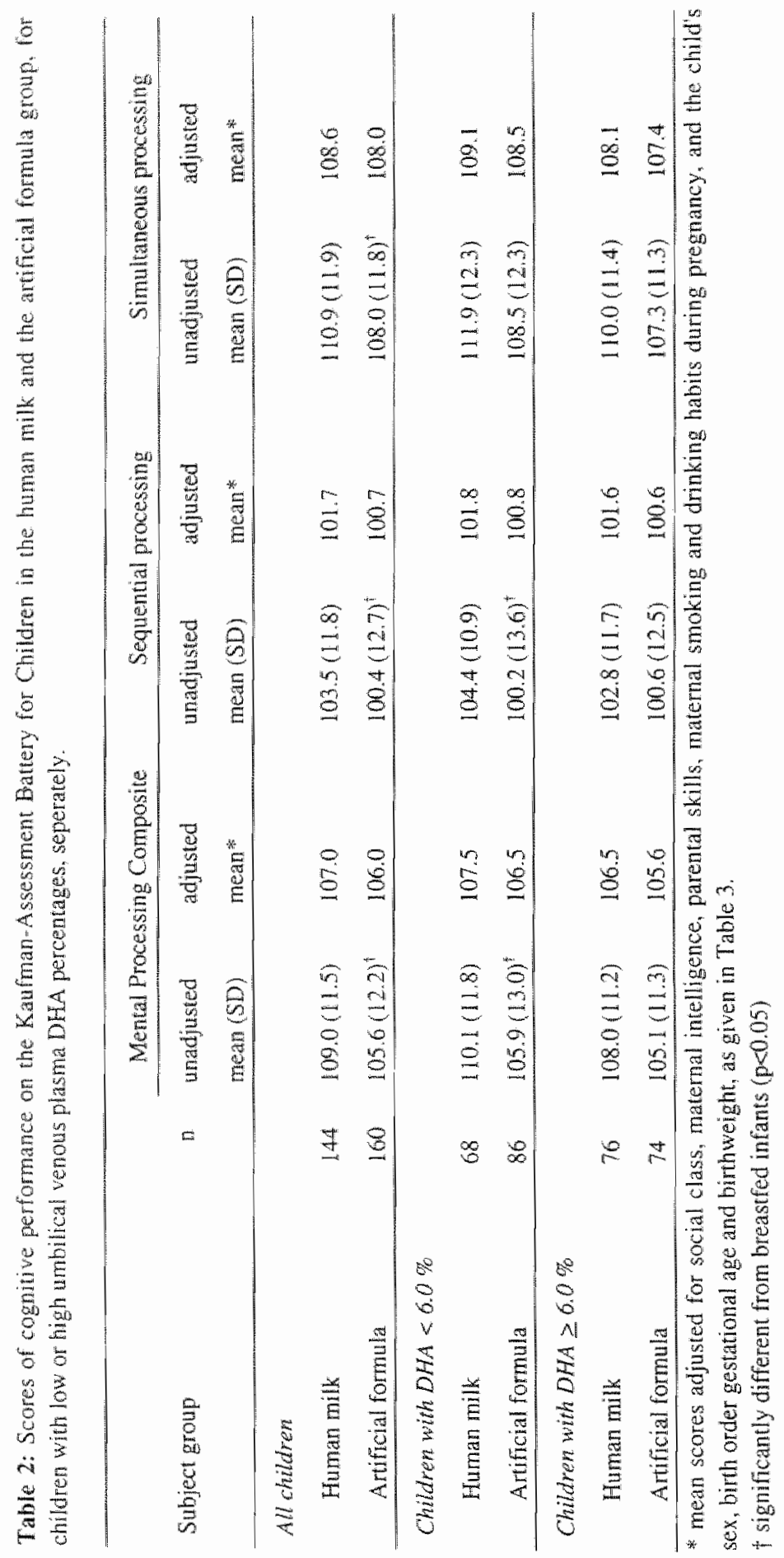




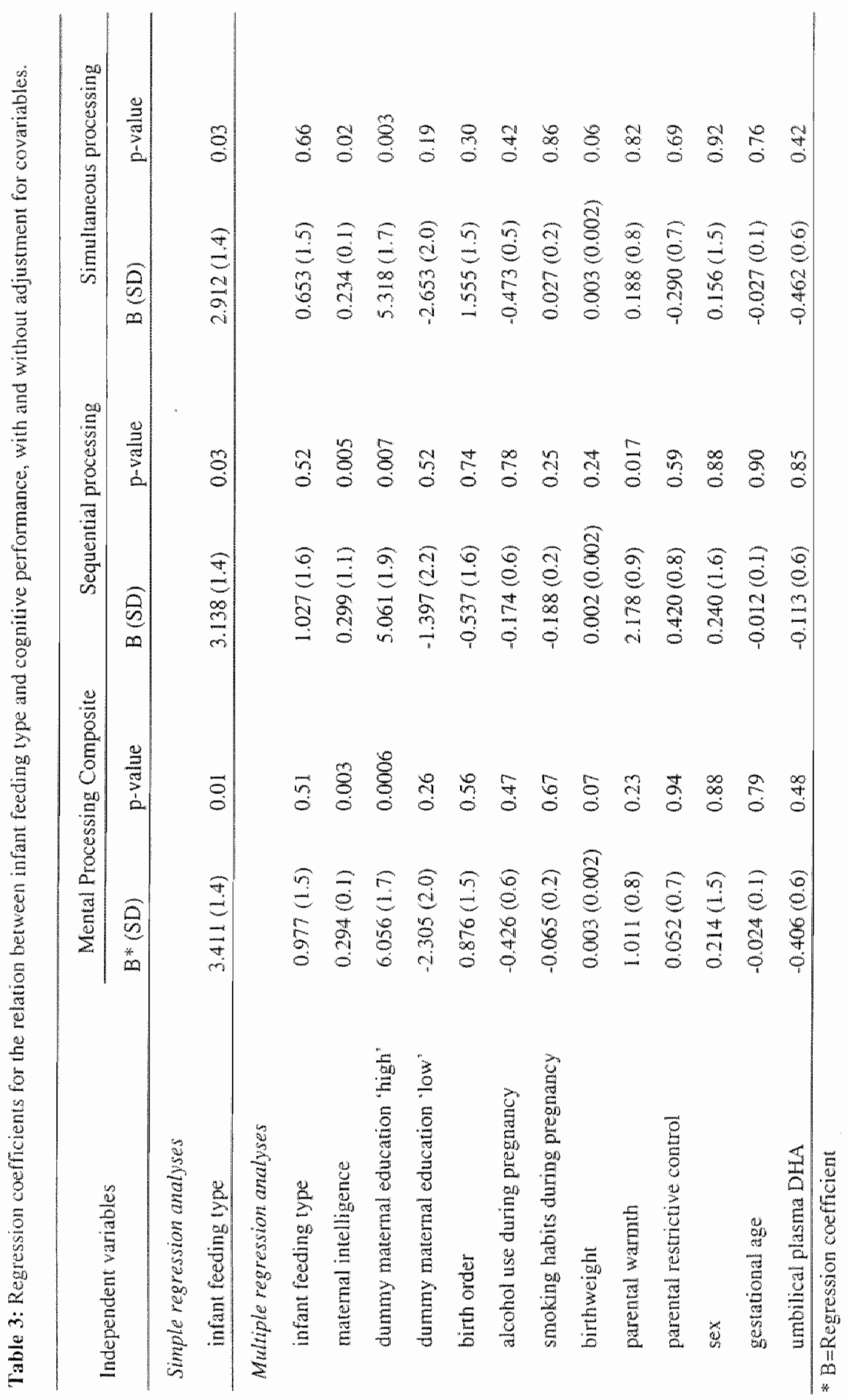


Simple regression analyses showed significant differences between formula and breasted children in tolal Mental Processing Composite (MPC, 3.4 points, $p=0.01$, see Tables 2 and 3 and Figure 1), "Sequential processing" (3.1 points, $p=0.03$ ) and 'Simultaneous processing' (2.9 point, $\mathrm{p}=0.03$ ), in favour of the breasted children (Tables 2 and 3 ). Also, duration of breasteeding was significantly associated with Mental Processing Composite $(r=0.2, p=0.002)$, "Sequential Processing" $(r=0.1$, $\mathrm{p}=0.03)$ and 'Simultaneous Processing" $(r=0.2, \mathrm{p}=0.004)$.

Multiple regression analyses with infant feeding type as independent variable, cognitive performance as dependent variable and social class, maternal intelligence, parenting skills, maternal smoking and drinking habits during pregnancy, and the child's sex, birth order, gestational age, birthweight and umbilical plasma DHA status as covariables resulted in the regression models given in table 3 . The difference in cognitive function between the two infant feeding groups was not significant anymore after adjustment for the mentioned covariables ( $p=0.51$ for MPC (Figure 1), 0.52 for "Sequential processing" and 0.66 for "Simultaneous processing"). The only significant predictors in these regression models were social class (reflected by 2 dummy variables for maternal educational level) and matemal intelligence. Parental warmth was significant only in the model for 'Sequential Processing'. The adjusted means for cognitive function, calculated with the results from these multiple regression analyses, are given in Table 2. Multiple regression analyses with "duration of breastfeeding" as independent variable instead of 'infant feeding type', resulted in regression models comparable to the models given in table 3. After correction for the mentioned covariables, there was no significant association between duration of breastfeeding and Mental Processing Composite $(r=0.1, p=0.19)$, 'Sequential Processing' $(r=0.1$, $p=0.32$ ) or 'Simultaneous Processing' $(r=0.1, p=0.24)$.

Seperate uncomected regression analyses for children with umbilical plasma DHA percentages either below or above median revealed a significant association between infant feeding habits and cognitive function in the group of children with a low DHA status at birth (DHA $<6.0 \%$ of total fatty acids, $\mathrm{p}=0.04,4.2$ points difference in MPC), whereas the same association in the group of children with median or above median DHA values was not significant $(p=0.13,2.8$ points difference, for unadjusted means see table 2 and figure 1). However, adding an interaction term for 'infant lecding by umbilical plasma DHA percentage" to the regression analyses did not result in a significant interaction effect $(p=0.35)$. Thus, the difference in infant feeding eftect on cognition between children with either a high or a low initial DHA status was not statistically significant.

"Sequential processing" scores of the children with an initial DHA status below median were 4.2 points lower in the formula group as compared with the breasteeding group $(\mathrm{p}=0.04)$. In the group of children with a high initial DHA status, this difference was only 2.2 points $(p=0.27)$. The difference in "Simultaneous processing' between formula and breastfed children was not significant in children with either a low or a high umbilical plasma DHA status $(3.4$ points, $p=0.09$ and 2.6 points, $p=0.16$, respectively). The interaction term 'infant feeding by umbilical plasma DHA percentage" was not significant in the regression models with "Sequential

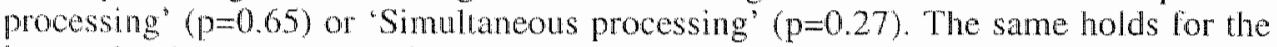
interaction between 'breastfeeding duration" and "umbilical plasma DHA percentage' $(p=0.54$ for MPC scores, $p=0.75$ for 'Sequential processing' and $p=0.46$ for 'Simulaneous processing'). 
The corrected associations between infant feeding habits and cognitive scores were also not significant in the groups of children with either low or high umbilical plasma DHA values seperately $(p=0.95$ and 0.46 , respectively, for total MPC scores, $p=0.59$ and 0.65 , respectively, for "Sequential processing" and $p=0.75$ and 0.49 , respectively. for 'Simultaneous processing'). Again, no significant interaction of 'infant feeding by umbilical plasma DHA percentage' was found in either of the models $(p=0.87$ for the model with MPC, 0.98 for 'Sequential processing' and 0.78 for 'Simultaneous processing"). The interaction between "breastfeeding duration" and "umbilical plasma DHA percentage" was also not statistically significant $(\mathrm{p}=0.96$ for the model with MPC, 0.92 for 'Sequential processing' and 0.83 for 'Simultaneous processing').
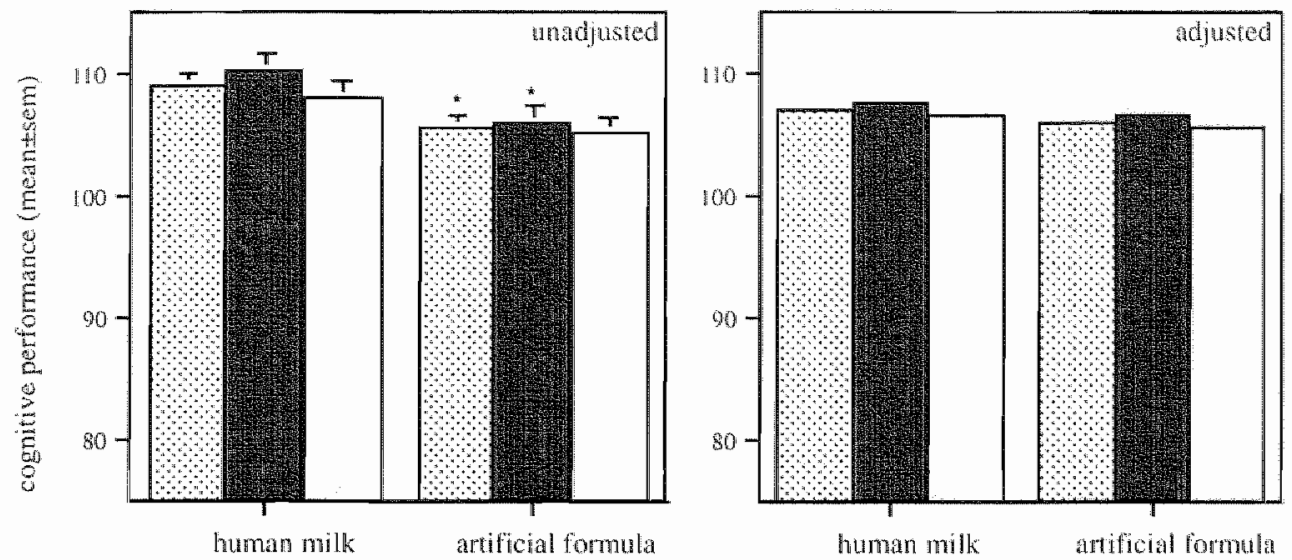

all children children with low umbilical plasma DHA $\square$ children with high umbilical plasma DHA

Figure 1: Cognitive performance in the human milk $(n=144)$ and the artificial formula group $(n=160)$, for children with low or high umbilical venous plusma DHA percentages, separately. Score in the right figure are adjusted for social class, matternal intelligence, parental skills. matemal smoking and drinking habits during pregnancy, and the child's sex, birh order gestational age and birthweigh, * means significantly different from human milk group $(\mathrm{p}<0.05)$

\section{Discussion}

In agreement with many other studies (1-11), we found a significant difference in cognitive function between formula and breastfed children, in favour of the breastfed children, and a significant association between cognitive function and breastfeeding duration.. However, after adjustment for social class, matemal intelligence, parenting skills, maternal smoking and drinking habits during pregnancy, and the child's sex, birth order, birthweight and umbilical plasma DHA status, this diflerence was no longer significant (see Figure 1). The impossiblity of randomization makes correction for these potential confounding factors necessary $(13,37)$. Not in all studies the cognitive differences disappeared after correction for potential confounders (1-11). A recent meta-analyses of 11 studies showed that the differences between both feeding groups adjusted for the appropriate covariables were smaller than the unadjusted differences, but still statistically significant (13). However, it cannot be excluded that correction for additional potential confounders, like maternal IQ or parenting skills, 
funther reduces the differences in intelligence between formula and breastfed children. Jacobson et al (36) found the IQ differences in 4- and 11-year-old children, who received either human mik or artificial formula, to persist after adjustment for social class and education. However, the feeding type effect was no longer significant after correcting for maternal $1 Q$ and parenting skills $(15,36)$. The results of our study, which also included maternal intelligence and parenting skills as covariables, are in line with those found by Jacobson ef al: after correction for these covariables (among others) there was no significant association between infant feeding habits and childhood cognitive function. This suggests that it is not the infant nutrition itself that is associated with later intellectual development, but that other, envirommental, factors may explain the variation in cognitive function, for instance maternal intelligence, parenting style and/or health behavior $(6,38,39)$. The lower parental educational level and intelligence in mothers who gave their child artificial formula supports this idea in our study.

The second aim of this study was to investigate the influence of docosahexaneoic acid (DHA) status at birth on the relationship between infant feeding type and cognitive development in full-term infants. In contrast to human milk, standard artificial formula does not contain preformed LCPUFA. Therefore, it does not contribute to the postnatal LCPUFA supply. The potentially negative consequences of the use of artificial formulas on later health and/or development may be more pronounced in children with a low LCPUFA status at birth as compared with children with a high initial LCPUFA status. At first sight, the difference in cognitive function between artificial formulas and human milk is larger in children who had low DHA values in umbilical plasma than in children with high DHA values at birth (see Figure 1). Only in the first group, this difference is statistically significant, which confirms our hypothesis. However, the interaction term for infant feeding by umbilical plasma DHA percentage was not significant, neither was the interaction between breastfeeding duration and umbilical plasma DHA percentage, which implies that infant feeding effects are not significantly different for children with low or high DHA values. After correction for potential confounders, the effect of infant feeding type on cognitive performance was not significant in any of the DHA groups. Thus, the DHA status at birth has no significant influence on the association between infant nutrition and cognitive performance. Although the focus of this chapter was on DHA. the inlluence of AA was also investigated, since this LCPUFA is also absent in slandard artilicial formulas. None of the regression models resulting from these analyses showed a significant interaction between infant feeding habits and umbilical plasma AA percentage (data not shown). It can be concluded that neither DHA nor AA at birth significantly inlluence the association between infant feeding habits and cognitive performance.

The range of breastfeeding duration in our population was between $<1$ month and 40 months (mean duration 4.6 months \pm 4.6 months). Since any cutoff in breastleeding duration is arbitrary, we chose to define the breastfeeding group as "all children who received human milk, even if it was for a very short period". Of course, other group definitions could have lead to different results. However, repetition of the regression analyses only for the children who received human milk for more than 3 months as compared with exclusively formula-fed children provided similar results: a highly significant difference in cognitive function between those groups $(p=0.006)$, which disappeared atter correction for the mentioned covariables (partial $p=0.62$ ), and no significant interaction between infant feeding and umbilical plasma DHA 
percentage. These findings are in line with the results of the regression analyses with "breasteeding duration" as independent variable instead of "infant feeding type".

In summary, we found no association between cognitive performance at 7 years of age and infant feeding habits, and no influence of the DHA status at birth on this relation However, it cannot be excluded that the initial DHA or AA status still plays a role in intervention studies. It is recommended to take the initial LCPUFA status into account in future studies. It should be added that our results do not detract from the proven values of breastfeeding and human milk (40).

\section{Literature}

1. Rodgers B. Feeding in infancy and later ability and attaiment: a longitudinal study. Dew Mod Child Neurol 1978:20:42』-6.

2. Lucas A, Morley R. Cole TJ. Lister G. Leeson-Payne C. Breast milk and subsequent intelligence quotient in children born preterm. Lancet 1992:339:261-4.

3. Morley R, Lucas A. Influence of early diet on outcome in preterm infants. Acta Paediatr Suppl $1994 ; 405: 123-6$.

4. Rogan WJ, Gladen BC. Breast-feeding and cognitive development. Early Hum Dev $1993 ; 31: 181-93$.

5. Taylor B, Wadsworth J. Breast feeding and child development at five years. Dev Med Child Neurol 1984:26:73-80.

6. Morley R. Colle TJ, Powell R, Lucas A. Mother's choice to provide breast millk and developmental outcome. Arch Dis Child 1988;63:1382-5.

7. Fergusson DM, Beautrais AL, Silva PA. Breast-feeding and cognitive development in the first seven years of life. Soc Sci Med 1982;16:1705-8.

8. Morrow-Tlucak M, Haude RH, Ernhart CB. Breastfeeding and cognitive development in the first 2 years of life. Soc Sci Med 1988:26:635-9.

9. Pollock JI. Long-term associations with infant feeding in a clinically advantaged population of babies. Dev Med Child Neurol 1994:36:429-40.

10. Temboury MC, Otero A, Polanco I, Arribas E. Influence of breast-feeding on the infant's intellectual development. J Pediatr Gastroenterol Nutr $1994 ; 18: 32-6$.

11. Florey CD, Leech AM, Blackhall A. Infant feeding and mental and motor development at 18 months of age in first born singletons. Int I Epidemiol 1995:24:S21-6.

12. Bauer G. Ewald LS, Hoffman J. Dubanoski R. Breasteeding and cognitive development of Uree-year-old children. Psychol Rep 1991:68:1218.

13. Anderson JW, Johnstone BM, Remley DT. Breast-feeding and cognitive development: a metit Analysis. Am J Clin Nutr 1999;70:525-35.

14. Malloy $\mathrm{MH}$. Berendes $\mathrm{H}$. Does breast-feeding influence intelligence quotients at 9 and 10 years of age? Early Hum Dew 1998:50:209-17.

15. Jacobson SW, Jacobson JL. Breastfeeding and intelligence Lancet 1992;339:926.

16. Rice RD. Breastfeeding and intelligence. Lancet $1992 ; 339,6134$.

17. Crawford MA, Costeloe $\mathbb{K}$, Laurance B, Leall A, Leighfield MI. Breastfeeding and intelligence. Lancet 1992:339:614.

18. O'Brien JS, Fillerup DL. Mead JF. Quantification and fatty acid and fatty aldehyde composition of ethanolamine, choline, and serine glycerophosphatides in buman cerebral grey and white matter. J Lipid Res 1964:5:329-38.

19. Sastry PS. Lipids of nervous tissue: composition and metabolism. Prog Lipid Res 1985:24:69176.

20. Farquharson J, Cockbum F, Patrick WA, Jamieson EC, Logan RW. Infant cerebral cortex phospholipid fatty-acid composition and dien. Lancet $1992 ; 340: 810-3$. 
21. Farquarson I. Infant cerebral contex and dietry faty acids. Cur J Clin Mutr 1994-48:524-6.

22. Furquharson I Jamieson EC. Abhasi KA, Patrick. WJ, Logan RW, Cockbum F. Effect of diet on the fattly acid composition of the rnajor phospholipids of infant cerebral cortex. Arch Dis Child $1995 ; 72: 198-203$.

23. Makrides M. Neumann MA, Byard RW. Simmer K, Gibson RA. Faty acid composition of brain, retina, and erythrocytes in breast- and formula-fed infants. Am J Clin Nutr 1994:60:18994.

24. Agostoni C, Trojan S, Bellu R, Riva E, Giovannini M. Neurodevelopmental quotient of healthy term infants at 4 months and feeding practice: the role of long-chain polyunsaturated faty acids. Pediatr Res 1095,38:262-6.

25. Willats P. Forsyh JS. DiModugno MK. Varma S, Colwin M. Effect of long-chain polyunsaturated fatty acids in infant formulat on problem solving at 10 months of age. Lancer 1998;352:688-91.

26. Willats P. Forsyth JS. DiModugno MK, Varma S. Colvin M. Influence of long-chain polyunsaturated fatly acids on infant cognitive function. Lipids 1998;33:973-80.

27. Birch EE, Garfield S, Hofman DR, Uauy R, Birch DG. A randomized controlled trial of early dielary supply of long-chain polyunsaturated fatty acids and mental development in term infants. Dev Med Child Neurol 2000;42:174-81.

28. Makrides M, Neumann MA, Smmer K, Gibson RA. A criticall appraisal of the role of dietary long-chain polyunsaturated faty acids on neural indices of term infants: a randomized. controlled trial. Pediatrics 2000; 105:32-8.

29. Lucas A. Stafford M. Morley R. Abbott R. Stephenson T, MacFadyen U, Elias-Jones A, Clements $H$. Efficacy and safely of long-chain polyunsaturated fatty acid supplementation of infant-fomula milk: a randonised trial. Lancet 1999:354:1948-54.

30. Agostoni C. Trojan S, Bellu R, Riva E, Bruzzese MG, Giovannimi M. Developmental quotient at 24 months and fatly acid composition of diet in early infancy: a follow up study. Arch Dis Child 1997;76:421-4.

31. Scot DT, Janowsky IS, Carroll RE, Taylor JA, Auestad N, Montalto MB. Formula supplementation with long-chain polyunsaturated faty acids: are there developmental benefuts? Pediatrics 1998;102:E59.

32. Al MDM, Houwelingen ACr, Kester ADM. Hasart RHM, Jong EAPd, Hornstra G. Maternal essential fatty acid pattern during nomal pregnancy and their relationship to neonatat essential fitly acid stutus. Bro I Nutr 1995:74:55-68.

33. Kaufman AS, Kaufman NL. Kaufman Assessment Battery for Children. Circle Pines, Minnesota: American Guidunce Service; 1983.

34. Rilven J, Court J, Raven J. Standard Progressive Matrices, Oxfiord: Oxford Psychologists Press; 1996.

35. Kirkwood BR. Essentials of medical statistics. Oxford: Blackwell; 1988.

36. Jatcobson SW, Chodo LM, Jacobson JL. Breastfeeding effects on intelligence quotient in 4 and 11-year-old children. Pediatrics 1999; 103:E71.

37. Jacobson SW. Assessment of long-chain polyunsaturated fatty acid nutritional supplementation on infant neurobehavioral development and visual acuity. Lipids 1999:34:151-60.

38. Pollock JI. Mother"s choice to provide breast milk and developmental ontcome. Arch Dis Child $1989 ; 64: 763-44$.

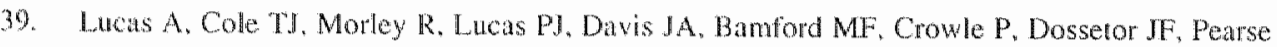
R. Boon A. Faciors associated with matemal choice to provide breast milk for low birthweight ivfints. Arch Dis Child 1988:63:48-52.

40. American Academy of Pediatrics Work group on breastfeeding. Breastfeeding and the use of human milk. Pediatrics 1997; 100: 1035-39. 


\section{4}

Long-chain polyunsaturated fatty acids at birth and motor function at 7 years of age

Esther C. Bakker

Johan S.H. Vles

Arnold D.M. Kester

Marielle Kroes

Carlos E. Blanco

Gerard Hornstra 


\begin{abstract}
Long chain polyunsaturated falty acids (LCPUFA) very rapidly accrue during the contral nervous system (CNS) growth spurt. This particularly concerns arachidonic acid (AA: 20:4n-6) and docosahexaenoic acid (DHA: 22:6n-3), which are thought to play important roles in CNS development and function. The aim of this study was to investigate the relation between motor function at 7 years of age and LCPUFA levels both in umbilical venous plasma phospholipids, representing the prenatal fatty acid avallability, and in plasma phospholipids sampled at 7 years.

Motor function was assessed with the Movement-Assessment Battery for Children and the Mastricht. Motor Test in 304 children, born at term, at 7 years of age as part of a follow-up study. Both movement quantity (the ability of the child to perform a movement) and quality (how the movement is performed) were measured. Backward stepwise regression analyses were done to study the relation between motor outcomes and LCPUFA status. Gender, cognitive performance, gestational age and age at measurement were included as covariables.

The results showed a positive nelation between umbilical plasma DHA and the Maastricht Motor Test total score and movement quality score, corrected for the mentioned covariables. In the regression models predicting movement measured guantitatively, the contribution of DHA and AA (both at birth and at 7 years of age) was not significant.

The finding that the DHA status in umbillical plasma, in contrast to the LCPUFA status in plasma at 7 years, is associated with movement quality suggests that prenatal LCPUFA availability may be more important for later motor function than childhood dietary LCPUFA intake.
\end{abstract}




\section{Introduction}

The central nerwous system (CNS) contains high amounts of long chain polyunsaturated faty acids (LCPUFA), especially arachidonic acid (AA: $20: 4 n-6)$ and docosahexaenoic acid (DHA: 22:6n-3) (1). These faty acids can ather be supplied by nutrition or synthesized from their (essential) precursors linoleic acid (LA: 18:2n-6) on alpha-linolenic acid (ALA: $18: 3 n-3)$, respectively (2). During the last trimester of gestation and in the first postnatal year, the CNS undergoes a growth spurt, so an adequate supply of LCPUFA to the child during this period can be important for optimal CNS development $(2,3)$.

Several studies have shown the impontance of postnatal dietary LCPUFA for infant development (4-6). It can be hypothesized that prenatal LCPUFA supply also exerts an influence on CNS development, because rapid CNS growth already starts prenatally. The absolute accretion rates of the $n-3$ fatty acids are even greater in the prenatal period compared with the postnatal period $(7,8)$.

Most studies investigating the relation between LCPUFA and infant development have focused on visual and cognitive function. However, the study of other, more specific, developmental domains might provide more information about the specific actions of LCPUFA in the CNS $(9,10)$. Since motor function imvolves several CNS domains, this aspect of child development is interesting to relate to perinatal LCPUFA values. Therefore, we investigated the relation between motor function at 7 years of age and LCPUFA values both in umbilical plasma, representing the prenatal fatty acid availability, and in venous plasma sampled at 7 years of age.

\section{Methods}

\section{Study population}

The study described in this chapter is part of a follow-up study investigating the relationship between essential fatty acid status at birth and cognitive, visual and motor function at 7-8 years of age. The eligible study population consisted of 750 Caucasian children of 7 years old, born between December 1990 and January 1994 in the course of an earlier study on maternal and neonatal LCPUFA status and pregnancy outcome (11). As described in Chapter 2, 306 of these children eventually participated in the follow-up study. Written informed consent was obtained from the parents of each participant. The study was approved by the Ethics Committee of the Universily Hospital Maastrich/Universiteit Maastricht.

\section{Measurement of motor function}

At 7 years of age all children were assessed at the Universily Hospital Maastricht for cognitive, visual and motor function. Furthermore, the neurological function of the children was examined in a standardized way by a child neurologist (JSHV). The focus of the present sudy is on motor performance, which was measured in two ways.

First, the Movement Assessment Battery for Children (Movemont-ABC) (12), a standardized test to measure motor function quantitatively, was administered. This test requires the child to perform eight tasks grouped under the headings of manual dexterity ( 3 items), ball skills ( 2 items), static balance ( 1 item) and dynamic balance (2 items). Raw scores on each item are converted to normative scores ranging from 0 to 5 with high scores indicating poor performance. The total score, the sum of the item scores, ranges from 0 (excellent) to 40 (extremely poor).

Quality of movement, the way in which a child performs movements, might be an even more important indicator of brain maturation and integrity than movement 
quantity, the abilily of a child to perform certain movements (13-15). Most motor tests, including the Movement- $\mathrm{BBC}$, only measure quantitative aspects of movement, or measure quality of movement only observationally (12). Therefore, motor function was also assessed with a new lest, the Mastricht Motor Test (manual in preparation), which measures motor function not only quantitatively, but qualitatively as well. This lest has been shown to yield valid and reliable results in 5-6-year-old children (16). The Maastricht Motor Test consists of 20 tasks, of which both quantity and quality is scored (see Table 1). This results in 34 quantitative items and 36 qualitative items, covering the areas of static balance ( 14 items), dynamic balance ( 20 items), ball skills ( 8 items) and manual dexterity (28 items). All 70 items are scored on a three-point scale from 0 to 2 , with low scores indicating poor performance. These scores are summed to produce a total score ranging from 0 (extremely poor) to 140 (excellent); the total quantity score ranges from 0 to 68 ; the total quality score from 0 to 72 .

Table 1: Tasks and ilems of the Matastricht Motor Test

\begin{tabular}{|c|c|c|c|}
\hline Domain & 'Task & $\begin{array}{l}\text { Quanitative } \\
\text { items }\end{array}$ & $\begin{array}{l}\text { Qualitative } \\
\text { items }\end{array}$ \\
\hline \multirow[t]{5}{*}{ Static Ballance } & Standing, closed eyes & 1 & 1 \\
\hline & Standing, closed eyes, stretched arms & 1 & 1 \\
\hline & Standing on one leg (left/right) & 2 & 2 \\
\hline & Standing on toes & 1 & 1 \\
\hline & Stork position (leftright) & 2 & 2 \\
\hline \multirow[t]{2}{*}{ Dynamic Balance } & Walking on heels & 1 & 2 \\
\hline & Tiptoe & 1 & 2 \\
\hline \multirow[t]{5}{*}{$=$} & Hopping at the place on one leg (leftright) & 2 & 2 \\
\hline & Hopping forward on one leg (leftright) & 2 & 2 \\
\hline & Jumping at the place & 1 & 1 \\
\hline & Long-jump & 1 & 1 \\
\hline & Heel-to-toe walking on a line & 1 & 1 \\
\hline \multirow[t]{3}{*}{ Ball skills } & Catching & 1 & 1 \\
\hline & Bounching & 1 & 1 \\
\hline & Kücking (leftright) & 2 & 2 \\
\hline \multirow[t]{5}{*}{ Mantail Dexterity } & Pronation/supination (leftrighthothy & 3 & 3 \\
\hline & Finger-thumb opposition (terigrightboth) & 3 & 3 \\
\hline & Hand tapping (lefu/right) & 2 & 2 \\
\hline & Foot tapping (lelthrigho) & 2 & 2 \\
\hline & Drawing berween lines (leftright) & 4 & 4 \\
\hline
\end{tabular}

\section{Measurement of fany acid status and covariables}

Fatty acid prolites of umbilical venous plasma phospholipids and of venous plasma phospholipids sampled at 7 years of age were determined as described before (Chapter 2). Faily acid data are presented as relative levels (\% of total fatty acids, wt/wt). "The following covariables were included in the analyses: gender, cognitive function, gestational age and age at measurement. Cognitive function was assessed at 7 years of age, as a part of the follow-up study (Chapter 2), and included in these analyses becatse motor function is known to be associated with cognition $(15,17)$. 


\section{Statistical analyses}

Data are presented as means (SD). The Mann-Whitney U resi was used to test differences between boys and girls and between formula- and breast-fed children. Outcome data were screened for normality and if necessary $\log$-transformed to obtain a nomal distribution. "The relation between motor function of the children at 7 years of age and their fatty acid status at bith was investigated with backward stepwise multiple linear regression analyses, thereby identifyng other predictors as well. The scores on the two tests for motor performance were the dependent variables and docosahexaenoic acid and arachidonic acid the (separate) independent variables. Gender, cognitive performance, gestational age, and age at measurement were included as covariables in the initial model. In each step of the analyses, the least significant cowariable was removed from the regression model (after checking confounding), except for the fatty acid variable, which was always retained in the model. This procedure resulted in a final regression model containing only the faty acid variable and the (other) significant predicting variables. The relation between motor function and fatty acid status at 7 years (as a measure of fatry acid supply in later life) was studied similarly. The Maastricht Motor Test quantity scores could not be transformed to normality, because of a ceiling effect. Therefore, we used logistic regression on the dichotomized scores; median or higher versus lower than median scores. In the statistical analyses a p-value of $<0,05$ was considered significant, unless mentioned otherwise. No earlier studies on this subject have been published, but power calculations indicate that our sample size of more than 300 children was sufficient to get a $90 \%$ chance of a significant result when the true correlation equals 0.20 .

Table 2: Clinical characteristics of the study population $(n=300)$

\begin{tabular}{|c|c|c|}
\hline Variable* & $\begin{array}{l}\text { Boys } \\
n=170\end{array}$ & $\begin{array}{l}\text { Girls } \\
\mathrm{n}=136\end{array}$ \\
\hline \multicolumn{3}{|l|}{ parental characterisics } \\
\hline maternal age at delivery (yrs) & $30.3(4.5)$ & $292(3.6)^{\dagger}$ \\
\hline matternal weight $(\mathrm{kg})$ & $66.0(11.2)$ & $64.8(11.3)$ \\
\hline smoking during pregnancy (ges/no, \%) & $27 / 73$ & $35 / 65$ \\
\hline alcohol use during pregnancy $(y e s / n o, \%)$ & $23 / 77$ & $23 / 77$ \\
\hline matemal education (high/middle/kw, w) & $56 / 41 / 3$ & $65 / 30 / 5$ \\
\hline paternal education (high/middloflow, \%) & $59 / 39 / 2$ & $63 / 34 / 3$ \\
\hline $\begin{array}{l}\text { det ivery (sponaneous waginalwacum or } \\
\text { forceps extraction/Ceasarean secrion. \%) }\end{array}$ & $72 / 22 / 6$ & $79 / 16 / 5$ \\
\hline \multicolumn{3}{|l|}{ child characteristios } \\
\hline age at measuroment (yrs) & $7.3(3.0)$ & $7.3(2.9)$ \\
\hline gestational age (weeks) & $39.8(1.7)$ & $40.0(1.4)$ \\
\hline birth order (forst childother. \%) & $66 / 34$ & $65 / 35$ \\
\hline binth weighn $(g)$ & $3377(510)$ & $3223(492)^{8}$ \\
\hline birth length $(\mathrm{cm})$ & $50.4(2.4)$ & $49.3(2.3)^{t}$ \\
\hline head circumference at birth $(\mathrm{cm})$ & $34.6(1.6)$ & $33.9(1.8)^{t}$ \\
\hline Apgar score- 5 & $9.6(0.7)$ & $9.6(0.9)$ \\
\hline Infant feeding babits (numan milk/formula. W) & $49 / 51$ & $45 / 55$ \\
\hline
\end{tabular}

\footnotetext{
* values are either mean (SD) or percentages of study population
}

it significantly different from the boys ( $\mathrm{P}<0.05$ ) 


\section{Results}

Stindy population

The follow-up study population consisted of 306 children, 170 boys and 136 girls with a mean age of 7.3 years (range 6.6-8.1 years). The neurological function, as measured with a standard neurological examination, performed in 262 of the children. by the child neurologist (JSHV), was within the normal range. Only 1 child was excluded from the analyses, because of complete paralysis of his left arm due to a birth trauma (Erb's paralysis). Clinical characteristics (mean \pm SD) of the participating children are given in Table 2. There were no differences in baseline clinical characteristics between the participants and non-participants, except for a small difference in umbilical plasma arachidonic acid percentages. One hundred and fortyfour children had been breasted (mean duration of breastfeeding 4.6 months \pm 4.6 months, range <1 month-40 months), 161 children only received artificial formulas without LCPUFA. The breastfeeding group was defined as 'all children who received human milk, even if it was for a very short period'.

We were permitted to take a venous blood sample at follow up of 261 of the 306 children. The latty acid status at birth (in umbilical plasma phospholipids) and at 7 years of age (in venous plasma phospholipids) are given in in Table 3. At 7 years of age, the fatty acid values were comparable to adult values.

Table 3: Fatty acid composition of phospholipids of umbilical plasmat and of venous plasmat at 7 years of age

\begin{tabular}{|c|c|c|c|c|}
\hline \multirow{2}{*}{$\begin{array}{l}\text { Fatty acid* } \\
\text { (\%w//wt of } \\
\text { tolat FA) }\end{array}$} & \multicolumn{2}{|c|}{$\begin{array}{c}\text { umbilical plasma PL } \\
\text { mean (SD) }\end{array}$} & \multicolumn{2}{|c|}{$\begin{array}{c}\text { plasma PL at: } 7 \text { years } \\
\text { mean (SD) }\end{array}$} \\
\hline & boys $(n=170)$ & girls $(n=136)$ & boys $(n=144)$ & $\operatorname{girls}(n=116)$ \\
\hline Total FA (mg/L) & $567.3(108.4)$ & $624.4(128.0)^{\dagger}$ & $1054.3(150.7)$ & $1067.7(144.4)$ \\
\hline $18: 2 n-6$ & $7.8(1.4)$ & $7.5(1.2)$ & $23.0(2.2)$ & $23.4(2.3)$ \\
\hline $20: 4 n-6$ & $16.5(1.6)$ & $16.8(1.6)$ & $9.2(1.3)$ & $9.2(1.2)$ \\
\hline $22 \cdot 5 n-6$ & $0.85(0.27)$ & $0.79(0.26)^{t}$ & $0.33(0.08)$ & $0.30(0.08)^{*}$ \\
\hline$\sum n-6$ LCPUFA & $23.3(1.5)$ & $23.5(1.5)$ & $13.0(1.3)$ & $12.8(1.4)$ \\
\hline $18: 3 n-3$ & trace & trace & $0.20(0.07)$ & $0.19(0.07)$ \\
\hline $20: 5 n-3$ & $0.23(0.11)$ & $0.23(0.12)$ & $0.51(0.25)$ & $0.49(0.18)$ \\
\hline $22: 64-3$ & $6.1(1.4)$ & $6.1(1.4)$ & $2.8(0.7)$ & $2.8(0.7)$ \\
\hline $2 n-3$ LCPUPA & $69(1.5)$ & $0.9(1.6)$ & $4.3(0.9)$ & $4.2(0.8)$ \\
\hline
\end{tabular}

*FA=fatly acids, $18: 2 n-6=$ litholeic acid, $20: 4 n-6=$ arachidonic acid, $22: 5 n-6=0$ sbond acid, $2 n-6$ LCCUFA $=$ sum of the $n-6$ LCPUFA $(20: 3,20: 4,22: 4,22: 5) .18: 3 n-3=$ alphaw linollenic acid. $20: 5 n-3=$ cicosapentanonoic acid, 22:6n-3=docosahexacnoic acid, $\Sigma$ a-3 LCPUFA=sum of the 1-3 LCPUFA (20:5, 22:5, 22:6).

t significantly different from the boys $(\mathrm{P}<0.05$ )

\section{Mowement-ABC}

The total score on the Movement-ABC was available for 304 children, 2 boys refused to co-operate. Scores on this test were log-transformed to obtain a normal distribution of the results in our population. Mean values of boys and girls are given in Table 4, where lower scores on this test imply better motor function. Although the tolal score on this test did not differ significantly between boys and girls $(p=0.06)$, girls scored better on manual dexterity $(p=0.006)$, static balance $(p=0.02)$ and dynamic balance $(p=0.005)$. There were no differences between formula- and breastfed children in total Movement-ABC score (data not shown). 
Table 4: Results of Movement-ABC and Mastricht Mocor Test

\begin{tabular}{|c|c|c|c|}
\hline \multirow{2}{*}{ Test } & \multicolumn{2}{|c|}{ Mean (SD) } & \multirow[b]{2}{*}{ p-wane } \\
\hline & $\begin{array}{l}\text { boys } \\
(n=168)\end{array}$ & $\begin{array}{l}\text { girls } \\
(\mathrm{n}=136)\end{array}$ & \\
\hline \multicolumn{4}{|l|}{$\begin{array}{l}\text { Movement }-A B C \\
(n=304)\end{array}$} \\
\hline total score & $7.7(5.0)$ & $6.7(50)$ & 0,00 \\
\hline mamual dexterity & $2.3(2.4)$ & $1.7(2.4)$ & 0.006 \\
\hline ball skills & $3.2(2.2)$ & $3.6(2.3)$ & 0.26 \\
\hline static balance & $1.0(1.2)$ & $0.7(1.0)$ & 0.02 \\
\hline dynamic balance & $1.2(1.4)$ & $0.8(1.1)$ & 0.005 \\
\hline \multicolumn{4}{|l|}{$\begin{array}{l}\text { Maastricht Motor test } \\
(n=290)\end{array}$} \\
\hline total score & $109.8(12.5)$ & $1.17 .0(11.5)$ & $<0.0001$ \\
\hline \multicolumn{4}{|l|}{ Quantity } \\
\hline tolal score & $60.8(3.8)$ & $61.6(3.2)$ & 0.03 \\
\hline static balance & $13.2(1.6)$ & $13.5(1.0)$ & 0.02 \\
\hline dymamic balance & $16.9(1.3)$ & $17.3(1.1)$ & 0.003 \\
\hline ball skills & $7.9(0.4)$ & $7.7(0.9)$ & 0.08 \\
\hline mantual dexterity & $23.0(2.0)$ & $23.0(1.6)$ & 0.98 \\
\hline \multicolumn{4}{|l|}{ Quality } \\
\hline total score & $49.0(10.3)$ & $55.4(9.2)$ & $<0.0001$ \\
\hline static balance & $6.8(4.3)$ & $9.5(3.4)$ & $<0.0001$ \\
\hline dynamic balance & $15.7(3.9)$ & $17.3(3.5)$ & 0.0003 \\
\hline ball skills & $6.3(1.3)$ & $6.4(1.4)$ & 0.69 \\
\hline manual dexterity & $20.1(4.8)$ & $22.3(4.6)$ & $\leq 0.0001$ \\
\hline
\end{tabular}

*Lower scores on the Movement-ABC reflect better motor performance, while the opposite is true for the Maastricht Motor 'Test.

tp-value for the difference between boys and girls (Mann Whitney U test).

Figure 1 shows the total scores on the Movement-ABC, according to quartiles of umbilical plasma DHA or AA percentage, repectively.

Backward stepwise multiple regression analyses, with either DHA or AA in umbilical plasma as independent variable (retained in the model in each step) and gender, cognitive performance, gestational age and age at measurement as covariables, resulted in a model with "cognitive performance" and 'age' as significant predictors (see Table 5). The (corrected) association between DHA or AA and IogMovement-ABC outcomes was not significant (partial $p=0.35$ and 0.74 , respectively). Comparable regression models were obtained for the two LCPUFA at 7 years of age (Table 5). Again, DHA and AA showed no association with log-Movement-ABC outcomes at 7 years of age (partial $p=0.99$ and 0.50 , respectively). 

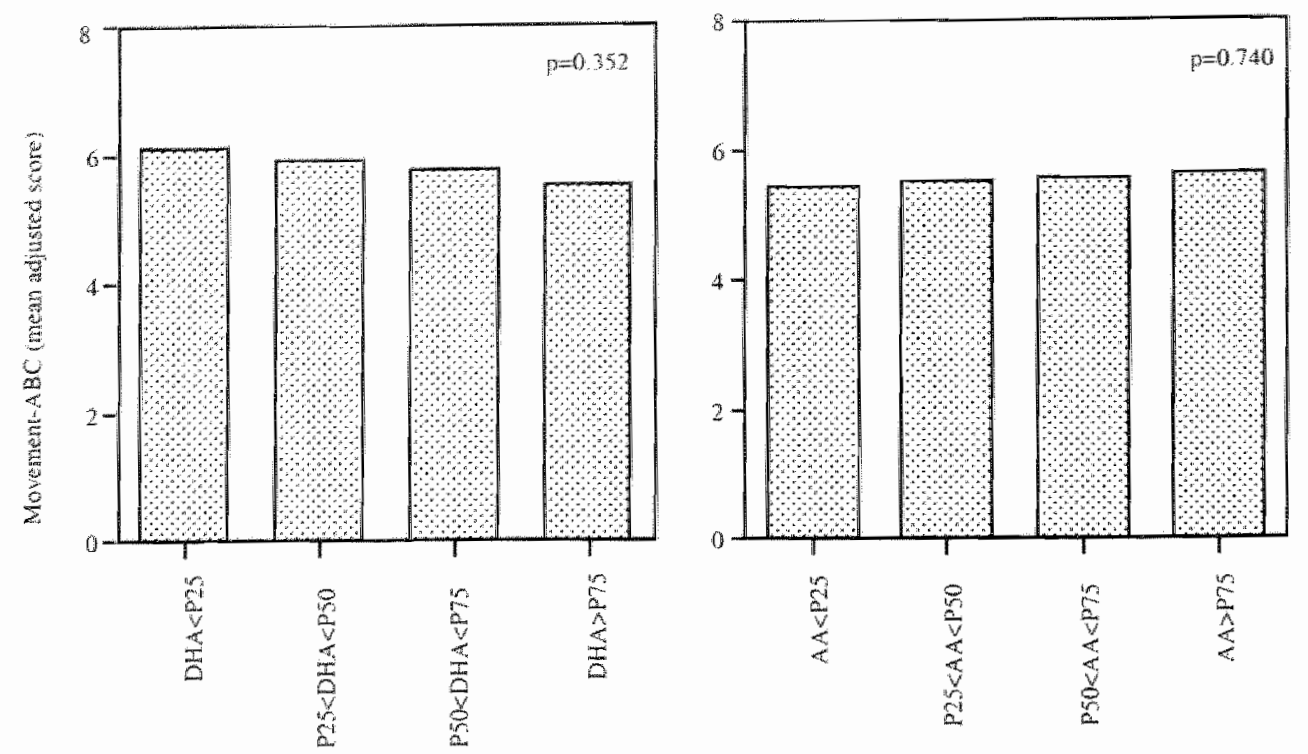

Tigure 1: Movement-ABC tolal scores a 7 years of inge $(\mathrm{n}=304)$, according to quartiles of umbillical plasma DHA or AA percentage, adjusted for cognitive function and age.
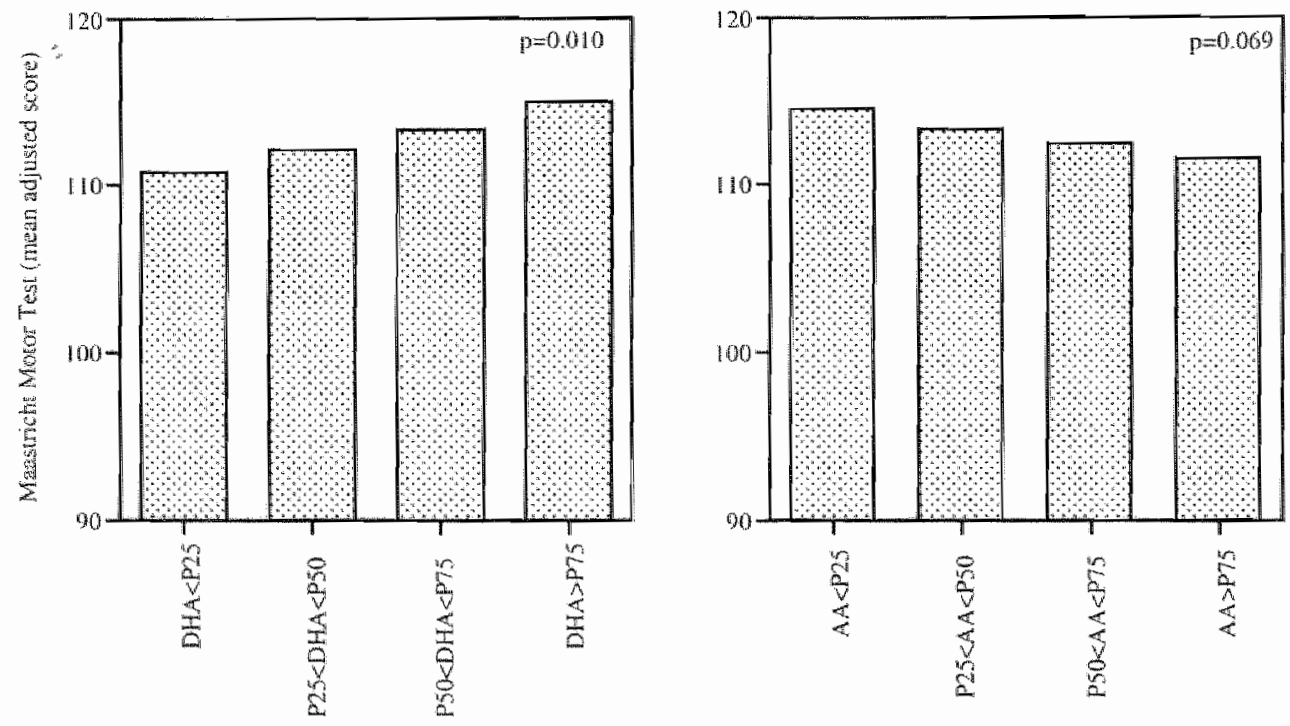

Wigure 2: Maastricht Motor Test total seores at 7 year of age $(n=290)$, according to quartiles of umbitical plasma DHA or AA percentage, adjusted for cognitive function. age gender and gestational age (only with $A$ A). 
Table 5: Regression coefficients for the relation between LCPUFA status and (log Movement-ABC total score, corrected for covariables*.

\begin{tabular}{|c|c|c|c|c|c|c|}
\hline \multirow{2}{*}{ Variables in model } & \multicolumn{3}{|c|}{ wmbilical plasma } & \multicolumn{3}{|c|}{ plawna of 7 years of age } \\
\hline & $\mathrm{B}(\mathrm{SD})$ & Beta & p-yalue & $B(S D)$ & Beta & $p-w a l u e$ \\
\hline DHA & $-0.012(0.01)$ & .0 .05 & 0.352 & $0.00002(0.03)$ & 0.00005 & 0.999 \\
\hline cognitive function & $-0.011(0.002)$ & -0.40 & $<0,0001$ & $-0.012(0.002)$ & 0.42 & $<0.0001$ \\
\hline age & $-0.017(0.006)$ & -0.14 & 0.008 & $-0.014(0.007)$ & -0.12 & 0.03 \\
\hline $\mathrm{AA}$ & $0.004(0.01)$ & 0.02 & 0.740 & $-0.010(0.02)$ & .0 .04 & 0.505 \\
\hline cognitive function & $0.011(0.002)$ & -0.40 & $<0,0001$ & $-0.012(0.002)$ & 0.42 & $<0.0001$ \\
\hline agge & $-0.017(0.006)$ & -0.14 & 0.009 & $-0.015(0.007)$ & -0.1. & 0.027 \\
\hline
\end{tabular}

* results of backward stepwise multiple regression analyses. B=regression coefficient. Beta=standardized regression coefficient. The initial models incinded 5 variables (docosahexaemoic acid status (DHA) or arachidonic acid status (A., \%, wh/wi), the child's gender, cognitive performance, gestational age and age at measurement). A negative regression coefficient means a positive association with motor function.

Table 6: Regression coefficients for the relation between LCPUFA status and Matastrich Motor Test total score, corrected for covariables*.

\begin{tabular}{|c|c|c|c|c|c|c|}
\hline \multirow{2}{*}{ Variables in model } & \multicolumn{3}{|c|}{ umbilical plasma } & \multicolumn{3}{|c|}{ plasma ar 7 yaars of age } \\
\hline & $\mathrm{B}(\mathrm{SD})$ & Beta & p-vallue & $\mathrm{B}(\mathrm{SD})$ & Beta & p-value \\
\hline DHA & $1.143(0.46)$ & 0.13 & 0.01 & $1.295(0.97)$ & 0.07 & 0.185 \\
\hline cognitive function & $0.381(0.05)$ & 0.37 & $<0.0001$ & $0.412(0.06)$ & 0.40 & $<0.0001$ \\
\hline age & $0.864(0.22)$ & 0.20 & 0.0001 & $0.914(0.24)$ & 0.21 & 0.0002 \\
\hline gender & $7.158(1.29)$ & 0.28 & $<0.0001$ & $6.038(1.37)$ & 0.24 & $<0,0001$ \\
\hline$A A$ & $-0.747(0.41)$ & .0 .10 & 0.069 & $0.479(0.56)$ & 0.05 & 0.389 \\
\hline cognitive function & $0.363(0.05)$ & 0.35 & $<0.0001$ & $0.416(0.06)$ & 0.40 & $<0.0001$ \\
\hline age & $0.800(0.22)$ & 0.19 & 0.0004 & $0.954(0.24)$ & 0.22 & 0.0001 \\
\hline gender & $7.146(1.30)$ & 0.28 & $<0.0001$ & $6.051(1.37)$ & 0.25 & $00.000 \mathrm{I}$ \\
\hline gestational age & $0.124(0.06)$ & 0.11 & 0.037 & & & \\
\hline
\end{tabular}

* See table 5 for legend, a positive regression coefficient means a positive association with motor function.

\section{Maastrich Moror Test}

The Maastricht Motor Test was performed in 290 of the 306 children, in 11 children accomplishment of this test was impossible due to organizational reasons, 4 children did not co-operate well enough, I child did not feel well. The total score on this test, consisting of total scores for both quantitative and qualitative motor function, was normally distributed in our study population, as was the total qualitative score. The total quantitative score showed a ceiling effect, which could not be solved by transformation of the data. Therefore, the data of this variable were dichotomized in scores lower than median $(<62)$ and median or higher scores $(\geq 62)$ to perform logistic regression analyses. Table 4 shows total quantity and quality mean scores of boys and girls separately. Differences between boys and girls were found for total score $(p<$ $0.0001)$, total quantity score $(p=0.03)$, total quality score $(p<0.0001)$, static balance 
quanticy score $(p=0.02)$ and quality score $(p<0.0001)$, dynamic balance quantity score $(p=0.003)$ and quality score $(p=0.0003)$, and manual dexterty quality score $(p<0.0001)$, all in favor of the girls. The total score on the Maastricht Motor Test was not significanty different between formula- and breastfed children (data not shown). Figure 2 shows the Mastricht Motor Test total scores, according to quartiles of umbilical plasma DHA or AA percentage, respectively.

Table 6 shows the results of the backward stepwise multiple regression analyses predicting the total score of the Mastricht Motor Test with umbilical plasma DHA and $\mathrm{AA}$ as independent variables, respectively. Corrected for gender, age at measurement, and cognitive performance, DHA at birth showed a significant positive relation with movement outcomes (partial $p=0.01$ ). The corrected (negative) contribution of umbilical plasma $\mathrm{AA}$ was not significant (partial $\mathrm{p}=0.07$ ). Backward stepwise regression analyses with DHA and AA in plasma sampled at 7 years of age, again resulted in models with gender, cognitive performance and age as significant covariables. DHA and AA did not play a significant role in predicting the Maastricht Motor Test total score (partial $p=0.19$ and 0.39 , respectively).

The same analyses with the Maastricht Motor Test quality score as dependent variable resulted in similar models with cognitive performance, gender and age as significant covariables (data not shown). Umbilical plasma DHA showed a significant positive association with the Maastricht Motor Test quality score (partial $p=0.01$ ). The relation between umbilical plasma AA and the Maastricht Motor Test quality score was negative and of borderline significance (partial $p=0.052$ ). At 7 years of age, the resulting models also contained gender, cognitive performance and age as significant Covariables. As in the analyses with the Maastricht Motor Test total score, the role of DHA and $A A$ was not significant (partial $p=0.19$ and 0.58 , respectively).

Backward stepwise logistic regression analyses with the dichotomized Maastricht Motor Test quantity score resulted in final regression models with no significant contribution of DHA or AA, either in umbilical plasma (partial $p=0.30$ and 0.78 respectively) or in plasma sampled at 7 years of age (partial $p=0.12$ and 0.34 , respectively). So children with a quantity score median or higher did not differ from children scoring below median in these LCPUFA values.

\section{Discussion}

Movements of the human body result from a complex interaction between muscles and the nervous system. Neuronal cells are known to contain high amounts of longchain polyunsaturated fatty acids (LCPUFA), having a specific role in nervous system function. Our aim was to investigate the relation between motor function at 7 years of age and LCPUFA values both in umbilical plasma and in plasma sampled at 7 years.

Two aspects of motor function were measured: quantity (the ability of the child to perform a movennent) and quality of movement (how the movement is performed). Gender differences were found for both aspects, in favour of the girls. This is consistent with results of other studies $(18,19)$. Movement quantity, as measured with the new Maastricht Motor Test, showed a ceilng effect in our 7-year-old study population, which was not surprising, since validation and reliability studies for this test were restricted to 5-6-year old populations. Nevertheless, there was a good correlation between this quantitative movement outcome and the movement quantity as measured with the Movement-Assessment Battery for Children ( $r=0.62, p<0.0001$ ). Fortunaty, the scores on the more sensitive movement quality scale of the Maastricht Motor Test showed a normal distribution in our population. For this reason, the total 
score on the Maastricht Motor Test may be a better reflection of the movement quality than of the mowement quantity.

Results of backward stepwise regression analyses consistently showed a significant contribution of cognitive performance and age to the motor outcomes, consistent with the literature $(12,15,17)$. Gender was an additional significant predictor when quality of movement was considered (in the models predicting the Maastrich Motor "Test total score and quality score). The resulting regression models show a positive relation between umbilical plasma DHA and movement quality outcomes, when contected for the mentioned covariables. In the models predicting movement quantity, the contribution of DHA and AA (both at birth and at 7 years of age) was not significant. Since movement quality may predict developmental problems like attention deficit hyperactivity disorder (ADHD) and leaming problems $(14,15,17)$, this finding is in line with the idea that LCPUFA status might also be associated to this kind of disorders $(20,21)$. Umbilical plasma AA percentage was negatively associated with movement quality outcomes. Although this association was not statistically signilicant (partial $p=0.052$ ), further attention for this LCPUFA is warranted.

Earlier studies relating perinatal LCPUFA to motor performance are rare, and never included a follow-up measurement at 7 years of age. In preterm infants a positive association was found between Bayley"s Psychomotor Development Index (PDI) and plasma DHA $(22,23)$. Similarly, in a cohort of 101 low-birthweight, formula-fed infants, a positive relationship was found between Bayleys's PDI at 19 months and red blood cell DHA contents at the postnatal age of 6 weeks (24). Furthermore, Bayley's PDI was higher in infants with birthweights $\leq 1250 \mathrm{~g}$ fed $\mathrm{AA}+\mathrm{DHA}$ supplemented formulas as compared with a control group (25). In a randomized study, as part of a cohort study in low-birthweight infants, infants who received $0.43 \%$ DHA showed higher red blood cell. DHA contents at 6 weeks postnatally and a higher PDI at 19 months than those who received $0.20 \%$ DHA (24). Several randomized trials in term human infants did not obtain differences in motor development at 6,12 or 18 months between infants fed formula with and without LCPUFA (26-31). Motor development was measured with the Bayley Scales of Infant Development II (Psychomotor Development Index), which measures motor performance in a quantitative way (32). Hence, the results of our follow-up study agree with earlier findings of studies with shorter follow-up durations, indicating that there is no evidence for a beneficial effect of LCPUFA on quantitative motor performatice in term infants. None of the studies relating perinatal DHA to child development used quality of movement as outcome.

Hypotheses about the mechanisms underlying the functional roles of DHA in the CNS include specific effects of this LCPUFA on lipid bilayer structure and dynamics (33). Changes in membrane fatty acid composition could iead to changes in membrane fluidity and membrane protein function (transporters, receptors, enzymes), thereby influencing the process of signal transduction in the CNS $(34,35)$.

The finding that the DHA status in umbilical plasma, in. contrast to the LCPUFA status in plasma at 7 years, is associated with movement quality suggests that prenatal LCPUFA availability may be more important for later motor function than childhood dietary LCPUFA intake. Since neonatal LCPUFA values can be influenced by maternal diet during pregnancy (11), maternal LCPUFA intake during pregnancy can be expected to influence later movement quality of the child. Intervention studies will be necessary to find out wether DHA supplementation of mothers during pregnancy indeed has beneficial effects on this aspect of child development. 


\section{Literature}

1. Sastry PS. Lipids of nervous tissue: composition and metabolism. Prog Lipid Res 1985:24:69176

2. Innis SM. Essentalfaty acids in growh and development. Prog Lipid Res 1991:30:39-103.

3. Reisbick S. Neural Development. In: Carlson S. Neuringer M Reisbick S. editors. Assessment of infom visuat and cognitive function in relation to long chain polyunsaturated fatry acids. Basel: Edinones Roche: 1996 . p. 10-8.

4. Makrides M, Neumann M. Simner K. Pater J. Gibson R. Are long-chain polyunsantuated fatty acids essential nutrients in infancy? Lancet 1995:345:1463-8.

5. Birch EE, Hoffruan DR, Uauy R. Birch DG, Prestidge C. Visual acuity and the essentiality of docosahexaenoic acid and arachidonic acid in the diet of term infants. Pediat Res 1998;44:201. 9.

6. Willats P. Forsyuh JS, DiModugno MK, Varma S. Colvin M. Effect of long-chain polyunsaturated faty acids in infant formula on problem solving at 10 months of age. Lancet $1998 ; 352: 688-91$

7. Clandinin MT, Chappell IE, Lcong S, Heim T, Swyer PR, Chance GW. Intauterine fatty acid accretion rates in human brain: implications for fatty acid requirements. Early Hum Dev $1980 ; 4: 121-9$

8. Clandinin MT, Chappell JE, Leong S, Heim T, Swyer PR, Chance GW. Extraterine fatly acid accretion in infant brain: implications for fatly acid requirements. Early Hum Dev $1980 ; 4 ; 131$ 8.

9. Carlson SE, Neuringer M. Polyunsaturated fatty acid status and neurodevelopment: a summary and critical analysis of the literature. Lipids 1999:34:171-8.

10. Carson SE. Behavioral methods used in the study of long-chain polyunsaturated fatty acid mutrition in primate infants. Am J Clin Nutr 2000;71:5268-74.

11. Al MDM , Houwelingen ACv, Kester ADM., Hasaart RHM, Jong EAPd, Hornstra Gr. Maternal essential fatty acid patrern during nomal pregnancy and their relationship to neonatal essential fatly acid status. Br J Nutr 1995;74:55-68.

12. Henderson SE, Sugden DA. Movement Assessment Battery for Children. London: The Psychological Corporation Ltd; 1992.

13. Gablyard CP. Livelong motor development. Boston: McGraw Hill Companies; 1996.

14. Towwen BCI... Examination of the child with minor neurological dystunction. London: Spastics Intermational Medical Publications; 1979

15. Weigghis-Kupens N, Baers W. Fetter WP. Hempell MS, Mulder PG. Touwen BC. et al, Minor neurological dysfuncion and quality of movement in relation to neonatal cerebral damage and subsequent development. Dew Med Child Neurol 1994:36:727-35.

16. Kroes M. Vissers Y. Sleipen F. Feron F, Kessels F, Bakker E, et al. Reliability and validity of ar qualitative and quantitative motor test for 5-to 6 year-old children. Submitted for publication.

17. Soonami-Lunsing RJ. Hadders-Algra M, Olinga AA. Huisjes HJ, Touwen BC. Is minor neurological dysfunction at 12 years related to behaviour and cognition? Dev Med Child Neurol 1993\%35:321.30.

18. Honderson SE, Hall D. Concomitants of clumsiness in young schoolchildren. Dew Med Child Nearrol 1982:24:448460. 
19. Johnston $\mathrm{O}$. Short H, Crawford J. Poorly coordimated children: a survey of 95 cases. Child Care Healin Dev 1987,13:361-76.

20. Stevens LJ, Zentall SS, Deck NL. Abate ML, Watkins BA, Lipp SR, et al. Essential fatty acid metabolism in boys with atention-deficit hyperactivity disorder. Am J Clin Nutr 1995;62:7618.

21. Burgess J, Stevens $L$, Zhan W. Peck $\mathbb{L}$. Long-chain polyunsaturated faty acids in children with attention-deficit hyperactiwity disorder. Am I Clin Nutr 2000;71:327S-30S.

22. Bjerve KS. Thoresen L, Bonaa K. Vik T. Johnsen H. Brubakk AM. Chinical studies with alphalinolenic acid and long-chain n-3 fatty acids. Nutrition 1992;8:130-2.

23. Bjerve KS, Brubakk AM, Fougner KJ, Johnsen H. Midthell K. Vik T. Omega-3 ratty acids. essential faty acids with important biological effects, and serum phosplotipid fany acids as markers of dietary omega 3-fatty acid intake. Am J Clin Nutr 1993;57,580 1.\$5.

24. Woltil H, Beusekom C, Okken-Beukens M, Schatsma A, Muskiet F. Okken A. Development of low-birthweight infants at 19 months of age correlates with early intake and status of longchain polyunsaturated fatty acids. Prostaglandins Leukot Essent Fatry Acids 1999;61:235 4 1.

25. O'Connor DL, Hall R, Adamkin D, Auestad N, Castillo M, Connor WE, et al. Growh and development in preterm infants fed long-chain polyunsaturated fatty acids: a prospective, randomized controlled trial. Pediatrics 2001;108:359-71.

26. Carlson S. LCPUFA and functional development of preterm and term infants. In: Bindels $\mathbb{I G}$. Goedhar AC, Visser HKA, editors. Recent developments in infani nutrition. Dordrecht: Kluwer Academic Publishers; 1996. p. 218-24.

27. Scott DT, Janowsky IS, Carroll RE, Taylor JA, Auestad N, Montalto MB. Formula supplementation with long-chain polyunsaturated fatty acids: are there developmental benefits? Pediatrics 1998;102:E59.

28. Lucas A, Stafford M. Morley R, Abbott R. Stephenson T, MacFadyen U, et al. Efficacy and safety of long-chain polyunsaturated fatty acid supplementation of infant-formula milk: a randomised trial. Lancet 1999;354:1948-54.

29. Birch EE, Garfield S, Hoffman DR, Uauy R, Birch DG. A randomized controlled trial of early dietary supply of long-chain polyunsaturated fatty acids and mental development in term infants. Dev Med Child Neurol 2000:42:174:81.

30. Makrides M, Neumann MA. Simmer K. Gibson RA. A critical appraisal of the role of dietary long-chain polyunsaturated faty acids on neural indices of lerm infants: a randomized. controlled trial. Pediatrics 2000;105:32-8.

31. Auestad N. Halter R. Hall RT. Blatter M, Bogle ML, Burks W, et al. Growth and development

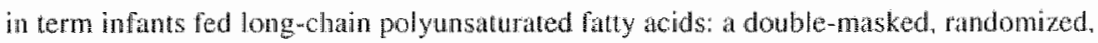
parallel, prospective, multivariate study. Pediatrics 2001:108:372-81.

32. Bayley N. Bayley Scales of Infant Development. New York: Psyclological Corporation; 1969.

33. Stubbs CD. The structure and function of docosahexaenoic acid in membranes. In: Sinclair $A$. Gibson R. editors. Essential fatly acids and eicosanods: Invited papers from the third international congress. Champaign. Illinois: American Oil Chemists' Society: 1992, p. 116-21.

34. Fernstrom ID. Effects of dietary polyunsaturated fatty acids on neuronal function. Lipids $1999: 34: 161.9$.

35. Kurlak $\mathbb{L} O$, Stephenson TJ. Plausible explanations for effects of long chain polyunsaturated fatly acids (LCPUFA) on neonates. Arch Dis Child Fetal Neonatal Ed 1999:80:F148-54. 


\section{Dietary DHA and infant visual function: a review of literature}

Esther C. Bakker Carlos E. Blanco

Gerard Hornstra 


\begin{abstract}
The human central nervous system, including the retina, contains high amounts of long-chain polyunsaturated fatty acids (LCPUFA), especially docosahexaenoic aid (DHA). Since, in contrast to human milk, most standard artificial formula's are devoid of LCPUFA, neonates who receive formula may have a slower retinal development than breastfed neonates.

Functional effects of dietary DHA are found in animals, but results of studies in human infants are not consistent. Possible explanations for these inconsistencies include differences between studies in composition of formulas and human milk, in other potential confounding factors, in age at visual function measurement and in initial fatty acid values at birth.

Because visual development is not complete until at least 3 years of age, further studies to investigate the long-term effects of DHA on the functioning of the vistal system, including the initial fatty acid levels, are recommended.
\end{abstract}




\section{Introduction}

The retina, the light-sensitive part of the eye, is part of the centrall nervous system. The membrane phospholipids of the central nervous system tissues contain large amounts of long chain polyunsaturated faty acids (LCPUFA), especially arachidonic acid (AA: 20:4n-6) and docosahexaenoic acid (DHA: 22:6n-3). These fatty acids can be supplied by nutrition or synthesized from their (essential) precursors hnoleic acid (LA: 18:2n-6) or alpha-linolenic acid (Al A: 18:3n-3), respectively. These precursors cannot be synthesized by the human body and are therefore called essential fally acids" (EFA). Retinal photoreceptor membranes contain the body's highest concentrations of DHA. Recognition of this fact led to the hypothesis that dietinduced alterations in retinal faty acid composition could lead to changes in revinal function (1).

Because the central nervous system, including the retina, mainly develops during late pregnancy and in the first postnatal year, ar adequate supply of EFA and LCPUFA to the child during this period is very important. During normal development in utero, the fetus is supplied with these fatty acids by the mother via transport through the placenta. Neonates are dependent on human milk or formula for their LCPUFA supply. Human milk generally contains linoleic acid, alpha-linolenic acid, $\mathrm{AA}$ and DHA. Standard artificial formula's for term nonates are devoid of LCPUFA. It has been reported that formula-fed human infants have slower functional development of the visual system than breasted infants (2-5). However, results of studies which investigate the relation between LCPUFA and visual function are not consistent. In this narrative review of literature, some possible explanations for this inconsistency are suggested. For a systematic review and meta-analysis on this subject we refer to SanGiovanni et al. $(6,7)$.

First, the functioning of the visual system is described. Then the effects of dietary DFA on fatty acid composition of the retina in both animals and humans are discussed. The next section gives an overview of studies with preterm and term human neonates in which the functional effects of DHA in the retina are described. Finally, possible explanations for the inconsistencies between studies in human infants are discussed and suggestions are given for future research.

\section{Functioning and development of the visual system}

Vision is a process that begins when light is focused by cornea and lens onto the retina. The retina consists of pigment epithelium and five main classes of colls. Photoreceptor cells (rods and cones) lie in the deep surface of the retina. The cones are responsible for color vision and high visual acuity and the rods are mainly responsible for vision in the dark. They are connected to bipolar cells that subsequently connect to ganglion cells and to optic nerve fibers. Side-lo-side connections ane achieved by the horizontal and amacrine cells (8).

Photoreceptor cells transform light energy into a neural signal. This transformation starts in the outer segments of the photoreceptor cells. In these segments a lightsensitive photochemical is found in a stack of membranous disks. In the case of the rods, this is rhodopsin, and in the cones it is one of several photochemicals collectively called iodopsin. The composition of iodopsin only differs from rhodopsin in the protein portion of the photochemicals, thus making the cones selectively sensitive to different wavelenghs. Neural signals from the photoreceptors are processed in the other retina cells, resulting in nerve impulses sent via the axons of retinal ganglion cells through the optic nerve and optic tract to the brain (1). 
In the third urimester of gestation, rapid cortical growth takes place, e.g. in the primary wisual (strate) cortex. The formation of the central retina, however, is not complete until childhood $(9,10)$. Cone photoreceptors of the newborn central retina are so large ( 7.5 um in diameter), that not many of them can fit into the available area. This low number of photoreceptors per retinal area causes the neonate to have a low discriminative spatial resolution. In about 3 years the cones reach their normal adult width of $2 \mu \mathrm{m}$. During this period, the cone density in the central retina increases from 18 to 42 photoreceptors per 100 um, on the average. The cortical neural network and the optic nerve remain unmyelinated and immature during this period (9). Therefore, visual acuity does not reach adult levels until at least 3 years of age, (11, 12), although it shows a plateau between 6 and 12 months of age (13). With some methods, adult responses can be found at an earlier age, because different methods of acuity measurements adress different aspects of the wisual system $(11,14)$.

\section{DHA in the retina}

The structural lipids of the disk membranes in photoreceptor outer segments consist primarily of phospholipids (80-90 of total lipid). DHA can account for up to 35 mol\% of the total fatty acids in these phospholipids (15). The highest levels of DHA are found in the retina as well as in the cerebral cortex, Since studies in artificial membranes have shown that the photochemical activity of rhodopsin is influenced by the DHA content in the disks $(1,16)$, accretion of this fatty acid, or lack thereof, could markedly affect retinal development and visual acuity.

Few studies measured the DHA content of the human retina tissue in relation to the infant diet $(17,18)$. Martinez (17) determined prenatal and postnatal fatty acid accretion by analyzing the lissues of infants who were born at different gestational ages and died after birth from causes that were not related to the central nervous system. She found an increase in retinal DHA as a percentage of total fatty acids, together with a decrease in A. DHA proportions tended to plateau in the retina by 40 weeks of gestation (17). Makrides et al. (18) did not find differences in retinal DHA between breast-fed infants and formula-fed infants. With postmortem samples from predominantly term infants, the fatty acid compositions (total lipids) of the retinas of 12 predominantly breastfed infants were compared with that of 16 predominantly formula-fod infants. Although breastfed infants had a greater percentage of DHA in their red blood cells (RBC) and brain cortex relative to those fed formula, no difference was lound in retinal DHA between both groups. There were also no associations between length of breasteeding or age at death and retinal. DHA. These results can be explained with the plateau in DHA accretion described by Martinez (17). This platean is already reached at birth in term infants. Since the retina is known to be able to recycle DHA (19), the differences in dietary DHA between formula and breasted infants probably do not lead to differences in retinal DHA.

Animal studies suggest that dietary manipulation has large effects on DHA in retinal phospholipids. Diets low in n-3 fatty acids resulted in a low DHA content of the retinal phospholipids as compared with a control group $(20,21)$ and feeding a diet containing DHA resulted in higher DHA levels in the retina than feeding diets with only $18: 3 n-3$ or diets deficient in n-3 fatty acids $(22-27)$. However, many animal studies do not distinguish between pre-and postnatal fatty acid supply, because they often look at second generation animals. So the results of these studies are not necessarily comparable to studies in humans. 


\section{Functional effects of DHA on the retina}

\section{Methods}

The possible effects of dietary DHA on visual function can be measured using a variety of methods. Here, we discuss three of them: the electroretinogram, Visual Evoked Potentials, and one of the behavioral acuity tests: the Teller Acuity Card procedure. Because these various methods measure different aspects of visual function, test results are not necessarily comparable to each other $(9)$.

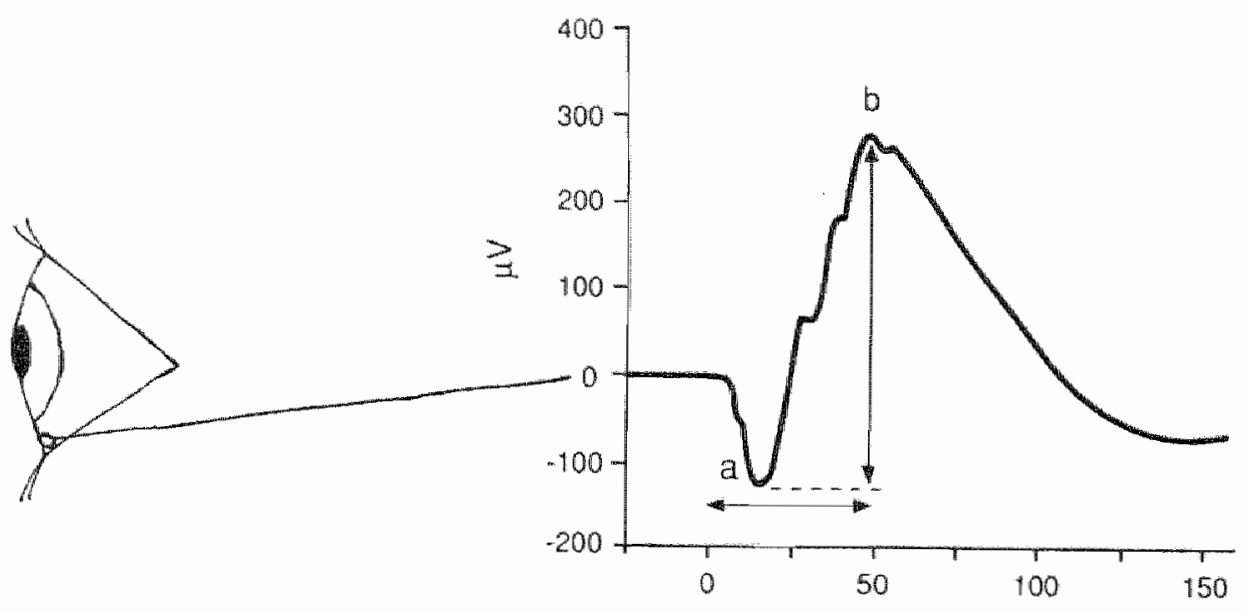

Figure 1: Schematic representation of the electroretinogram measurement

The electroretinogram (ERG) measures the retinal response upon a light stimulus of adequate intensity (28). This response includes an inicial a-wave of negative polarity, followed by a larger, positive b-wave. B-wave amplitude is measured from the trough of the a-wave to the peak of the b-wave (vertical arrow, see Figure 1). Latency is the period between the light stimulus and the trough of peak of the a-wave or b-wave, respectively (horizontal arrow).

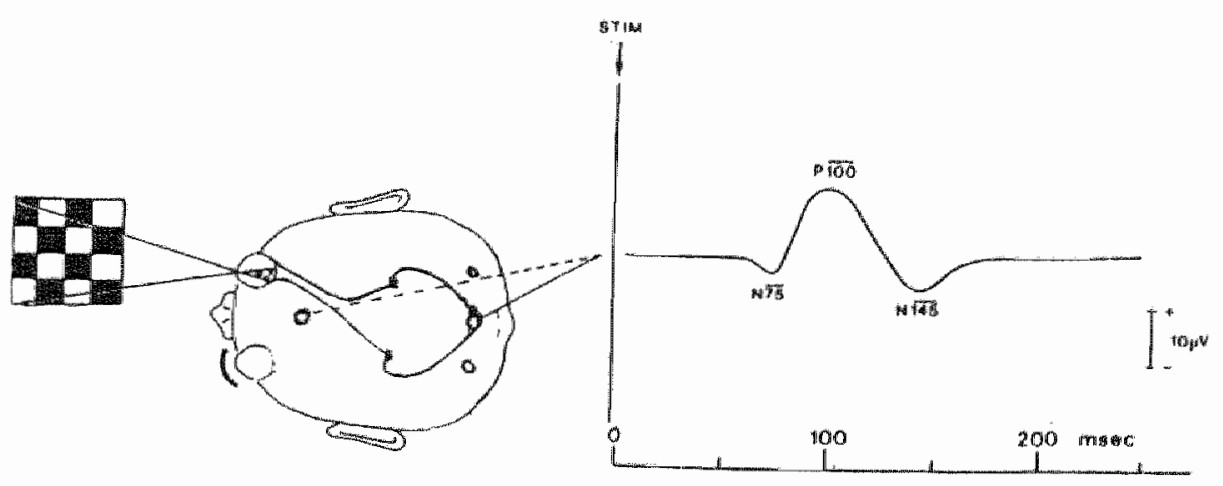

Figure 2: Schematic representation of Visual Evoked Potentals 
Visual Evoked Potentials (VEP) measure the child's cortical responses to at changing visual stimulus (for instance a reversing checkerboard), presented on a video screen. Depending on the reversal rate, a discrete wave-form can be obtained (see Figure 2). First, a negative peak (N75) is identified at about 75 msec after stimulus change (latency); at about $100 \mathrm{msec}$ a positive peak occurs (P100), again followed by a negalive peak at about $145 \mathrm{msec}$ (N145). The amplitude is defined as the difference in potential between the N75 peak and the P100 peak. By varying the check size(or spatial frequency), this method can also be used to estimate the visual acuity, which measurcs the maximal spatial resolution of the whole visual system (12).

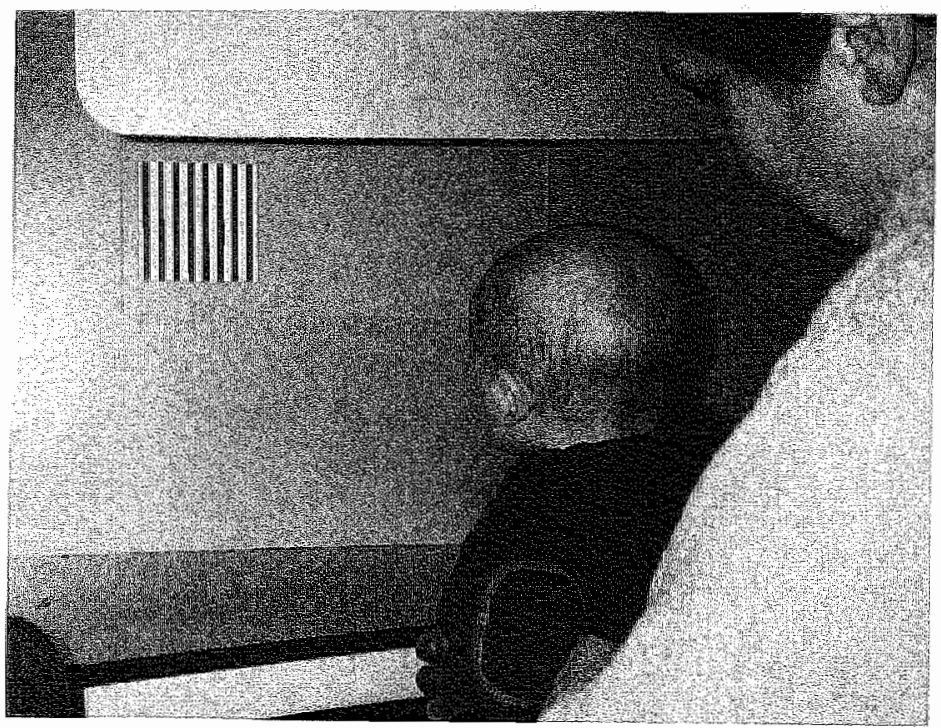

Figure 3: The Teller Acuity Card procedure

Behavioral acuity tests, measure visual acuity directly, by interpreting the child's reaction upon a visual stimulus. Preferential looking methods, including the Teller Acuily Card procedure, use the infant's innate tendency to gaze at a pattern rather than a blank gray field (12). With the Teller Acuity Card method, a card with a black-andwhite grating of a particular spatial frequency (stripe width) is presented to the infant (sec Figure 3). If the infant is able to perceive this stripe-pattern, it will fix the attention on this part of the card. If not, the child will loose attention. The finest stripe pattern that can be distinguished repeatedly is taken as an acuity estimate.

Consistent with the effects of dietary manipulation on retinal DHA composition, functional effects of dietary DHA are found in animal studies $(20,21,29,30)$. Results of studies in human inlants are not very consistent. Here, results of studies in both preterm and term infants are discussed. 
Table 1: Studies investigating the relation between dietary DHA and visual function iti preterm infants

\begin{tabular}{|c|c|c|c|c|c|c|}
\hline First author (ref) & n & $\begin{array}{l}\text { dietary DHA } \\
(\text { of })^{*}\end{array}$ & $\begin{array}{l}\text { diet } \\
\text { duration } \\
\text { (months) }\end{array}$ & Methods & $\begin{array}{l}\text { Age } \\
\text { (morths } \\
\text { iffer term) }\end{array}$ & Resuls \\
\hline Vauy (31) & 42 & $0-0.35$ & 4 & ERG & 0 & + \\
\hline Birch $(32)$ & 71 & 0.0 .35 & 4 & $\mathrm{ERG}$ & $0+4$ & $\begin{array}{l}+\operatorname{sit} 2 . \\
0 \text { at } 4 \text { monils (mo) }\end{array}$ \\
\hline $\operatorname{Binch}(2)$ & 83 & $0-0.35$ & 4 & $\mathrm{VEP} / \mathrm{TAC}$ & 0.4 & + \\
\hline $\operatorname{Birch}(3)$ & 30 & $\mathrm{HM} / \mathrm{F}(0.0 .29)$ & 4 & $\mathrm{VEP} / \mathbb{T A C}$ & 4 & + \\
\hline Carlson (33) & 67 & 0.0 .2 & 9 & TAC & $2,4.6 .5+12$ & $\begin{array}{l}+ \text { at } 2 \text { and } 4 \mathrm{mo} \\
0 \text { at } 6.5 .9 \text { and } 12 \text { mo }\end{array}$ \\
\hline Carlson $(34,35)$ & 58 & 0.0 .2 & 2 & $\mathrm{TAC}$ & 2 & $+\mathrm{at} 2.0 \mathrm{al} 4 \mathrm{mo}$ \\
\hline $\operatorname{Legf}(36)$ & 18 & HM/F $(0-0.27)$ & 0.3 & ERG/TAC & $0-3$ & - ERG. O TAC \\
\hline Faldella (37) & 58 & $0-0.23$ & 3 & $\mathrm{ERG} / \mathrm{VEP}$ & 3 & 4 VEP $0 \mathrm{ERO}$ \\
\hline $0^{\prime}$ Connor (38) & 470 & 0.0 .26 & 12 & TAC/ERG & 2.4 .65 & + ERG 6 mo.0TAC \\
\hline
\end{tabular}

* HM=human milk. F=standard artificial fomula (observational sludies)

ERG=Eleciroretinogram, VEP=Visual Evoked Potentials, TACEPreferential looking/leller Acuity Cards

4 a positive influence of dietary DHA on visual function is indicated with at,+ 0 means no influence, indicates a negative influence.

\section{Preterm infonts}

Because preterm infants miss part of the fatty acid accretion in utero, postnatal laty acid supply by human milk or formula seems to be very important. Table 1 gives an overview of functional studies in preterm infants. These studies are shorily described here, beginning with the studies that used electroretinograms (ERG), followed by the studies measuring visual acuity, either with the VEP method or with the preferential looking method. Birch, Uauy et al. $(31,32)$ recorded ERG's as a measure of visual function in preterm, very-low-birth-weight infants at term ( 36 weeks postconceptional age) and at 4 months after term (57 weeks postconceptional age). Four different infant diets were compared: human milk, a fomula supplemented with marine oil, containing DHA and EPA (eicosapentacnoic acid, 20:5n-3), a standard com oil formula, low in ALA and a standard soybean oil formula, relatively high in ALA. They found a decreased rod response in the corn oil lormula group at term $(31,32)$. but not at 4 months after term (32). Furthermore, rod responses correlated significantly with red blood cell and plasma n-3 LCPUFA (31). Cone function was not significantly related to dietary essential fatty acids $(31,32)$. The same method was used by faldella et al. (37) and Leaf et al. (36). Faldella et al. compared 12 preterm infants fed breastmilk with 25 preterm infants fed standard formula and 21 preterm infants fed formula supplemented with LCPUFA $(0.23 \%$ DHA, $0.08 \%$ EPA and $0.35 \%$ AA) at 52 weeks of postconceptional age. They found no differences in ERG recordings between the three groups, although visual evoked potential (VEP) mensurements indicated slower visual maturation in preterm infants who did not receive LCPUFA (37). Leaf et al. (36) recorded ERGs at 40 weeks of postconceptional age in 18 premaure infants. Most of the ERG recordings were not significantly difrerent between nine infants with high breast milk intake ( $74 \%$ of tolal diet) and nine infants with low breast milk intake (17.5\% of total diet), although the first group had a 
significanty lower amount of DHA in plasma and red blood cell phospholipids. They even found a negative correlation between rod function and DHA levels in both plasma and red blood cells.

The effects of $\mathrm{n}-3$ fatty acids on visual acuity of preterm infants were measured by several authors. Birch et al. $(2,3)$ used both the VEP method and the preferential looking method. With both methods, they found poorer visual acuity in preterm infants fed a com oil formula than in those fed a marine oil-supplemented formula or human milk at term ( 36 weeks postconceptionall age) and at 4 months after term (57 weeks postconceptional age). Inlants fed a soybean oil formula also had poorer VEP acuity than the marine oil-supplemented group at 4 months. Cartson et al. (33-35) used the acuity card procedure to compare visual acuities of preterm infants fed a standard formula or a marine oil-supplemented formula. Infants fed standard formula had significantly poorer acuity at $2(33-35)$ and 4 months (33) compared with infants fed supplemented formula, but these differences were not present anymore at $6.5,9$, and 12 months. Leaf et al. (36) also measured visual acuity with the Teller acuity cards at 40 weeks postconceptional age and at 3 months post term, but no correlations of DHA in diet or blood phospholipids were found with visual acuity at both ages. In the recent study of $\mathrm{O}^{\prime}$ Connor et al. (38) four feeding groups were compared: a group fed standard artificial formula without LCPUFA, two groups fed artificial formula with DHA and AA from either fish/fungal oil or egg yolk, and a human milk fed group. Visual acuity measured by acuity cards at 2,4 , and 6 months of age was not different among these groups. Visual acuity measured by VEP in a subgroup of 157 children was better in both $A A+D H A-s u p p l e m e n t e d$ groups as compared with the control group, and closer to that of the human milk group at 6 months of age $(38)$.

In summary, dietary DHA seems to influence some aspects of visual function in preterm infants, at least until 2 months after term.

\section{Term infonris}

The results of studies in term infants are summarized in table 2 . The relation between dietary DHA and visual development in term infants seems consistent, as long as the VEP method is used. Birch et al. $(2,3)$ found that term breast-fed infants had significantly better visual acuity scores than formula-fed infants at 4 months after birth (measured as Visual Evoked Potentials (VEP) and preferential looking scores). Makrides et al. (4.40) reported significantly better VEP-acuicy scores in breastfed term infants than in torm infants fed standard formula at 16,22 and 30 weeks after birth. They also observed a positive correlation between the DHA-content of red blood cells and VEP-acuity. At an age of 16 and 30 weeks, infants who received LCPUFA-supplemented formula had acuities matching those of fully breastfed infants (40). Jorgensen at (47) also described an effect of diet on VEP acuity at 4 months. However, there was no statistical difference between DHA-supplemented formulas and standard formula or human milk. Using the VEP method at different ages, also Auestad ot al. (43) did not find diflerences between term infants fed formulas with DHA, with DHA plus AA, or withou LCPUFA. Birch et al. (45) found significantly poorer VEP-acuitios in infants fed standard formula as compared with infants fed human milk or formula supplemented with DHA or with DHA and AA from single cell oils at 6,17 and 52 weeks of age, but not at 26 weeks of age. In the recent study of Makrides et al. (49) the VEP acuities of a human milk group, a control formula group, a DHA-supplemented formula group and a DHA+AA supplemented formula group were compared. There were no differences among the randomized formula 
groups for VEP acuity at either 16 or 34 weeks of age. Breastfed infants had better VEP acuiry at 34 weeks of age, but not at 16 weeks, compared with all formula-fed infants.

Table 2: Studies investigating the relation between dietary DHA and visual function in term infints*

\begin{tabular}{|c|c|c|c|c|c|c|}
\hline $\begin{array}{l}\text { First authors } \\
\text { (rer.) }\end{array}$ & $\mathrm{n}$ & $\begin{array}{l}\text { dietary DHA } \\
(\mathscr{w})^{*}\end{array}$ & $\begin{array}{l}\text { diet } \\
\text { duration } \\
\text { (months) }\end{array}$ & Methods ${ }^{3}$ & $\begin{array}{l}\text { Age } \\
\text { (months) }\end{array}$ & Results $^{\ddagger}$ \\
\hline Birch (2) (3) & 49.30 & HM/F $(0-0.29)$ & $2-4$ & VEP/TAC & 4 & + \\
\hline Birch (3) & 43 & HM/F $(0-0.29)$ & 12 & other & 36 & + some tests \\
\hline Makrides (4) & 16 & $\mathrm{HM} / \mathrm{F}$ & 5 & VEP & 5 & + \\
\hline Inmes $(39)$ & 35 & $\mathrm{HM} / \mathrm{F}(0-0.22)$ & 3 & TAC & $0.5,3$ & 0 \\
\hline Makrides $(40)$ & 79 & $0-0.36$ & 30 & VEP & $4+7$ & + \\
\hline Carlson (41) & 58 & $0-0.1$ & $>3$ & TAC & $2,4,6,9,12$ & $\begin{array}{l}+ \text { al } 2 \text { months. } \\
0 \geq 4 \text { moncs }\end{array}$ \\
\hline Innis (42) & 433 & $\mathrm{HM} / \mathrm{F}$ & 0.9 & TAC & 9 & 0 \\
\hline Jorgensen (5) & 33 & $\mathrm{HM} / \mathrm{F}(0-0.53)$ & 4 & $\mathrm{TAC}$ & 1.2 .4 & + \\
\hline Auestad (43) & 197 & $0-0.9$ & $3-12$ & TACNEP & $2,4,6,9,12$ & 0 \\
\hline Innis (44) & 172 & 0.0 .3 & 3 & $\mathrm{TAC}$ & 3 & 0 \\
\hline Birch (45) & 108 & $0-0.36$ & $>4$ & VEPITAC & $1.5,4,6, \| 2$ & $\begin{array}{l}\text { to VEP, } \\
0 \text { at } 1.5 \mathrm{mo}, 0 \mathrm{TAC}\end{array}$ \\
\hline Courage (46) & 100 & 0.02 & $>3$ & $\mathrm{TAC}$ & $3,6,18$ & $\begin{array}{l}+ \text { at } 3 \text { and } 6 \text { mo, } \\
0 \text { at } 18 \text { months }\end{array}$ \\
\hline Jorgensen (47) & 62 & $0-0.38$ & 4 & VEP & 4 & $\begin{array}{l}+\mathrm{HM}>\mathrm{F} \\
\text { OF-DHA Ys. F }\end{array}$ \\
\hline Bakker (48) & 74 & $\mathrm{HM} / \mathrm{F}$ & 0.7 & TAC & 7 & 0 \\
\hline Makrides (49) & 114 & 0.0 .35 & 7 & VEP & $4+7$ & 0 \\
\hline Auestad (50) & 404 & 0.0 .14 & 12 & TAC & $2,4,6,12$ & 0 \\
\hline
\end{tabular}

* For legend, see Table 1

Studies using the Teller Acuity Card method give less consistent results. Birch at al. (3) reported differences in Teller acuity at 4 months between breasted and formula-fed infants. Breastfed infants scored higher acuities as compared with formula-fed infants and acuity was correlated with n-3 fatty acids in RBC membranes. Furthermore, Jørgensen et al. (5) compared breastfed infants with formula-fed infants at 1,2 and 4 months. They found that the increase in visual acuity, measured by Teller Acuty Cards, developed more rapidly in breastfed infants compared to formula-red infants. This was paralleled by a DHA decrease in RBC (PC and PE) of formula-fed infants, resulting in a significantly lower DHA level at two and four months as compared to breast-fed infants. Carlson et al. (41) compared term infants fed a formula enriched with DHA plus AA from egg yolk lecithin with infants fed a standard formula without LCPUFA, or human milk. They measured the visual acuity with Teller acuity Cards at 2, 4, 6,9 and 12 months. At 2 months, breast-fed inlants and infants fed the supplemented formula had better acuities than infants fed the standand formula. Beyond the age of 4 montins, however, there was no relation any more between type of diet and visual acuity (4l). 
Other studies were unable to demonstrate significant relations between $\mathrm{n}-3$ fatty actds in the diel and Teller acuily in term infants. Innis el al. $(39,42,44)$ used the Taller Acuily Cards in three studies with children born at term. In the first study (1994), they compared the visual acuity of 17 breastfed infants with that of 18 infants fed standard formula at the age of 14 days and 3 months. This study did not show any differences in visual acuity between both groups, despite substantial differences in RBC and plasma lipid DHA contents. In their second study (1996), Innis et al. moasured the visual acuity of 433 term intants at 9 months of age. In this study, no influence of infant diet (human milk or formula) on visual acuity was observed either. In their third study (1997), they compared the Teller acuity of breastfed children with that of children fed different formulas. Again, no differences were found between the groups. These findings agree with our recent study in 7 month old infants (Chapter 6 ). We compared infants fed standard formula with infants fed human milk, but we did not find differences between both groups in visual acuity, in spite of differences in fatty acid values in red blood cells and blood plasma phospholipids (48). The findings of Innis at also agree with those reported by Auestad at. (43), who compared Teller-and VEP-acuities of infants fed with different formulas (with DHA, with DHA and $A A$ and without LCPUFA from egg yolk) and human milk. No differences between the different groups at the ages of $2,4,6,9$ and 12 months were observed. In their recent study, Birch ef al. (45) did not find an effect of diet on visual acuity as measured with acuity cards either. They measured visual acuity at $6,17,26$ and 52 weeks of age in infants fed human milk or one of three formulas: standard formula, formula supplemented with DHA or with DHA and AA from single cell oils. Courage et al. (46) compared the Teller acuity of three groups of infants, fed ether human milk, standard formula or evaporated cow-milk formula. Infants fed human milk had significantly higher visual acuity scores at 3 and 6 months of age than infants fed evaporaled cow-milk. However, no differences were found between the standard formula group and the other two groups. At 18 months of age, the difference in visual acuity between human milk fed intants and infants fed evaporated cow-mik formula had clisappeared.

Recently, Auestad et al. (50) published another large DHA and AA supplementation trial, in which they measured the Teller Acuities of more than 400 children. Although the AA and DHA levels in plasma and red blood cells were highen in human milk group and the AAHDHA supplemented groups as compared with the control formula group, no differences in visual outcomes were found between those groups. In summary, results of studies in term infants are not consistent.

\section{Discussion}

Animal studies demonstrate that the DHA concentration in retinal phospholipids can be modulated by dietary manipulation. However, in term human infants no inflience of detary DHA on retinal DHA concentration was found, in spite of influences on DHA levels in red blood cell lipids (18). So the DHA content in blood lipids, which is often taken as a reflection of the DHA content of the retina, may not be a correct indicator for the retinal DHA content. In preterm infants, no information is atvalable about the influence of dietary DHA on retinal DHA concentrations. It would be useful to have more information on the postnatal retinal fatty acid accretion and the influence of the dietary DHA content on the retinal DHA values in these infants. In these infants, nutrition might have a stronger influence on retinal DHA values than in term infants, because they miss part of the fatty acid accretion in wtero. 
The finding of Martinez et al. (17) that DHA proportions tend to plateau in the human retina by 40 weeks of gestation, argues in favor of this thypothesis: pretem infants did not yet reach the plateau DHA values in their retinas at birth, so their postnatal DHA accretion may still be influenced by dietary DHA intake.

Functional effects of dietary DHA are found in animals, but results of studies in human infants are not consistent. There are various explanations possible for this phenomenon:

In different studies different methods are used, which can account for some of the inconsistencies. Some methods are sensitive enough to measure small differences. while others are not. Because each testing technique provides useful but not identical information about acuity, the acuity obtained must be interpreted within the framework of the methodology with which it was obtained (12). However, in the present review, inconsistencies in term infants are found even beween studies that use the same method: e.g. the Teller Acuity Card procedure. Therefore, the use of different methods does not adequately explain the inconsistencies between studies.

A second explanation is based on the composition of formulas and human milk. There are large differences in composition of formulas and/or human milk between studies, for example differences in the relative amounts of LA and ALA. Because these precursors of AA and DHA, respectively, are converted by the same enzymes, their ratio can have an influence on the rate of synthesis of these two LCPUFA. So, it seems possible that a very high LA/ALA ratio in formula, like in the study of Martinez $(66 / 1)(17)$, can cause a decrease in retinal DHA, resulting in functional effects. However, Jensen et al. (51) found no effect of the LA/ALA ratio in the infant diet (varying from 4.8 to 44 ) on visual function as assessed by transient visual evoked responses. Furthermore, the recent study of Makrides et al. (52) did not show differences in VEP acuity at 16 and 34 weeks between infants fed formulas with a LA/ALA ratio of either 10 or 5 . So, differences in LA/ALA ratios between studies do not seem to be a sufficient explanation for inconsistencies between studies, either. Differences between studies in other components of human milk and formula can still be a possible explanation for the inconsistencies between studies, however.

There are differences in other confounding factors between studies as well. Studies which compare human milk with formula-feeding can not be randomized for ethical and practical reasons. Therefore, confounding is more likely to occur in these studies. In the study described in Chapter 6 (48), no influence of some potential confounders, like smoking and drinking habits during pregnancy and socioeconomic status of the family, was found on the relationship between DHA in blood and diet and visual acuity. However, many other possible confounders were not investigated. Because the influence of possible confounders is not reported in most of the discussed studies, this could be an explanation for inconsistencies between studies as well.

It is also possible that the effect of dictary DHA on retinal function is only present in periods of rapid development. Studies in infants aged younger than 4 monhs secm to show an effect of dietary DHA on visual function, while studies in older infants do not find such an effect. This argues in favour of the explanation that an influence of dietary DHA on visual function can only be found in periods of rapid development. If so, infants who receive nutrition with DHA possibly reach the plateau-valucs for visual function earliet than infants who receive nutrition withou DHA, but eventually they all reach the plateau values. The results of most studies support this theory. although some exceptions exist: Innis et al. (39) did not find an iniluence of dietary DHA at 14 days and 3 months of age, while Jorgensen el al. (5) still observed this 
influence at 4 months. Even if this explanation for inconsistencies is accepted, it is important to know the meaning of the differences that are found in periods of rapid development. Are influences of dietary DHA on visual function only transient, or do long term effects exist? Since fine wisual acuity does not reach adult values until at least 3 years of age (11,12). it is possible that dietary DHA has an influence on adult visual acuity scores. As far as we know, visual function in later life has never been correlated to essential fatty acids. So further studies on the long term effects of DHA on visual function are necessary.

Differences between studies can also be explained by large variations in initial DHA values at bith. Fatty acid supply during the period of rapid retinal development (3rd trimester of pregnancy) may be more important for visual functioning than fatty acid status and supply at the moment of wisual acuity measurement. So, it is also possible that in infants born with very low DHA values dietary DHA has an effect on visual function, while this is not the case in infants whose initial DHA values are higher. Maybe the lowest DHA values in one study are sufficient, while the lowest value in another study is inadequate for optimal visual development. This explanation is supported by the consistent results in premature infants. Premature infants are known to have a lower DHA status at birth as compared with infants born at term (53). In premature infants dietary DHA has a positive influence on visual development in almost all studies. This confirms the idea that initial DHA values also play a role. Some studies reported the initial fatty acid values $(31,32,36,40,45,46)$. Unfortunately, these studies are not directly comparable, because they differ in age at first blood sampling (range 0-10 days), in lipid class, and in the way in which the fatty acids are expressed. Furthermore, the reported initial fatty acid walues are hardly used in the statistical analyses. So, a second recommendation for future research is to take into account the initial fatty acid levels and, if possible, even use the maternal fatty acid status during pregnancy as an indicator of fetal fatty acid supply.

A final remark concerns the focus on DHA. Because DHA is the major fatty acid in the retinal phospholipids and effects of dietary DHA are found on visual function, this overview focusses on the effects of dietary DHA on fatty acid composition and function of the retina. But we have to keep in mind that the described effects are not necessarily isolated DHA effects.

\section{Conclusion}

Results of studies which investigate the effects of dietary DHA on visual function in human infants are not consistent. Possible explanations for these inconsistencies include differences between studies in composition of formulas and human milk, in other potential confounding factors, in age at visual function measurement and in initial fatty acid values at birth. Future research should take into account these initial fatly acid levels and, if possible, even use the maternal essential fatty acid status during pregnancy as an indicator of fetal fatty acid supply. Furthermore, the long-term clitects of DHA on visual function should be studied, because nothing is known about the inlluence of DHA on adult visual acuily lewels, which are not reached until at least 3 years of age. Finally, not much is known about the postnatal retinal fatty acid accretion and the influence of diet on the retinal DHA values in preterm infants. 


\section{Literoture}

1. Neuringer $M$. Assessment of retinal function and vision in infants. In: Curlson $S$, Neuringer $M$, Reisbick S, editors. Assessment of infant wisual and cognitive funciton in relation to long chain polyunsaturated fatty acids. Basel: Editiones Roche: 1996. p. 19-48.

2. Birch $E E$, Birch $D G$, Hofman $D R$, Uaty $R$. Dietary essential fatty acid supply and visual acuity development. Invest Ophthalmol Vis Sci 1992:33:3242-53.

3. Birch E, Birch D, Hoffman D, Hale L. Everett M, Uauy R. Breast feeding and optimal visual development. J Pediatr Ophthalmol Strabismus 1993;30:33-8.

4. Makrides M, Simmer K, Goggin M. Gibson RA. Erythrocyte docosahexaenoic acid correlates with the visual response of healthy, term infants. Pediatr Res 1993;33:425-7.

5. Jorgensen $M H$, Hermell $O$, Lund $P$. Holmer $G$, Michaelsen KF. Visual acuity and erythrocyle docosahexaenoic acid status in breast fed and formulat fed term infants during the first four months of life. Lipids 1996:31:99-105.

6. SanGiovamni JP, Parra-Cabrera S, Colditz GA. Berkey CS, Dwyer JT. Meta-analysis of dietary essential faty acids and long-chain polyunsaturated faty acids as they relate to visual resolution acuity in healthy preterm infants. Pediatrics $2000 ; 105: 292-8$.

7. SanGiovanni JP, Berkey CS, Dwyer JT, Coldiz GA. Dietary essental fatly acids, long-chan polyunsaturated fatty acids, and visual resolution acuity in healthy fulterm infants: a systematic review. Barly Hum Dev 2000;57:165-88.

8. Jumpsen J. Clandinin MT. Brain development: Relationship to dietary lipid and lipid metabolism. Champaign, Illinois: AOCS Press; 1995.

9. Innis SM, Lupton BA, Nelson CM. Biochemical and functional approaches to study of fatty acid requirements for very premature infants. Nutrition 1994;10:72-6.

10. Larsen WJ. Human Embyology. New Yonk: Churchill Livingstone; 1997.

11. Sokol S. Maturation of visual function studied by visual evoked potentials. In: JE D, editor. Visual Evoked Potentials. Amsterdam: Elsevier Science Publishers, B. V.; 1990. p. 35-44.

1.2. Birch E. Visual acuity testing in infants and young children. Ophthalmol Clin $N$ Am 1.989:2:369.89.

13. Teller D. Teller Acuity Card Handbook. Ohio: Vistech Consultants, Inc.: 1990.

14. Catford GV, Oliver A. Development of visual acuity. Arch Dis Child 1973:48:47-50.

15. Fliesler SJ. Anderson RE. Chemistry and metabolism of lipids in the vertebrate retina. Prog Lipid Res 1983:22:29-131.

16. Wiedmann TS, Pates RD, Beach JM. Salmon A, Brown MF. Lipidmprotein inferactions mediato the photochemical function of rhodepsin. Biochamistry 1988:27:6469-74.

17. Martinez M. Tissue levels of polyunsaturated fatty acids during early buman development. I Pediatr 1992; 120:S129-38

18. Makrides M, Neumann MA, Byard RW, Simmer K, Gibson RA. Fatly acid composition of brain, retina, and erythrocytes in breast-and formula-fed infants. Am J Clin Nut 19\%4;60:189. 94.

19. Stinson AM. Wiegand RD. Anderson RE. Recycling of docosahexacnoi acid in rat reinas during $\mathrm{n}-3$ fatly acid deficiency. J. Lipid Res. 1991:32:2009-17.

20. Neuringer M. Comor WE, Van Petten C. Barstad L. Dielary onega-3 ratty acid deficiency and wisual loss in infant rhesus monkeys. J Clin Invest 1984;73:272-6.

21. Neuringer M. Connor WE Lin DS, Barstad H. Luck S. B Bochemical and runctional elTects of prenatal and postratal omega 3 fatty acid deficiency on retina and brain in rhesus monkeys. Proc Nat Acad Sci U S A 1986:83:4021-5.

22. Hrboticky N, MacKinnon MJ. Innis SM. Reina fatty acid composition of piglets fed from birth with a linoleic acid-rich vegetable-oil formula for infants. Arn J Clin Nutr 1994;53:483-90. 
23. Craig Schmidn MC, Steh KE, Lien EL. Reinal faty acids of piglets fed docosahexaenoic and arachidonic acids from microbial sousces. Lipids 1996;31:53-9.

24. Weisinger HS, Vingrys A., Sinclair AJ. Dietary manipulation of long-chain polyunsaturated faty acids in the retina and brain of guinea pigs. Lipids 1995;30:471-3.

25. Sut M. Wherbicki AA, Lien E. Clandinin MT. Relationship between dietary supply of longchatn fatly acids and membrane composition of long- and very long chain essential fatty acids in developing tat photoreceptors. Lipids 1996;31:61-4.

26. Pawlosky RJ, Denkins $Y$, Ward $G$, Salem $N$. Ir. Retinal and brain accretion of longuchain polyunsaturated faty acids in developing felines: the effects of com oil-batsed maternal diets. Am J Clin Nutr 1997:65:465 -72.

27. Alessandri IM, Goustard B, Guesnet P. Durand G. Docosahexaenoic acid concentrations in reinat phospholipids of piglets fed an infant formula enriched with long-chain polyunsaturated fatty acids: effects of egg phospholipids and fish oils with different ratios of eicosapentaenoic acid to docosthexaenoic acid. Am J Clin Nutr 1998:67:377-85.

28. Fishman CA. The electrotetinogram and electo-nculogram in retinal and choroidal disease. Rochester: American Academy of Ophthamology and Otolaryngology; 1975.

29. Benolken RM. Anderson EE. Wheeler TG. Membrane fatty acids associated with the electrical response in visual excitation. Science 1973;182:1253-4.

30. Weisinger HS, Vingrys AJ. Sinclair A.J. The effect of docosahexaenoic acid on the electroretinogram of the guinea pig. Lipids 1996:31:65-70.

31. Uauy RD. Birch DG. Birch EE. Tyson JE. Hoffman DR. Effect of dietary omega-3 fatty acids on retinal function of very-low-birth-weight neonates. Pediatr Res 1990;28:485-92.

32. Birelh DG. Birch EE, Hoffman DR, Uauy RD. Retinal developnent in very-low-birh-weight intants fed diets differing in omega-3 fatty acids. Invest Ophthalmot Vis Sci 1992;33:2365-76.

33. Canlson SE, Werkman SF, Rhodes PG. Tolley EA. Visual-acuity development in heallhy - preterm infants: effect of marine-oil supplementation. Am J Clin Nutr 1993;58:35-42.

34. Carison SE, Werkman SH. Peeples JM. Wilson WM. Long-chain fatty acids and early visual and cognitive development of preterm infants. Eur I Clin Nutr 1994:48:S27-30.

35. Carlson SE Werkman SH, Tolley EA. Effect of long chain $n$ fatty atcid supplementation on visual acuily and growth of preterm infants with and without bronchopulmonary dysplatsia. Am J Clin Nutr 1996:63:687-97.

36. Leaf A. Gosbell A. McKenzie L. Sinclair A, Favilla I. Long chain polyunsaturated fatty acids and visual lunction in preterm infants. Early Hum Dev $1996,45: 35-53$.

37. Faldelli G, Govoni M, Alessandroni R. Marchani E, Savioli GP. Bagi PL, Spano C. Visaal evoked potentials and dietary long chan polyunsaturated fatty acids in preterm infants. Arch Dis Child Fetal Neonatal Ed 1990:75:108-12.

38. OComnor DL., Hall R. Adamkin D, Auestad N, Calstillo M, Connor WE, Connor SL, Fitzgerald K. Groh-Wargo S. Fantmun EE, Jacobs 1, Janowsky J, Lucas A, Margeson D. Mena P. Ncuringer M, Nesin M. Singer L. Siephenson T, Szabo J, Zemon V. Growh and development in preterm infants fed long-chain polyunsaturated fatty acids: a prospective, randomized controlled trial. Pediatrics 2001:108:359-71.

39. Innis SM, Nelson CM. Rionx MF. King DJ. Development of visual acuity in relation to plasma and eryihocyte omegit 6 and onsega-3 hatly acids in heatiby term gestation infants. Am I Clin Nutr $1994 ; 60: 347-52$.

40. Makrides M. Neumann M, Simmer K. Pater J, Gibson R. Are long-chain polyunsaturated fatty acids essential nutrients in infancy? Lancet 1995;345:1463-8.

41. Catson SE. Ford AJ. Werkiman SH. Peeples M. Koo WW. Visual acuity and faty acid status of term infants fed lnuman milk and formulas with and without docosahexaenoate and arachidonte from egg yolk lecithin. Pediatu Res 1996;39:882-8. 
42. Imnis SM, Nelson CM, Lwanga D. Rioux FM, Waslen P. Feeding formula without andhidonit acid and docosahexatenoic acid has no effect on preferential looking acuity or recognition memory in healthy full term infants a 9 mo of age. Am J Clin Nur 1096:64:40-6.

43. Auestad N, Montalto MB, Hall RT. Fitzgerald KM. Wheeler RE, Comor WE. Neuringer M. Connor SL. Taylor JA. Hartmann EE. Visual aculty, erythrocyte faty acid composition. and growth in term infants fed formulas with long chain polyunsaurated faty acids for one year. Pediatr Res 1997:41:j-10.

44. Imnis SM. Akrabawi SS, Diersen Schade DA. Dobson MV. Gay DG. Visual acuity and blood lipids in term infants fed human milk or formulae. Lipids 1997;32:63-72.

45. Birch EE, Hoffman DR. Uauy R. Birch DG. Prestige C. Visual acuity and the essentiality of docosahexaenoic acid and achidonic acid in the diet of term infants. Pediatr Res 1998:44:201. 9.

46. Counage ML, McCloy UR, Herzberg GR, Andrews WL, Simmons BS. McDonald AC. Mercer $\mathrm{CN}$, Friel JK. Vistal acuity development and fatty acid composition of erythocytes in full-term infiants fed breast milk, commercial formula, or evaporated milk. J Dev Behav Pedialr $1998 ; 19: 9-17$.

47. Jorgensen MH, Holmer $G$, Lund P. Hernell O, Michaelsen KF. Effect of formulit supplemented with docosahexaenoic acid and gamma-linolenic acid on fatty acid status and visual acuity in term infants. J Pediatr Gastroenterol Nutr 1998;26:412-21.

48. Bakker EC, van Howwelingen AC. Homstra G. Early nutrition, essential fatty acid status and visual acuity of term infants at 7 months of age. Eur J Clin Nutr 1999:53:872-9.

49. Makrides M, Neumann MA, Simmer K, Gibson RA. A critical appraisal of the role of dietary long-chain polyunsaturated fatty acids on neural indices of term infants: a randomized. controlled trial. Pediatrics 2000;105:32-8.

50. Auestad N, Halter R, Hall RT, Blatter M, Bogle ML, Burks W, Erickson JR. Fitzgerald KM, Dobson V, Innis SM, Singer LT, Montalto MB, Jacobs JR, Qiu W, Bornstein MH. Growth and development in term infants fed long-chain polyonsaturated fatty acids: a double-masked, randomized, parallel, prospective, multivariate study. Pediaurics 2001;108:372-81.

51. Jensen $\mathrm{CL}$, Prager TC, Fraley JK, Chen H, Anderson RE, Heïrd WC. feffect of dietary linoleic/alphatinolenic acid ratio on growth and visual function of term infants [see comments]. J Pediatr 1997:131:200-9.

52. Makrides M. Neumann MA. Jeffrey B. Lien EL. Gibson RA. A randomized trial of different ratios of linoleic to alpha-linolenic acid in the diet of term infants effects on vistal function and growth. Am J Chin Nutr 2000;71:120-9.

53. Foreman van Drongelen MM. al MD, van Houwelingen AC. Blanco CE, Hornstra G.

Comparison between the essential faty acid status of pretern and full-tem intants, masured in umbilical vessel walls. Early Hum Dev 1995:42:241.51. 
". 


\section{6}

\section{Early nutrition, essential fatty acid}

status and visual acuity of term infants at 7 months of age

Based on European Journal of Clinical Nutrition 1999; 53: 872-79

Esther C. Bakker

Adriana C.v. Houwelingen

Gerard Hornstra 


\begin{abstract}
In term infants the reported relationship between visual acuity and dietary fatty acid compostion is not consistent, possibly due to confounders, which were mostly neglected in the studies concerned. In the current study, therefore, the relation between visual acuity and dietary fatty acid composition, and the influence of potential confounders on this relation was investigated.

The essential fatty acid status was determined at 7 months of age in red blood cell and plasma phospholipids of breastfed and formula-fed infants, born at term. Visual acuity was measured with Teller Acuity Cards. Information about potential confounding factors was obtained during an intervew and with a retrospective questionnaire.

This study, like others, showed that the concentration of docosahexaenoic acid (DHA, 22:6n-3) is lower in plasma and red blood cell phospholipids of formula-fed. infants compared to that of breasted infants. However, no differences in wisual acuity could be found between the two groups. Moreover, no significant relationship was found between the amounts of docosahexaenoic acid in plasma and red blood cell phospholipids and the visual acuity. Although dummy (pacifier) use showed a significant positive correlation with visual acuity, it did not influence the relationship between the essential fatty acids in the infant diet and visual acuity. There was also no confounding influence of smoking habits and alcohol use during pregnancy, socioeconomic background and other potential confounders.

It can be concluded that, at 7 months of age, there is no association between fatty acid status, infant diet, potential confounders and visual acuity.
\end{abstract}




\section{Introduction}

The essential fatty acids (EFA) linoleic acid (LA, 18:2n-6) and alpha-linolenic acid (ALA, 18:3n-3) cannot be synthesized by the human body (1). Dietary supply of these fatty acids is important, because they are precursors for several other fatly acids with important functions (2). The biologically active fatty acids, the long chain polyunsaturated fatty acids. (LCPUFA), can be synthesized from the parent fatty acids (LA and ALA) by alternate desaturation and elongation. Some of the derived fatty acids, particularly the LCPUFA arachidonic acid (AA, 20:4n-6) and docosahexaenoic acid (DHA, 22:6n-3), are found in high proportions in the central newous system 3 , 4). and play an important role in its development (5). Therefore, these LCPUFA can also be considered essential. Low dietary intake of EFA can potentially disturb the growth and development of the central nervous system (including the retina), resulting in functional impanment $(3,6)$. Because the nervous system of a child mainly develops during late pregnancy and in the first postnatal year, an adequate supply of EFA to the child during this period is very important. The fetus is supplied with these fatly acids by the mother via transport through the placenta. Neonates depend on breasteeding or artificial formulas for their essential fatty acid supply (3). Breastmilk generally contains LA, ALA and LCPUFA (including AA and DHA), whereas standard artificial formulas do not contain these LCPUFA (3). Therefore, infants fed exclusively with standard formula are dependent on their own synthesis of the LCPUFA necessary for growth and development. It is not known, however, whelher neonates possess adequate fatty acid desaturating capacity to meet their LCPUFA requirements.

In several studies it has been found that the functional development of cerebral cortex and retina is slower in formula-fed preterm infants in comparison with breastfed premature infants (6-9). In term infants, however, this relation is not: consistent. Birch et al. $(7,8,10)$ found that term breastfed infants had significantly better visual acuity scores than formula-fed infants at 6,17 and 52 weeks after birth, measured as Visual Evoked Potentials (VEP). In the first two publications $(7,8)$ these authors also found better preferential looking scores in term breastfed infants as compared with term formula-fed infants. Makrides et al. (1 1) observed a significantly better VEP-acuity and higher amounts of DHA in tem breastled infants as compared with tem formula-fed infants at 22 weeks after birth, as well as a positive correlation between the DHA content of red blood cells and the VEP-acuity (11). At an age of 16 and 30 weeks, infants who received human milk or LCPUFA-enriched formula also had better VEP-acuity-scores than infants led standard formula (12). Furthermore, Carlson et al. (13) found that term infants fed either human milk or DHA and AA supplemented formula had better Teller Acuity Card scores as compared with infants fed standard formula, at an age of 2 months, but not beyond 4 months of age ((13). Recently, Jørgensen et all. (14) found differences in swept stcady-state VEP scores between breastfed term infants and infants fed standard formula, at 4 months of ange.

Three other studies were unable to demonstrate significant relations between n-3 fatty acids in the diet and visual acuity in term infants. Auestad el al. (15) found no differences between term infants receiving human milk, standard formula, and formulas supplemented with DHA or DHA and A A 2, 4, 6, 9 and 12 months of age. Imnis et al. $(16,17)$ observed no differences in visual acuily between term infants fed standard formula and infants fed human milk at 14 doys, 3 and 9 months, in spite of lower DHA-contents in plasma and red blood cells in the formula-group at 14 days 
and 3 momhs. Birch el al (10) did not find any effect of diet on visual acuity at 6,17 , 26 and 52 wecks of age either.

Thus, the results of studies on visual acuity in term infants in relation to their diet are not consistent, possibly due to the influence of confounding factors like smoking habits and alcohol use during pregnancy, and socio-economic background. These factors may have an influence on the development of the central nervous system, as reflected by the visual acuity. The studies mentioned above reported few of these factors. Therefore, the current cross sectional study investigates the influence of the essential fatty acid status and some potentially confounding factors on the wisual acuity at 7 months of age, in children born at term.

\section{Methods}

\section{Study population}

The study population consisted of 74 healthy, singleton, term (gestational age 37 42 wecks) infants of 7 months (range 6-8 months), recruited al child health centres in the southert part of the Netherlands. There were no infants with neurological dysfunction or motor problems (according to the child health centre physicians). Parents of eligible infants were provided a brief information letter. Written informed consent was obtained from the accompanying parent(s) of each participant. The study was approved by the Ethics Committee of the University Hospital Maastricht Universiteit Maastricht.

\section{Analyical procedures: and measurements}

Capillary blood samples were taken from 47 infants. Parents from 27 infants did not give permission to take a blood sample from their child, four samples were too smat to reliably determine fatty acid profiles in red blood cell phopholipids. Fatty acid profiles were determined in plasma and red blood cell (RBC) phopholipids using the following methods. About $1 \mathrm{~mL}$ capillary blood was collected in EDTA containing tubes. Within 8 hours after blood collection, plasma was separated from the $\mathrm{RBC}$ by centrifugation ( $\mathrm{pm}=3000, \mathrm{~g}=503, \mathrm{t}=10 \mathrm{~min}, 4^{\circ} \mathrm{C}$ ) and collected in plastic tubes, which were lightly closed under nitrogen and stored at $-50^{\circ} \mathrm{C}$ until fatty acid analysis. The remaining $\mathrm{RBC}$ were washed twice with EDTA-containing saline (Na2EDTA.2H2O 28,64 g, NaCl $7 \mathrm{~g}, 1201000 \mathrm{ml}$ ), centrifuged (rpm=1500, $\mathrm{g}=126$, $t=15 \mathrm{~min}, 4^{\circ} \mathrm{C}$ ), and collected in plastic lubes, which were tightly closed under a strcam of mitrogen and stored at $-50^{\circ} \mathrm{C}$ until fatty acid analysis. Within one week after sampling, totall lipids were extracted from the RBC as described by $\mathrm{Bligh}$ and Dyer (18). Plasma lipids were extracted as described by Folch et al. (19). L-alphadinonadecanoyl lecithin (PC19:0) was used as an internal standard to calculate the quantative fatty acid amounts. The phospholipid (PL) fraction was separated from the total lipid extract using aminopropyl bonded silica columns $(500 \mathrm{mg})(20)$. Heptadecenoic acid (17:1) was added to the samples to check carry over of free fatty acids during the phospholipid separation procedure. The PL fraction was bydrolyzed and the resulting latty acids methylated with boron-trifluoride in methanol (21). The fatty acid composition of the PL was then determined by gas liquid chromatography using a polar (BPX70,50 $\mathrm{m}$ with $0.22 \mathrm{~mm}$ ID and $0.25 \mathrm{~mm} 1 \mathrm{~m} / \mathrm{m}$ thickness) and a nonpolai column (BP-1, $50 \mathrm{~m}$ with $0.22 \mathrm{~mm}$ ID and $0.1 \mathrm{~mm}$ film thickness, both SGE, Bester B.V., Amstelveen, The Netherlands), with He (head pressure $370 \mathrm{kPa}$ ) as carrier gas. The injection temperature was $250^{\circ} \mathrm{C}$ and the detection temperature $300^{\circ}$ C. The starting temperature of the column was $160^{\circ} \mathrm{C}$. After 4 minutes, the 
temperature increased up to $200^{\circ} \mathrm{C}$ with a rate of $66^{\circ} \mathrm{Cminute}$ and finally to $270^{\circ} \mathrm{C}$ wh a rate of $7^{\circ} \mathrm{C}$ minute. The split ratio was 1:40. Fatly acid data are presented as relative amounts (\% wtwt, see the tables $2 \mathrm{a}$ and $b$ ).

\section{Measurement of visual acuity}

The binocular visual acuity of all 74 infants was measured with the "Teller Acuity Card-method following the acuity card procedure (22). This method is based on the observer's interpretation of the infants looking behavior. In this method a card with a black-and-white grating of a particular spatial frequency (stripe width) is presented to the intant. If the infant is able to perceive this stripe-pattern, it will fix the attention on this part of the card. If not, the child will loose attention. The linest stripe pattern that can be distinguished repeatedly is taken as an acuity estimate. All infants were measured by the same observer (ECB), who was blind for the feeding group the infant belonged to. A conversion table is used to determine acuity (cycles/degree) from the finest grating that can be distinguished (cycles/centimeter) at a lixed distance of 38 centimeter $(22,23)$. Because acuity scores are on a logarithmic rather than a linear scale, means and standard deviations of acuity scores cannot be determined by simple linear addition and division (22). Therefore, individual acuities were transformed to ${ }^{16} \log$ cycles/degree before the analyses were conducted. After calculating the means and $\mathrm{SD}$ for each group, the means were transformed back to cycles/degree and SD expressed in octaves (SD of log acuity scores $/ 0.301$ ), according to the standard procedure $(22)$.

\section{Measurement of potentially confounding factors}

The parent who accompanied the infant was interviewed immediately after completion of the visual acuity measurement. Moreover, 62 parents completed and returned a retrospective questionnaire. With these methods we measured the following potential confounding factors: duration of breastfeeding, ages of mother and infant, gestational age, parity, birth weight and length, current weight and langth of the infant, sex, smoking and drinking habits during pregnancy and lactation, dummy (pacifier) and thumb use of the infant and socioeconomic status of the family (based on maternall educational level and father"s job). Gestational age has been shown to be related to the essential fatty acid status at birth (24). Ethanol exposure causes a decrease in DHA in brains and retimas of felines (25). Furthermore, smoking also decreases LCPUFA, including DHA, in tissues of rhesus monkeys (26), If these factors have an influence in humans as well, drinking and smoking habits during pregnancy and lactation may disturb the essential fatty acid metabolism in the developing infants. Dummy use and socioeconomic status of the family were measured because they are thought to be associated with the functioning of the central nervous system (27). In addition, maternal age, parity, birth weight and length, current weight and length, sex and duration of breastfeeding were measured, because these factors may have an influence on the essential fatty acid status as well.

\section{Siatistical analysis}

All data are presented as mean (SD). To investigale the relation between visual acuity and the EFA-status of the infants, linear regression was used with ${ }^{10}$ Log visual acuity (cycles/deg) as dependent variable and the fatty acids of interest (\% w $/$ wh) as independent variables. The influence of potential confounding factors on visual acuity was studied by linear regression. The influence of these factors on the relation 
between visual acuity and EFA-status was studied by introducing these variables separately as continuous covariables in a multiple linear regression analysis. The influence of discrete variables on visual acuiry was analysed by Students' t-tests and chi-squarc tests. To study the influence of diet (formula or human milk) on visual acuity and on the status of several fatty acids. Students" t-tests were used in which breasted infants were compared with formula-fed infants. In all statistical analyses a significancy level of $\mathrm{P}<0.05$ was taken, unless mentioned otherwise. Sample sizes were calculated according to standard methods (28), based on expected group means of $0.37( \pm 0.06) \operatorname{logMAR}$ and $0.44( \pm 0.07) \log \mathrm{MAR}$ (data from Jorgensen et al., 1998). To achieve a power of 0.90 at an overall-alpha of 0.05 , the sample size had to be at least 38 infants, preferably 19 children in each group. Ultimately, the human milk group consisted of 48 infants, the formula-group of 26 infants. Fatty acid profiles of 30 breastfed and 17 formula-fed infants could be determined.

Table 1: Clinical chanacteristics of the sudy poptation and potential confounders in the relation between essential fatty acid status and visual acuity.

\begin{tabular}{|c|c|c|}
\hline Variable: & $\begin{array}{l}\text { Human milk group } \\
\mathrm{n}=48\end{array}$ & $\begin{array}{l}\text { Artificial formulit group } \\
n=26\end{array}$ \\
\hline \multicolumn{3}{|l|}{ parendat characteristics } \\
\hline matemall age al delivery (yrs) & $31.0(3.5)$ & $29.7(4.4)$ \\
\hline parily & $1.7(0.7)$ & $1.6(0.8)$ \\
\hline smoking during pregnancy $(y e s / n o, \%)$ & $13 / 87$ & $23 / 77$ \\
\hline alcohol use during pregnancy (yes/no, \%) & $18 / 82$ & $17 / 83$ \\
\hline matemal edwation (high/middlefow, \%) & $46 / 49 / 5$ & $18 / 76 / 6$ \\
\hline paternal occupation (hightmidde/low, wh) & $28 / 33 / 39$ & $35 / 47 / 18$ \\
\hline \multicolumn{3}{|l|}{ child characteristics } \\
\hline age at mexsurement (weeks) & $30.2(2.3)$ & $30.2(2.0)$ \\
\hline gender (boys/girls, \%) & $50 / 50$ & $42 / 58$ \\
\hline gestationallage (weeks) & $39.8(1.5)$ & $39.5(1.6)$ \\
\hline birth weight (g) & $3442(498)$ & $3267(476)$ \\
\hline birth lengh $(\mathrm{cm})$ & $50.9(2.1)$ & $50.3(2.5)$ \\
\hline curent weight $(\mathrm{g})$ & $7864(960)$ & $7885(853)$ \\
\hline cutrent length (cm) & $68.0(2.4)$ & $65.4(2.7)$ \\
\hline dummy we (wisershon-fisers, \%) & $54 / 46$ & $72 / 28$ \\
\hline thumb use (users/not-rusers, \%) & $44 / 56$ & 35165 \\
\hline
\end{tabular}

* Values are cither meat (SD) or percentages of participants; no statistically significant differences were lound berween the two groups.

\section{Results}

Siudy population

Of the 74 participating infants, 48 received human milk, whereas 26 were fed cxclusively with standard artificial formula-feeding, which means they never received human milk. All infants in the human milk group were breastfed directly, except for 2 , who received the human milk from bottles, for practical reasons. The mean duration of breaslfeeding was 16 weeks, with a range between 1 and 35 weeks. Only 12 of the infants were exclusively breasted until the visual acuity measurement (mean duration of breastleeding 31 weeks). The standard formulas used contained $11.2-13.5 \mathrm{~g}$ linoleic 
acid and $1.35-2.2 \mathrm{~g}$ alpha-linolenic acid per $100 \mathrm{~g}$ lotal faty acids, but were devoid of LCPUFA. Within this cross sectional study it was not possible to take human milk samples, but from the study of Huisman et al. (29) is known that mature human milk of Dutch women contains 12.8-14.4 mol/100 mol LA. 1.1-1.2 mol/100 mol ALA. and 1.0-1.25 mol/100 mol n-6 LCPUFA and $0.40 \mathrm{~mol} / 100 \mathrm{~mol} \mathrm{n}-3$ LCPUFA. From 4 months, all infants received some solid food as well. The clinical characteristics of the study population and the values for the potential confounders are given in table 1 .

No significant differences were found for age, gestational age, birth number, birth weight, birth length and current weight and length or (other) potential confounding variables between the breastfed and the formula-fed infants.

Table 2a: Fatty acid composition (mean $+\mathrm{SD}$ ) of red blood cell phospholipids of breastfed infants compared to formula-fed infants.

\begin{tabular}{|c|c|c|c|}
\hline $\begin{array}{l}\text { Fatty acid" } \\
\text { (Wwt/wt of total FA) }\end{array}$ & $\begin{array}{l}\text { all breastfed infanis } \\
\qquad(n=29) \\
\text { mean duration of } \\
\text { breastreeding }=16 \text { weeks }\end{array}$ & $\begin{array}{c}\text { exclusively breasifed } \\
\text { infints }(n=6) \\
\text { mean duration of } \\
\text { breastfeeding }=31 \text { weeks }\end{array}$ & $\begin{array}{l}\text { Commula-fed infunts } \\
\qquad(n=14)\end{array}$ \\
\hline Total FA (mg/L) & $1000.2(235.3)$ & $1057.1(348.7)$ & $878.2(213.1)$ \\
\hline $18: 2 n-6$ & $11.2(0.9)$ & $10.8(0.5)$ & $11.0(0.9)$ \\
\hline $20: 4 n-6$ & $10.2(1.0)$ & $11.8(0.9)^{\mathrm{s}}$ & $10.1(1.1)$ \\
\hline $22: 5 n-6$ & $0.32(0.08)$ & $0.29(0.05)$ & $0.37(0.14)$ \\
\hline En-6LCPUFA & $15.0(11.3)$ & $16.7(1.2)^{\circ}$ & $15.0(1.8)$ \\
\hline $18: 3 n-3$ & $0.11(0.06)$ & $0.07(0.08)$ & $0.12(0.06)$ \\
\hline $20 \cdot 5 n-3$ & $0.29(0.11)$ & $0.27(0.10)$ & $0.32(0.10)$ \\
\hline $22: 6 n-3$ & $2.2(0.8)^{4}$ & $3.5(0.5)^{\mathrm{a}}$ & $1.6(0.1)$ \\
\hline$\sum n-3$ LCPUFA & $4.0(0.9)^{r}$ & $5.4(0.5)^{9}$ & $3.5(0.4)$ \\
\hline
\end{tabular}

"18:2n-6=linoleic acid, $20: 4 n-6=$ arachidonic acid, $22: 5 n-6=0$ sbond acid, $\sum n-6$ LCPUFA $=$ sum of the n-6 Long-chain Polyunsaturate faty acids $(20: 3,20: 4,22: 4,22: 5)$. 18:3n-3=alpha-linolenic acid, $20: 5 n-3=$ eicosapentaenoic acid, $22: 6 n-3=$ docosahexaenoic acid, $2 n-3$ LCPUFA $=$ sum of the $n-3$ LCPUFA (20:5. 22:5, 22:6).

the Significantly different from formula-fed infants: "p<0.0001, " $p<0.001$, $p<0.005$, $p<0.01,{ }^{c} p<0.05$

Table 2b: Fatty acid composition (mean + SD) of plasma phospholipids of breasted infams compared to formula-fed infanes.

\begin{tabular}{|c|c|c|c|}
\hline $\begin{array}{l}\text { Fatty acid } \\
(\% \text { w/ wh of tolal FA) }\end{array}$ & $\begin{array}{c}\text { all breastfed infants } \\
(\mathrm{n}=30) \\
\text { mean duration of } \\
\text { breastfeeding }=16 \text { weeks }\end{array}$ & $\begin{array}{l}\text { exclusively breasted } \\
\text { infunts }(n=6) \\
\text { mean duration of } \\
\text { breastleeding }=3 \text { ! weeks }\end{array}$ & $\begin{array}{l}\text { formulam } \times \text { fad } \\
\text { infants } \\
(n=17)\end{array}$ \\
\hline Total FA (mg/L) & 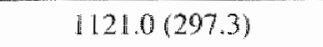 & $1126.7(226.1)$ & $1150.0(408.7)$ \\
\hline $18: 2 n-6$ & $24.0(2.2)$ & $23.0(2.0)$ & $23.7(2.6)$ \\
\hline $20: 4 n-6$ & $6.8(1.6)$ & $9.0(0.9)^{\mathrm{b}}$ & $6.4(1.1)$ \\
\hline $22: 5 \operatorname{in} 6$ & $0.24(0.09)$ & $0.22(0.03)$ & $0.30(0.13)$ \\
\hline En-6 LCPUFA & $9.8(1.9)$ & $11.9(1.9)^{\mathrm{c}}$ & $9.9(1.7)$ \\
\hline $18: 3 n-3$ & $0.14(0.09)$ & $0.10(0.09)$ & $0.15(0.12)$ \\
\hline $20: 5 n-3$ & $0.25(0.15)$ & $0.21(0.11)$ & $0.27(0.16)$ \\
\hline $22: 6 n-3$ & $2.2(0.9)^{a}$ & $3.6(0.7)^{2}$ & $1.6(0.3)$ \\
\hline En-3 LCPUEA & $3.2(1.0)^{t}$ & $4.7(0.6)^{3 t}$ & $2.7(0.4)$ \\
\hline
\end{tabular}

see table 2 a for legends 
The fatty acid composition (mean (SD), \%, wtwt) of red blood cell (RBC) phospholipids (PL) is given in table $2 a$ for the breastfed infants, the formula-fed infants and the subgroup of infants who were fully breasted until the measurement at 31 weeks of age. Table $2 b$ shows the same data for plasma PL.

In the breasted group the DHA and $\sum$ n-3 LCPUFA amounts in RBC and plasma PL were significantly higher than in the group fed formula. The amounts of the other fatly acids were comparable between both groups. In both plasma and RBC the subgroup of exclusively breastfed infants had higher levels of AA, En-6LCPUFA, DHA, and En-3LCPUFA than formula-fed infants.

No difference in visual acuity was observed between the diet groups $(\mathrm{p}=0.63)$. Infants who received human milk $(n=48)$ had a mean visual acuity score of 6.5 cyclesfdegree (SD:0.41 octaves). The visual acuity score of formula-fed infants $(n=26)$ was 6.7 cycles/degree (SD: 0.41 oclaves, see Figure 1). The subgroup of fully breastfed infants $(\mathrm{n}=12$ ) had a mean score of 6.6 cycles/degree with SD 0.48 octaves. Using linear regression analysis, no correlation was found between the duration of breastfeeding (weeks) and wisual acuity $(r=-0.019, p=0.87)$.

Multiple regression analyses were done for the total group and for the human milk group and the formula group separately. No significant relationship was found between visual acuity and the percentage of DHA and AA in red blood cell- $(r=0.10$, $p=0.52$ for DHA and $r=0.01, p=0.95$ for $A A)$ and plasma-PL $(r=0.15, p=0.32$ for $D H A$ and $r=0.17, p=0.25$ for $A A$ ). The other fatty acids did not show a relationship either. No influence on visual acuity was found for the maternal smoking habits and alcohol use during pregnancy and lactation, maternal age, gestational age, age at visual acuity measurement, birth weight and length, current weight and length, parity, sex, mother's educational level, father's job, and parents' sociomeconomic status. Only dummy use correlated with visual acuity. Dummy users showed a better visual acuity $6.9 \mathrm{cy} / \mathrm{deg}$ \pm 0.40 octaves) than non dummy users $(5.9 \pm 0.42)(p<0.05)$, independent of dummy use duration. In spite of this correlation, dummy use did not interfere with the relationships between visual acuity and either fatty acids in blood or the infant's diet. These relationships remained unchanged when dummy use or other factors were introduced as covariables.

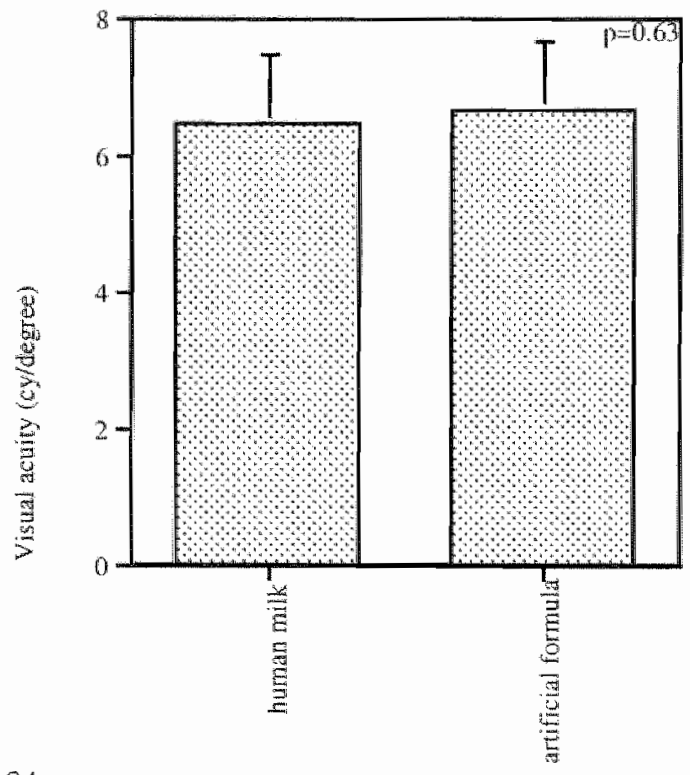

Figure 1: Visual acuity at 7 montix of age (mean \pm sem), as measured with the Teller Acuity Card procedure. for the human milk group $(n=48)$ and the artificial formula group $(n=26)$. 


\section{Discussion}

The aim of this study was to investigate in term infants the relation between visual acuity and dietary faty acid composition, and the infuence of potential confounders. on this relationship. At 7 months of age, visual acuity of infants who were breasted did not differ significantly from the visual acuity of infants who received artificial formula, although they had significantly higher amounts of certain LCPUFA in their plasma and red blood cell phospholipids. Moreover, the fatty acid percentages in plasma and red blood cells were not related to visual acuity at this age. None of the used covariables tumed out to be a confounder of these analyses.

Visual acuity is dependent on the development of the retina and the wisual cortex. which are both rich in DHA. The accumulation rate of DHA in these tissues reaches its maximum in the last trimester of pregnancy and continues to be high during the first months after birth $(30,31)$. In contrast to human milk, most antificial formulas do not contain $n-6$ LCPUFA and n-3 LCPUFA to supply the intant with A A and DHA. The present study, like other studies $(6,32-34)$, showed that the relative amounts of DHA and other essential fatty acids were lower in plasma and RBC of formula-fed intants compared with those of breastfed infants. These differences were more pronounced in the subgroup of infants who received human milk until 7 months of age as compared with the total group of breastfed infants (mean duration of breastfeeding: 16. weeks).

Despite these differences in fatty acid values in plasma and RBC PL, no dilference in visual acuity could be found between the breasted and formula-fed infants. This suggests that the DHA status in the plasma and red blood cells at the age of 7 monthis has no influence on the visual acuity at this age. In the current study, indeed no significant relationship was found between the amounis of DHA in plasma or red blood cell PL and the visual acuity.

A possible explanation for the absence of a relation between the amount of DHA in blood and visuall acuity could be that dietary DHA at seven months of age is not necessary for optimal visual development. It is possible that the DHA-status at an earlier age has a greater influence on visual acuity at 7 months than has the DHAstatus at 7 months itself. Possibly even the DHA intake of mothers during pregnancy has an influence, through DHA accretion in utero. Most of the studies, including ours, do not include EFA-values at birth.

It is possible that the faty acid status in blood (plasma and red blood cells) is not a good indicator for the presence of these fatty acids in the central nevous lissue. Several studies $(4,35,36)$ showed that the retina can retain and recycle DHA and other LCPUFA. Consequenty, formula-fed term children may already have accumulated sufficient amounts of DHA before the age of 7 months to reach an optimal status of this fatty acid in their retina tissue, in spite of their lower blood DHA values at 7 months of age. This is supported by postmortem examinations of term infants (age at death ranged from 2 to 48 weeks) as reported by Makrides et al. (37). They found no differences in retinal DHA between breasted and formula fod infants, in spite of differences in DHA levels in RBC PL. However, there are animal studies in which dietary manipulation showed to have large effects on DHA content of retinal phospholipids of rhesus monkeys (38), guinea pigs (39), rats (40) and febines (41). Unfortunately, in these animal studies, the fatty acid values in plasma and RBC were not measured and no breastfeeding group was included to compare with.

Probably, even the lowest PL amount of DHA found in this study was enough for visual function, as measured with the Teller Acuity Card method. So, in spite of low 
DHA levels in blood PL, formula-fed infants still have enough DHA for their visual development. If intial DHA levels are lower, like in premature infants (42), an effect of dietary DHA would be more likely. This could also explain the consistency of results in visual acuity studies with premature infants. Almost all these sudies showed an influence of dietary DHA on early visual acuity.

In the literature the relation between DHA and visual function is not consistent for Lerm infants. One explanation for this inconsistency between sudies may be the presence of confounding factors (as mentioned in Chapter 5). For instance, all sudies comparing a human milk group with a formula group were non-randomized. So, there may be other differences between both groups. In the current study, we related visual acuity at 7 months to various potentially confounding factors, like smoking and drinking habits during pregnancy, and socio-economic background. Furthermore, we looked at the use of a dummy (pacifier) in infancy. Gale \& Martyn (27) showed a negative association of dummy use with the functioning of the central nervous system, as measured by an IQ test. In the present sudy, of all potential confounding factors, only dummy use showed a positive correlation with visual acuity $(p<0.05)$. From the study of Gale \& Martyn, the opposite result was expected. Although dummy use correlated with visual acuity, it did not confound the relation between fatty acids in blood and diet and the visual acuity. Other variables also did not confound this relationship. So confounders do not seem to play a role in this relationship, suggesting other possible factors are responsible tor the inconsistency of results in visual acuity studies in term infants.

From our sudy and other data available, we can conclude that at 7 months there is no relationship between blood LCPUFA values and Teller Acuity in infants born at term. There are, however, some limitations of our study that should be noted. It is possible that the study groups were too small to detect any influence of counfounding factors on the relationship between visual aculy and LCPUFA. Power calculations on polentially confounding factors could not be made because data about the influence of these factors were not avallable. Consequently, it was not known what results could be expected. Furthermore, not all data of all infants were complete, so conclusions can not be extrapolated to other populations. In the present study the acuity was measured only once at 7 months. At this age, the fine visual acuity development is not yet complete, it only teaches the adult level at 3 or 4 years of age $(43,44)$. It might be possible that dietary DHA has an influence on adult visual acuity levels, even if this inluence not clearly visible during (late) infancy. As far as we know, adult visual acuity levels have never been measured in relation to essential fatty acids. So, further studies on the long term effects of $n-3$ fatty acids in infant nutrition on visual acuity are also necessary. 


\section{Literature}

1. Burr GO, Bur MM. A new deficiency disease produced by the rigid exclusion of fat from the diet. J Bul Chem 1929;82:345-67.

2. Uauy R, Treen M, Hoffman DR. Essential faty acid metabolism and requirements atumg development. Sem Perimat 1989;13:118-30.

3. Innis SM. Essential fatty acids in grown and development. Prog Lipid Res 1991:30:39-103.

4. Anderson RE, OBrien PJ, Wiegand RD, Koutz CA, Sitinson AM. Conservation of docosahexaenoic acid in the retina. In: Baxan $\mathrm{NG}$. al. e, editors. Neurobiology of essential fatry acids. New York: Plenum Press; 1992. p. 285-94.

5. Crawford MA. The role of essential faty acids in neural development: implications for perinatal nutrition. Am J Clin Nutr 1993;57.5703-9.

6. Uany R, Birch E, Birch D. Peirano P. Visual and brain function measurements in studies of n-3 fatty acid requirements of infants. I Pediatu 1992;120:5168-80.

7. Birch EE, Birch DG. Hofman DR. Uauy R. Dietary essential fatly acid supply and visual acuity development. Invest Ophthalmol Vis Sci 1992;33:3242-53.

8. Birch E. Birch D, Hoffman D. Hale L. Everett M. Uatu R. Breast-feeding and optimal visual development. J Pediatr Ophithalmol Strabismus 1993;30:33-8.

9. Carlson SE. Werkman SH, Rhodes PG. Tolley EA. Visual-acuity development in healliy preterm infants: effect of marine-oil supplementation. Am J Clin Nutr 1993:58:35-42.

10. Birch EE. Hoffman DR, Jauy R. Birch DG. Prestidge C. Visual aculy and the essentiality of docosahexaenoic acid and arachidonic acid in the diet of term infants. Pediatr Res 1998:44:2019.

11. Makrides M. Simmer K, Goggin M, Gibson RA. Erythrocyte docosahexaenoic acid correlates with the visual response of healthy, term infants. Pediatr Res 1993;33:425-7.

12. Makrides M. Neumann M, Simmer K, Pater J, Gibson R. Are long-chain polyunsaturated faty acids essentiall nutrients in infancy? Lancet 1995;345:1463-8.

13. Carlson SE, Ford AJ, Werkman SH. Peeples JM, Koo WW. Visual acuity and fatly acid status of term infants fed human milk and formulas with and without docosahexaenoate and arachidonate from egg yolk lecithin. Pediatr Res 1996;39:882-8.

14. Jorgensen MH, Holmer G, Lund P. Hernell O, Michaelsen KF. Effect of formula supplemented with docosahexaenoic acid and gamma-linolenic acid on fatty acid status and wistal acuity in term infants. I Pediatr Gastroenterol Nutr 1998;26:412-21

15. Auestad N. Montalto MB. Hall RT. Firgerald KM, wheeler RE. Connor WE. Neuringer M. Connor SL, Taylor JA. Harmann EL. Visual acuiry, erytbrocyte fatty acid composition, and growth in term infats fed fommas wh long chan polyunsaturated fatty acids for one your. Pediatr Res 1997;4:1-10.

16. Innis SM, Nelson CM. Rioux MF. King D. Development of visual acuity in relation to plasma and erythrocyte omega-6 and omega-3 fatty acids in healtiy term gestation infunts. Am 1 Clin Nutr 1994;60:347-52.

17. Innis SM, Nelson CM. Lwanga D. Rioux FM, Waslen P. Feeding formula without anachidonic acid and docosahexaenoic acid has no effect on prefercntial fooking acuity or recognition memory in healthy full term infants at 9 mo of age. Am J Clin Nut 1996;64:40-6.

18. Bligh ED, Dyer WI. A rapid method for total lipid extraction and purification. Can J Biochem Physiol 1959;37:911-7.

19. Folch 1, Lees M. Sloane Stanley GH. A simple method for the isolation and purification of total lipids from animal tissues. J Biol Chem 1957,226:497-509.

20. Kaluzny MA. Duncan LA, Marritt MV, Epps DE. Rapid seperation of tipid elasses in bigh yield a purity using bonded phase columns. I Lipid Res 1985;26:135-40. 
21. Morissen WR. Smith LM. Preparation of fatty acid methyl esters and dimethyl acetals from lipids wh boron fluoride-methanol. 1 Lipid Res 1964:5:600-8.

22. Teller D. Teller Acuity Card Handbook. Ohio: Vistech Consultants, Inc; 1990.

23. Teller DY, McDonald MA. Preston K, Lawson Sebrits S. Dobson V. Assessment of visual acuity in infants and clitdren: the acuity card procedure. Dev Med Child Neurol 1986:28:77989.

24. Houwelingen ACv, Foreman-Van Drongelen MMHP, Nicolini U, Kypros HN, Al MDM, Kester ADM, Horrstra G. Essential faty acid status of fetall plasma phopholipids: Similar to postnatal vatues obtained at comparable gestational ages. Early Hum Dev 1996:46:141-52.

25. Pawlosky RJ, Salem N, Jr. Ehanol exposure causes at decrease in docosahexaenoic acid and an increase in docosapentaenoic acid in feline brains and retinas. Am J Clin Nutr 1995:61:1284-9.

26. Brown KM, Morrice $\mathrm{PC}$. Duthie GG. Erythrocyte membrane fatty acid composition of smokers and non-smokers: eflects of vitamin $\mathbb{E}$ supplementation. European-Journal-of-ClinicalNutrition 1998;52:145-50.

27. Gale CR, Martyn CN. Breastfeeding, dummy use, and adult intelligence. Lancet $1996 ; 347: 1072-5$.

28. Kirkwood BR. Essentials of medical statistics. Ox ford: Blackwell; 1988.

29. Huisman M, Vanbeusekom CM, Lanting CI, Nujeboer HIJ Muskiet FAJ, Boersma ER. Triglycerides, fatty acids, sterols, mono and disaccharides and sugar alcohols in human milk and current types of infant formula milk. European Journal or Clinical Nutrition 1996;50:25560.

30. Clandinin MT, Chappell JE, Leong S, Heim T, Swyer PR, Chance GW. Intraterine fatty acid accretion rates in human brain; implications for farty acid requirements. Early Hum Dev $1980: 4: 121-9$.

31. Clandinin MT, Chappell IF, Leong S, Heim T, Swyer PR, Chance GW. Extrauterine fatty acid accetion in infant brain: implications for fatty acid requirements. Early Hum Dev 1980;4: 131 8.

32. Innis SM. Plasma and red blood cell fatty acid values as indexes of essential fatty acids in the developing organs of infants fed with milk or formulas. J Pediatr $1992 ; 120: 578-86$.

33. Innis SM, Akrabawi SS, Diersen Schade DA, Dobson MV, Guy DG. Visual acuity and blood lipids in term infants fed human milk or formulae. Lipids 1997;32:63-72.

34. Jorgensen MH. Hernell O, Lund P. Holmer G. Michaelsen KF. Visual acuity and erythrocyte docosahexatenoic acid status in breast fed and formula fed term infants during the first four months of life. Lipids 1996,31:99-105.

35. Stimson AM, Wiegand RD. Anderson RE. Recycling of docoshtexaenoi acid in rat retinas during n-3 faty acid defichency. J Lipid Res 1991:32:2009-17.

36. Wiegand RD, Koutz CA. Stinson AM, Anderson RE Conservation of docosahexaenoic acid in rod otter segments of rat retina during $n-3$ and $n-6$ fatly acid deficiency. I Neurochem $199) 157: 1690-9$.

37. Makrides M. Noumann MA. Byard RW. Simmer K. Gibson RA. Fatty acid composition of brain. retina, and erythrocyles in breast- and formula-fed infants. Am J Clin Nutr 1994;60:189. 94.

38. Neuringer M. Connor WE. Lin DS, Barstad L. Luck $S$. Biochernical and functional effects of prenatal and postnatal omega 3 fatty acid deliciency on retina and brain in rhesus monkeys. Proc Nall Acad Sci US A $1986,83: 4021-5$.

39. Woisinger HS, Vingrys AJ. Sinclair AJ. Dietary manipulation of long-chain polyunsaturated fatty acids in the retina and brain of guinea pigs. Lipids 1995:30:471-3. 
40. Suh M. Wierzbicki AA, Lien E, Clandinin MT. Relationship between dietary supply of longchain fatty acids and membrane composition of long-and very long chain essential fanty acids in developing rat photoreceptors. Lipids 1996,31:61 -4t,

41. Pawlosky RT, Denkins $Y$. Ward G. Salem M, Mr. Retiwa and brain accretion of long-chain polyunsaturated fatty acids in developing felines: the effects of com oil-based matemal diets. Am J Clin Nutr 1997;65:465-72.

42. Foreman van Drongelen MM, al MD, wan Houwelingen AC. Blanco CE Hornstra $\mathrm{G}$. Comparison between the essential fatty acid status of preterm and full-tem infants, measured in unbilical vessel walls. Early Hum Dev 1995:42:241-51.

43. Catford GV, Oliver A. Development of wisual acuity. Arch Dis Child 1973,48:47-50.

44. Touwen BCL. The development of vision during the first months of life. In Francois I, Maione M, editors. Pediatric ophthalmology. Chichester: John Wiley \& Sons; 1982. 


\section{7}

\section{Long-chain polyunsaturated fatty}

acid status at term birth and visual

\section{function at 8 years of age}

Esther C. Bakker

Margaret Tychon

Jos P.H. Reulen

Frank Spaans

Marcel Ten Tusscher

Johan S.H. Vles

Carlos E. Blanco

Gerard Hornstra 


\section{Abstract}

Several studies, although not all, have found a positive influence of postnatal consumption of long-chain polyunsaturated fatty acids (LCPUFA), especially docosahexaenoic acid (DHA), on visual function. The aim of this study was to investigate whether visual function at 8 years of age is associated with prenatal DHA availability as represented by the amount of DHA in phospholipids of umbilical. plasma.

The DHA status at birth and at 7 years of age of 59 children, born healthy and, except for 2 , at term, was related to their visual function at 8 years of age, by means of multiple regression analysis, correcting for the potential confounding factors sex, gestational age, breastfeeding duration and age at measurement. Visuall function was assessed by ophthalmologic measurements (including visual acuity, stereopsis and contrast sensitivity), visual evoked potentials (VEP) and electroretinography (ERG).

DHA in phospholipids of umbilical plasma (wto of total fatty acids) was found to be related to visual acuity (positive, $p=0.038$ ), VEP P100 peak latency and a-wave latency of the photopic ERG (both negative, $p=0.022$ and 0.037 respectively) at 8 years of age, after correction for gestational age, age at measurement, breastfeeding duration and sex (the latter only in the model predicting VEP P100 latency). DHA in plasma sampled at 7 years of age was not related to any of the visual outcome measures at 8 years of age.

DHA status at birth showed a positive relation with visual function at 8 years of age. Our findings suggest that prenatal DHA supply may be important for later visual development. 


\section{Introduction}

Long chain polyunsaturated fatty acids (LCPUFA), especially arachidonic acid (AA: 20:4n-6) and docosahexaenoic acid (DHA: 22:6n-3), are found in very high amounts in the membrane phospholipids of the central nerwous system (CNS) tissues (1). A and DHA can be supplied by nutrition or synthesized from their (essential) precursors linoleic acid (LA: 18:2n-6) or alpha-linolenic acid (ALA: $18: 3 n-3)$, respectively (2). The CNS of a child mainly develops during late pregnancy and in the first postnatal year. Adequate supply of LCPUFA to the child during this period may be very important for optimal CNS development $(2,3)$. The letus is supplied with. these fatty acids by the mother through the placenta. Neonates depend on breasteeding or artificial formula for their essential fatty acid supply.

The retina, the light-sensitive portion of the eye, is part of the CNS. Retinal photoreceptor membranes contain the body's highest concentrations of DHA (4). Therefore, it can be hypothesized that visual function can be influenced by DHA status. In several intervention studies a positive influence of postnatal LCPUFAsupplementation on visual function of term infants is found (5-7), although not all studies support these findings $(8,9)$. The prenatal LCPUFA availability may be of even greater importance for the development of the central nervous system, because the growth spurt of this system (including the visual system) already starts during the last intrauterine trimester. Since long term follow-up of study subjects has been recommended $(10,11)$, we investigated the hypothesis that the LCPUFA status at birth, in particular the DHA status, is associated with visual performance at 8 years of age.

\section{Methods}

\section{Study population}

The study described in this chapter is part of a follow-up study investigating the relationship between essential fatty acid status at birth and cognitive, visual and motor function at 7-8 years of age. The subjects invited for the study described in this chapter all participated in the follow-up at 7 years of age (see Chapter 2). Selection of children for the visual function measurements at 8 years of age was based on the availability of the fatty acid data at birth and at 7 years of age. The eligible study population consisted of 116 eight year old Caucasian children, all born in the course of an earlier study on matemal and neomatal LCPUFA status and pregnancy outcome (12). From this sudy, the following clinical characteristics of the study population were known as well: maternal age at delivery, maternal weight, smoking and drinking habits during pregnancy, parental education, information about the delivery, including the gestational age at delivery, the sex of the child, weight, length and head circumference at birth and Apgar score. Other data were collected at follow-up. Written informed consent was obtained from the parents of each participant. The study was approved by the Ethics Commitlee of the University Hospital MaastrichuUniversiteit Maastricht.

\section{Analyical procedures and measurements}

Fatty acid profiles in phospholipids of umbilical venous plasma were determined as described by $\mathrm{A}$ et al. (12). Analysis of the venous plasma samples taken at 7 ycars of age was slightly different, using the lipid extraction method of Bligh and Dyer (13) and a CP-sill 88 silica column (Chrompack $50 \mathrm{~m} \times 0.25 \mathrm{~mm}$, film thickness $0.2 \mu \mathrm{m}$ ) 
whih $5.0 \mathrm{He}$ as carrier gas (flow rate $0.7 \mathrm{~m} / \mathrm{min}$, see Chapter 2 for further details). Faty acid data are presented in relative concentrations (\% of total fatty acids, wdwt).

\title{
Measurements of visual function
}

Visual function at 8 years was assessed by ophthalmologic measurements, visual evoked potentials (VEP) and electroretinography (ERG). All subjects had normal eye alignment and normall fundi on dilated ophthalmoscopy. Objective refraction was measured monocularly with the Rodenstock RX-202 automatic refraction meter, after tratment with Cyclogyl( 30 minutes in advance. Ophthalmologic outcome measurements included maximal visual acuity, stereopsis, and contrast sensitivity. Maximal visual acuity was measured monocularly using a standard digit card (chart of numbers of different sizes, like Snellen), while children were optimally corrected, if necessary, for refraction errors. Stereopsis as assessed by the TNO stereopsis test. This test identifies the level of stereo-acuity between 60 and 480 seconds of arc. In case of a low score, stereo-acuiry was also measured with the Lang Card, which identifies stereomacuities of 200,400 and 600 seconds of arc. Contrast sensitivity was tested using the Vector Vision CSV-1000E test (fluorescent luminance source of 85 $\mathrm{cd} / \mathrm{m}^{2}$, that retro-illuminates a translucent chart. Vector Vision, Dayton, OH, USA) in a dark room. The contrast threshold for each eye was tested at 4 spatial frequencies: 3 , 612 and 18 cycles per degree (cpd). The log-wnits of these thresholds were used in the statistical analyses.

\begin{abstract}
VEP
VEPs were measured with optimal corrected visual acuity using high-contrast (95 \%) black and white pattern reversal checkerboard stimuli (field of view $25^{\circ}$ horizontally and $19^{\circ}$ vertically; check size 15 minutes of arc, stimulus frequency 1.7 $\mathrm{Hz}$ ). The child was sitting in a quiet darkened room at a distance of $100 \mathrm{~cm}$ from the screen. Each eye was stimulated monocularly in two separate measuring runs. Registrations were made with three $\mathrm{Ag}-\mathrm{AgCl}$ skin electrodes on the occipital scalp (positions $O_{1}, O_{x}$ and $O_{2}$ ), a reference electrode at $F_{2}$ and a ground electrode at $C_{z}$. Electrode positions were in accordance with the International 10-20 EEG System (14). VEP responses were registered with a standard EP-system (Nicolet Viking IV) having a frequency bandwidth of $0.5-100 \mathrm{~Hz}$. VEP properties were detemined in the grand average of the two separate runs having 150 stimuli in each run. The latencies (in msec) of the N75 and the P100 peak and the amplitude of the N75-Plo0 wave (uV) were determined (15) (see Chapter 5).
\end{abstract}

\section{ERG}

Electroretinographic recordings elicited by single flash stimuli were made according to the $1 \mathrm{SCEV}$ standards (16). Alter superficial anesthesia with Oxybuprocaine(10 (0.4\%) and Cyclogy (1) (1\%) ERG measurements under ganzeld stimulation were performed using a DTL-thread-electrode in ach eye (17) referenced 10 an electrocle al $F_{y}$. ERG signal bandpass was $0.5-300 \mathrm{~Hz}$. The DTL-wire was placed loosely and deep inside the lower lid conjunctival fornix. After 20 minutes of dark adaptation scotopic ERG rod responses wore determined using blue colored flashes at a rate of $0.5 \mathrm{~Hz}$ and a maximal white light intensity of $2.9 \mathrm{~cd}-\mathrm{s} / \mathrm{m}^{2}$. Five scotopic measurement runs were performed using flash intansities filtered by respectively 2.0 , $1.6,1.0,0.6$ and $0.3 \mathrm{log}$-units. The amplitude of the b-wave (from baseline to the top of the ERG curve) was determined at the intensity that did just not elicite an a-wave. 
Thereupon, the mixed cone-rod maximal scotopic response was evoked using a white flash intensity of $2.9 \mathrm{~cd}-\mathrm{s}^{2} \mathrm{~m}^{2}$. After 10 minutes of blue light adaptation $\left(34 \mathrm{~cd} / \mathrm{m}^{2}\right)$, photopic ERG responses were detemined using white flashes at a rate of $2.0 \mathrm{~Hz}$ and an intensity of $2.9 \mathrm{~cd}-\mathrm{s} / \mathrm{m}^{2}$. The amplitude and latency of the a- and b-wave were determined. Amplitudes were from the baseline to the bottom of the a-wave and from the bottom of the a-wave to the top of the b-wave, respectively. The a and b-wave latency was the interval from stimulus onset to respectively the a- and b-wave peak.

\section{Sratistical analyses}

All data are presented as mean (SD). Differences between two groups (participants/non-participants, human milk group/artificial formula group, boys/girls) were tested with Students" t-iests. The relation between visual function of the children at 8 years of age and their DHA status at birth was investigated with multiple linear regression analyses, including gestational age (18), age at measurement (18), infant feeding habits (19) (measured as "duration of breasteeding") and sex (only in case of the contrast sensitivity and VEP outcomes (15)) as covariables. Visual outcome measurements were the dependent variables and DHA the independent variable. The relation between DHA status at 7 years, as a measure of DHA supply in later life, and visual function was also studied. In the statistical analyses a significance level of $\mathrm{P}<$ 0.05 was taken, unless mentioned otherwise. All statistical analyses were periormed using the statistical computer program StatView version 5.0 (SAS Institute Inc.). Based on studies investigating the relation between postnatal LCPUFA intake and visual outcome in infants, a small correlation between prenatal LCPUFA and visual outcome was expected (20). Sample size calculations indicate that a number of 59 participants was needed to detect a correlation of 0.35 at $80 \%$ power and a significance level of $5 \%$.

Table 1: Clinical characteristics of the eliglible study population

\begin{tabular}{|c|c|c|}
\hline Variable* & $\begin{array}{l}\text { participants } \\
(\mathrm{n}=59)\end{array}$ & $\begin{array}{l}\text { non-participants } \\
(n=57)\end{array}$ \\
\hline \multicolumn{3}{|l|}{ parental characteristics } \\
\hline maternal age at delivery (yrs) & $30.0(4.1)$ & $28.7(4.0)$ \\
\hline maternal weight $(\mathrm{kg})$ & $63.9(11.8)$ & $63.2(10.9)$ \\
\hline smoking during pregnancy $(y e x / n o, \%)$ & $20 / 80$ & $23 / 77$ \\
\hline alcohol use during pregnancy (yes/mo, \% & 2278 & $20 / 80$ \\
\hline matemal education (high/widdle/low. \%) & $18 / 64 / 18$ & $20 / 56 / 24$ \\
\hline paternal education (hightmidde/low "\%) & $27 / 52 / 21$ & $22 / 51 / 27$ \\
\hline $\begin{array}{l}\text { delivery (spontaneous waginal/vacum or foreeps } \\
\text { extraction/Ceasarean sectiom. \%) }\end{array}$ & $71 / 24 / 5$ & $77 / 21 / 2$ \\
\hline \multicolumn{3}{|l|}{ child characteristics } \\
\hline age at measurement (yrs) & $8.1(0.5)$ & \\
\hline gestational age (weeks) & $39.8(1.5)$ & $39.7(1.5)$ \\
\hline gender (boysigins, \%) & $49 / 51$ & $56 / 44$ \\
\hline birth weight (g) & $3320(500)$ & $3249(496)$ \\
\hline birth length $(\mathrm{cm})$ & $49.9(2.3)$ & $49.6(2.3)$ \\
\hline head circumference $(\mathrm{cm})$ & $34.3(2.1)$ & $34.2(1.4)$ \\
\hline Apgar score-5 & $9.6(0.8)$ & $9.3(1.2)$ \\
\hline Infant leeding habits (human milk/formida. \%) & 49.51 & $39 / 61$ \\
\hline
\end{tabular}

* values are either mean (SD) or percentages of population 


\section{Results}

Sridy population

Of the 116 selected children $59(50 \%)$ participated. The main reason for not participating was their anxiety about the methods to measure visual function. The clinical characteristics (mean \pm SD) did not differ between participating and not participating children (Table 1). Mean age of the participants, 29 boys and 30 girls, was 8.1 years (range $7.0-8.8 \%$. All children were singletons, borm healthy at term (gestational age $37-42$ weeks), excepl for two who were born after 35 and 36 weeks of pregnancy, respectively. The netrological function at 7 years of age was normal in all. children. Twenty-nine children had been breasted, 8 children less than 3 months, 12 children between 3 and 6 months and 9 children 6 months or longer. The mean duration of breastfeeding was 5 months ( \pm 3.6 months). Thirty children received. artificial formulas without LCPUFA. No significant differences in visual outcomes were found between the formula and breast-fed children (data not shown). Four children were wearing glasses at the time of follow-up, 4 other children also needed refraction correction in order to complete all visual function measurements. The fatty acid profiles of umbilical plasma phospholipids and venous plasma phospholipids sampled at 7 years of age of all 59 participants are given in Table 2.

Table 2: Fatty acid composition of phospholipids of umbilical plasma and of venous plasma at 7 years of age

\begin{tabular}{|c|c|c|}
\hline $\begin{array}{l}\text { Falty acid } \\
(\% \text { w } \\
(\% \text { w of total FA) }\end{array}$ & $\begin{array}{c}\text { umbilical plasma PL } \\
\text { mean (SD) }\end{array}$ & $\begin{array}{c}\text { plasma PL } 7 \text { years } \\
\text { mean (SD) }\end{array}$ \\
\hline $18: 2 n-6$ & $7.8(1.7)$ & $23.7(2.4)$ \\
\hline $20: 4 n-6$ & $16.3(1.8)$ & $9.2(1.3)$ \\
\hline $22 \cdot 5 n=6$ & $0.82(0.26)$ & $0.33(0.07)$ \\
\hline$\sum \pi 6 \mathrm{LCP}$ & $22.9(1.8)$ & $12.9(1.3)$ \\
\hline $18: 3 n-3$ & $0.04(0.06)$ & $0.20(0.07)$ \\
\hline $20: 5 n-3$ & $0.25(0.13)$ & $0.48(0.17)$ \\
\hline $22: 6 n-3$ & $6.3(1.5)$ & $2.8(0.8)$ \\
\hline $\mathrm{En}-3 \mathrm{LCP}$ & $7.1(1.7)$ & $4.2(0.9)$ \\
\hline
\end{tabular}

* 18:2n-6=linoleic acid, $20: 4 n-6=$ arachidonic acid, $22: 5 n-6=$ Osbond acid. $\Sigma n-6 L C P=$ sum of the $n-6$

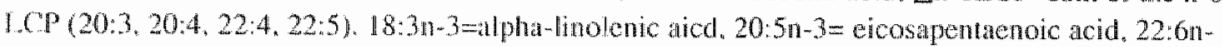
$3=$ docosihexacnoic acid, $\sum \mathrm{H}-3 \mathrm{LCP}=$ sum of the $\mathrm{n}-3 \mathrm{LCP}(20 ; 5,22: 5,22: 6)$. PL=phospholipids, $\mathbb{F} A=$ finty acids.

\section{Ophthalonologic outcomes}

Table 3 shows the mean results of all measurements. Because the results of the ophthatmologic measurements of the left and the right eye were highly correlated (Pearson correlation $=0.75, p<0.0001$ ), results of both eyes were averaged for further analyses. Regression analyses show that DHA in umbilical cord plasma is a significant (positive) contributor to visual acuity at 8 years when corrected for gestational age, age at measurement and infant feeding habits (partial $p=0.038$ ). The other significant predictors in this model were gestational age (partial $p=0.032$ ) and age at measurement (partial $p=0.0 \rrbracket 6$ ), the tolal model explained $19 \%$ of the variance (Table 4). Lack of variation in the stereopsis outcome ruled out this variable for nuther analyses. With respect to contrast sensitivity, differences between boys and girls were found. At 3 and $12 \mathrm{cpd}$, the boys scored significantly better (1.7 logunits) 
than the girls ( 1.6 log-units, $p=0.04$ and 0.03 respectively). At 6 and 18 cpd the differences were not significant, although they pointed into the same diroction. Contrast sensitivity was not significandy associated with DHA, when corrected for the mentioned potential confouders including sex.

\section{VEP measurements}

VEP measurements of the left and the right eye were highly correlated (Pearson correlation $=0.85, p<0.0001)$. For this reason data of right and left eye were averaged for further analyses. VEP results are shown in Table 3. In agreement with the literature (15) girls showed a larger N75-P100 amplitude (14.9 $\mu \mathrm{V}, \mathrm{p}=0.004)$, and shorter $\mathrm{N} 75$ and $\mathrm{P} 100$ latencies $(77.6 \mathrm{~ms}, \mathrm{p}=0.005$ and $107.9 \mathrm{~ms}, \mathrm{p}=0.0 \mathrm{l}$ respectively) compared with boys $(11.6 \mu \mathrm{V}, 81.1 \mathrm{~ms}$ and $112.7 \mathrm{~ms}$ respectively for the three VEP outcomes). Therefore, "sex" was included as a covariable in further analyses. In multiple regression analysis (Table 5), P100 latency was significantly predicted by DHA in umbilical plasma (partial $p=0.022$ ), and by sex (partial $p=0.015$, the total model explained $21 \%$ of the variance). The two other VEP outcones (N75-P100 amplitude and N75 latency) were not significantly predicted by DHA in umbilical plasma.

Table 3 : Visual outcomes* at 8 years of age

\begin{tabular}{|c|c|c|c|c|c|}
\hline Variable & Mean & \pm & $\mathrm{SD}$ & P5-P95 range & $n$ \\
\hline \multicolumn{6}{|l|}{ ophthalmological measures } \\
\hline $\begin{array}{l}\text { visual acuity } \\
\text { stereopsis (seconds of arc, expressed as } \\
\text { number of children) }\end{array}$ & 1.0 & \pm & 0.1 & $(0.8-1.25)$ & 59 \\
\hline 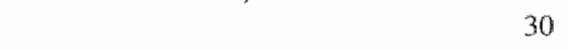 & 1 & \multicolumn{2}{|c|}{$(2 \%)$} & & \\
\hline 60 & 50 & \multicolumn{2}{|c|}{$(86 \%)$} & & 58 \\
\hline 120 & 3 & \multicolumn{2}{|c|}{$(5 \%)$} & & \\
\hline 200 & 1 & \multicolumn{2}{|c|}{$(2 \%)$} & & \\
\hline 240 & 3 & \multicolumn{2}{|c|}{$(5 \%)$} & & \\
\hline \multicolumn{6}{|l|}{ contrast sensitivity (log-units) } \\
\hline 3 cpd & 1.6 & \pm & 0.2 & $(1.3-1.9)$ & 54 \\
\hline $6 \mathrm{cpd}$ & 1.9 & \pm & 0.2 & $(1.6 .2 .3)$ & 54 \\
\hline $12 \mathrm{cpd}$ & 1.7 & \pm & 0.2 & $(1.2-2.0)$ & 54 \\
\hline $18 \mathrm{cpd}$ & 1.3 & \pm & 0.2 & $(0.8-1.6)$ & 54 \\
\hline \multicolumn{6}{|l|}{ VEP measurest } \\
\hline amplitude $N 75-P 100(\mu V)$ & 13.2 & \pm & 4.3 & $(5.7-20.3)$ & 55 \\
\hline Watency N75 (msec) & 79.4 & \pm & 4.8 & $(72,0-87.7)$ & 55 \\
\hline latency 100 (nsec) & 110.3 & \pm & 7.0 & $(100.5-124.3)$ & 54 \\
\hline \multicolumn{6}{|l|}{ ERG meastires } \\
\hline scotopic ERG b-wave & \multicolumn{3}{|c|}{ scotopic ERG b-wave } & & 29 \\
\hline \multicolumn{6}{|l|}{ plnotopic ERG } \\
\hline amplitude a-wave $(\mu \mathrm{V})$ & 35 & \pm & 14 & $(14-60)$ & 23 \\
\hline latency a-wave (msec) & 16.0 & \pm & 1.2 & $(13.5-18.3)$ & 25 \\
\hline amplitude b-wave $(\mu \mathrm{V})$ & 102 & \pm & 37 & $(44-152)$ & 25 \\
\hline Latency b-wave (msec) & 333 & $\#$ & 1.6 & $(30.0-36.6)$ & 26 \\
\hline
\end{tabular}

\footnotetext{
* both cyes are averaged
}

+ VEP checks 15 minutes of arc; values of Oz, O2 and Ol are averaged 
Table 4: Regression coefficients tor the model predicling visual acuity ( $n=59)$

\begin{tabular}{llrrr}
\hline Varable & B (SE) & Beta & T & p-value \\
\hline DHA umbilical plasma & $0.03(0.01)$ & 0.30 & 2.13 & 0.038 \\
gestational age & $-0.03(0.01)$ & -0.32 & -2.20 & 0.032 \\
age & $0.008(0.003)$ & 0.31 & 2.50 & 0.016 \\
infont feeding & $-0.005(0.004)$ & -0.14 & -1.17 & 0.245 \\
(intercept) & $1.16(0.51)$ & & 2.23 & 0.030 \\
\hline
\end{tabular}

* $\mathrm{B}=$ regression coefficient, Beta=standardized regression coefficient, $\mathrm{T}=$ partial $\mathrm{T}$-test

Table 5: Regression coefficients for the model predicting VEP PIOO latency (n=54)

\begin{tabular}{llrrr}
\hline Varialle & B (SE) & Beta & T & p-valune \\
\hline DHA umbilical plasma & $-1.68(0.71)$ & -0.35 & -2.38 & 0.022 \\
gestational age & $0.77(0.68)$ & 0.17 & 1.15 & 0.258 \\
age & $-0.10(0.19)$ & -0.07 & -0.51 & 0.614 \\
infatut feeding & $-0.02(0.27)$ & -0.01 & -0.07 & 0.946 \\
gender & $-4.60(1.82)$ & -0.33 & -2.53 & 0.015 \\
(intercept) & $1.01 .54(30.34)$ & & 3.35 & 0.002 \\
\hline
\end{tabular}

* see Tible 4 for legend

Table 6: Regression coefficients* for the model predicting the photopic ERG a-wave latency ( $n=25)$

\begin{tabular}{llrrr}
\hline Variable & B (SE) & Beta & T & p-value \\
\hline DHA umbilical plasma & $-0.43(0.19)$ & -0.55 & -2.23 & 0.037 \\
gestational age & $0.31(0.23)$ & 0.37 & 1.39 & 0.180 \\
age & $-0.08(0.05)$ & -0.36 & -1.74 & 0.098 \\
infant feeding & $-0.10(0.09)$ & -0.23 & -1.06 & 0.303 \\
(intercep) & $14.56(8.18)$ & & 1.78 & 0.090 \\
\hline
\end{tabular}

* see Table 4 for legend

\section{ERG measurements}

In 30 out of the 59 children ERG recordings were successful. ERG data of twentynine children are missing because they refused application of eyedrops or placing of the DTL wires or there were technical problems with the DTL-wires. The umbilical plasma DHA values of the children with successful $\mathbb{E R G}$ measures did not differ from those for whom ERG data were missing. Some amplitudes were not interpretable because of baseline artifacts in the ERG recording. Statistical analyses of the ERG measurements were again conducted with the right and left eye averaged data. Table 3 shows the results of both scotopic and photopic ERG measurements, that are comparable 10 normative values (21). There were no differences in ERG outcomes between boys and girls. With multiple regression analyses, a negative relation was found between DHA in umbilical plasma and the latency of the a-wave in the photopic ERG, corrected for gestational age, age at measurement and duration of breasteeding (partial $p=0.037$, the total model explained $28 \%$ of the variance, other predictons were not significant, Table 6). The other ERG outcomes were not related to umbilical plasma DHA, either.

DHA in plasma sampled at 7 years of age was not related with any of the visual outcomes. The same analyses were also done for the n-6 LCPUFA arachidonic acid. There were no associations between the percentage of this fatty acid in umbilical plasma phospholipids or plasma phospholipids at 7 years of age and the visual outcomes. 


\section{Discussion}

Several studies, although not all, have found a positive influence of postnatal consumption of long-chain polyunsaturated faty acids (LCPUFA), especially docosahexaenoic acid (DHA), on visual function $(20,22)$. Because the growth spurt of the central nervous system already starts during the last intraterine trimester, the prenatal LCPUFA availability may be of even greater importance for the development of the visual system.

In this study, the DHA status in phospholipids of umbilical plasma, a reflection of the prenatal DHA avallability, showed an association with visual acuity, the VEP PloO latency and the photopic ERG a-wave latency at 8 years of age, corrected for gestational age, age at measurement, duration of breastfeeding and sex (the latter only in analyses with VEP measurements). The first relation was positive, which means that a higher DHA status corresponds with better visual acuity (for adjusted means, according to umbilical plasma DHA quartiles, see Figure 1). The other two relations were negative, which means that a higher DHA status is associated with faster processing of visual information in visual cortex and retina respectively (Figure 1). These results suggest that prenatal DHA availability may be important for the development of the visual system.

Our observation is supported by the recent findings of Williams et al.(19) who reported an association between maternal DHA intake during pregnancy and stereoacuity at 3.5 years of age. Because this study used indirect measures for prenatal DHA availability, the authors recommended further research to determine the relation between DHA concentrations at birth and childhood visual outcomes. Unforlunately, the lack of variation in stereopsis outcomes in our rather small sample did nol allow statistical analyses with this outcome variable, but our results with other visual outcomes confirm that prenatal DHA might be important for visual development.
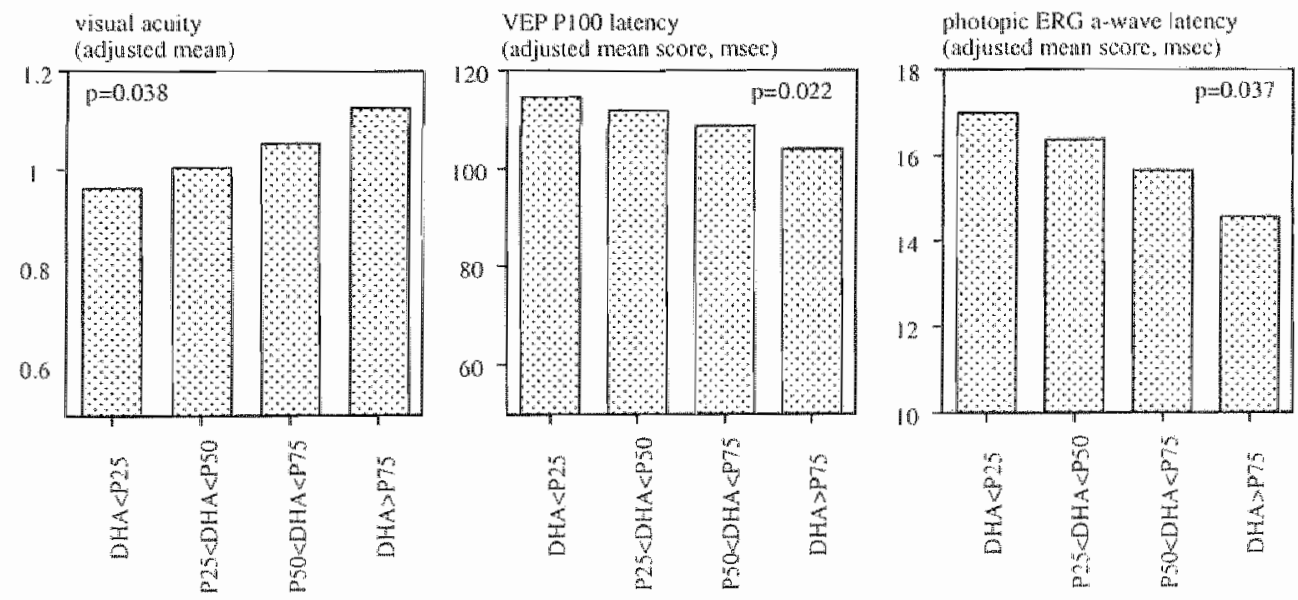

Figure 1: Visual acuity. VEP PIO0 latency and photopic ERO aw we latency, according 10 ambilical plasma DHA quartiles. 
Because many visual outcome variables were measured in the present study and the observed associations are weak, one should be aware of potential type I errors, which means that multiple testing can cause statistical significant relations by coincidence. Consequently, the reported results should be interpreted with care. There is, however, reason to believe that our results were not obtained by sheer chance. The three observed associations all suggest a positive effect of prenatal DHA availability on visual function, although each of the outcome variables is measuring visual function on a different level. A shortening of the photopic ERG a-wave latency is known to be a consequence of photoreceptor maturation (18) and VEP P100 latency is considered to be the most sensitive and reliable measure of optic nerve conduction velocity ( 15 ). Visual acuity can be considered to be a higher order visual function, which not only involves retinal and optic nerve function, but also cortical neuronal development (23). Our findings support a positive influence of DHA status on each of these three levels.

In the long-term development, DHA supply during later life can also play a role. Dietary DHA may be needed for the maintenance of the DHA concentration in membrane phospholipids. Furthermore, various parameters of the visual system do not reach adult values until at least 5 years of age, although the most rapid development takes place in the first year $(24,25)$. However, no significant association was found between DHA in plasma sampled at 7 years of age and the visual outcome measures at 8 years of age. This finding suggests that prenatal DHA supply may be more important for later visual development than childhood dietary DHA. This suggestion is supported by the fact that the retina is able to retain and recycle DHA $(26,27)$, so DHA availability in the period of rapid CNS development could have long lasting effects on the amount of DHA in the retina.

Studies in artilicial membranes have shown that the DHA content of the retina can have an influence on the function of the photoreceptor cells in the retina (28), possibly by changing the characteristics of the phospholipid bilayer of membranes $(29,30)$. Furthermore, changes in membrane fluidity, resulting from an altered DHA content of the membranes, could the process of signal transduction in the CNS (30). These could be the underlying mechanisms of the found associations between DHA and visual function.

Our results suggest that prenatal DHA avalability is important for later visual outcome. Neonatal LCPUFA values can be influenced by maternal diet during pregnancy (12), so maternal DHA intake can be expected to influence visual development. Intervention studies are necessary to find out whether DHA supplomentation of mothers during pregnancy could have beneficial effect on later visual performance of their children. 


\section{Literature}

1. Sastry PS. Lipids of nervous tissue: composition and metabolism. Prog lipid Res 1985:24:69. 176.

2. Innis SM. Essential farty acids in growth and development. Prog Lipid Res 1991;30:39-103.

3. Reisbick S. Neural Development. In: Carlson S. Neuringer M, Reisbick S, editors. Assessment of infant wisual and cognitive function in relation to long chain polyunsaturated faty acids. Basel: Editiones Roche; 1996. p. 10-8.

4. Flesler SJ, Anderson RE. Chemistry and metabolism of lipids in the vertebrate ratima Prog Lipid Res $1.983 ; 22: 79-131$.

5. Birch EE, Hoffman DR, Uauy R, Birch DG, Prestidge C. Visual acuity and the essentiatity of docosahexaenoic acid and arachidonic acid in the diet of term infants. Pediatr Res 1998:44:2019.

6. Carlson SE, Ford AJ, Werkman SH. Peeples IM. Koo WW. Visual acuity and fatty acid status of term infants fed human milk and formulas with and without docosahexaenoate and arachidonate from egg yolk lecithin. Pediatr Res 1996,39:882 8.

7. Makrides M, Neumann M. Simmer K. Pater J, Gibson R. Are long chain polyunsaturated fatty acids essential nutrients in infancy? lancet 1995:345:1463-8.

8. Auestad N, Montalto MB, Hall RT, Fizgerald KM. Wheeler RE Connor WE, Neuringer M. Connor SL. Taylor JA, Hartmann EE. Visual acuity, erythrocyte faty acid composition, and growth in term infants fed formulas with long chain polyunsaturated faty acids for one year. Pediatr Res 1997:41:1-10.

9. Imnis SM, Akrabawi SS, Diersen Schade DA, Dobson MV, Guy DG. Visual acuily and blood lipids in term infants fed human milk or fornulae. Lipids 1997;32:68-72.

10. Makrides M. Neumann MA. Gibson RA. Is dietary docosahexaenoic acid essential for tem inliants. Lipids 1996;31:115-9.

11. Gibson $\mathbb{R A}$, Neumann MA, Makrides M. Effect of dietary docosahexaenoic acid on brain composition and neural function in term infants. Lipids 1996;31:5177-81.

12. Al MDM. Houwelingen ACV. Kester ADM, Hasaart RHM, Jong EAPd, Hornstra G. Matemal essential fatty acid pattern during nomal pregnancy and their relationship to meonatal essential fatty acid status. Br J Nutr 1995:74:55-68.

13. Bligh ED, Dyer WJ. A rapid method for total lipid extraction and purification. Can I Biochem Physiol 1959;37:911-7.

14. Jasper $H$. Repont of the committee on methods of clinical examination in electroencephalography. Electroenceph Clin Neurophysiol 1958:10:370-5.

15. Chixppa K. Evoked Potentials in Clinical Medicine. New York: Raven Press; 1983.

16. Marmor MF, Zremer E. Standatd for clincal electroretinography (1994 update). Dow Ophthalmot 1995;89:199-210.

17. Dawson W. Trick G. Litzkow C. Improved electrode for electroreinography. Invest Opthal vis Sci 1997:18:988-91.

18. Leaf AA, Green CR. Exack A, Costeloe KL, Prior PF. Maturation of electroretinograms and visual evoked potentials in preterm infants. Dev Med Child Neurol 1995;37:814-26.

19. Willians. C. Birch EE. Emmet PM, Northstone K. Stereoacuily at age 3.5 y in children born full-tem is associated with prenatal and posthatal dietary factors: a report from a population based cohort study. Am J Clin Nutr 2001;73:316-22.

20. SanGiowani JP, Berkey CS, Dwyer JT, Coldiz GA. Dietary essential fatly acids, Iong-chain polynusaturated faty acids, and wisual resolution acuity in healthy fullerm infants: a systematic review. Early Hum Dev 2000,57: 165-88.

21. Jacobi PC, Ruther K, Miliczek. KD, Volker M. Zrenner E. Klinische Elektrorcinographie: slandardprotokoll und normwerte. Klin Monatsbl Augenheilkd 1993:202:27-42. 
22. SanGiovanni JP. parra-Cabrea $S$, Coldiz GA Berkey $C S$, Dwyer IT. Meta-analysis of dietary essential faty acids and long-chain polyunsaturated faty acids as they relate to visual resolution aculy in healthy preterm infants. Pediatrics 2000; 105:1292-8.

23. Birch E. Visuat acuity tesing in infants and young children. Ophthalmol Clin $\mathrm{N}$ Am $1989: 2: 369-89$

24. Sokol S. Jones K. Implicit time of pattem evoked potentials in infants: an index of maturation of spatial viston. Vision Res 1979;19:747-55.

25. Sokol S. Maturation of visual function studied by visual evoked potentials. In: JE D, editor. Visual Evoked Potentials. A mistendam: Elsevier Science Publishers, B.V.; 1990. p. 35-44.

26. Stinson AM. Wiegand RD. Anderson RE. Recycling of docosahexaenoi acid in rat retinas during $n-3$ fatty acid deficiency. J. Lipid Res. 1991;32:2009-17.

27. Anderson RE, OBrien PI, Wiegand RD. Koutz CA, Stinson AM. Conservation of docosahexaenoic acid in the retina. In: Bazan NG, al. e, editors. Neurobiology of essentiall fatty acids. New York: Plenum Press; 1992 p. 285-94.

28. Wedmann TS, Pates RD, Beach JM, Salmon A, Brown MF. Lipid-protein interactions mediate the photochemical function of thodopsin. Biochemistry 1988;27:6469-74.

29. Dratz E, Holte L.. The molecular spring model for the function of docosahexaenoic acid (22:6n 3) in biological membranes. In: Sinclair A. Gibson. R, editors. Essential fatiy acids and cicosunoids: invited papers from the third intemational congress. Champaigm: The American Oil Chemists' Society: 1992. p. 122-7.

30. Kurlak LO, Stephemson TI. Plausible explanations for effects of long chain polyunsaturated fatly acids (LCPUTFA) on neonates. Arch Dis Child Fetal Neonatal Ed 1999;80-F148-54. 
General discussion 
High amounts of long-chain polyunsaturated fatty acids (LCPUFA), especially docosalexaenoic acid (DHA) and arachidonic acid (AA) are present in the central nervous system (CNS) $(1,2)$. Since the most rapid accretion of these fatty acids in the CNS takes place during the CNS growth spurth, in the last intrauterine trimester and in the first year of life $(3,4)$, an adequate supply of LCPUFA to the CNS during this period might be important for later CNS function. The exact roles of the LCPUFA in the CNS have not yet been elucidated. The studies described in this thesis focussed on the relation between early long-chain polyunsaturated fatty acid availability and later cognitive, motor and wisual function. The relation between prenatal LCPUFA availability, as reflected by the umbilical venous plasma LCPUFA concentrations, and child development was investigated by a follow-up measurement at 7 or 8 years of age. The influence of postnatal dietary LCPUFA supply on later development was studied by comparing the performance of children fed standard artificial formula's without LCPUFA with that of children fed human milk, which contains LCPUFA. Furthermore, the relation between LCPUFA availability in plasma at 7 years of age and developmental outcomes at 7 or 8 years of age was also investigated.

\section{Prenatal LCPUFA availability and child development}

The fetus is supplied with essential fatty acids by the mother via transport through the placenta. Umbilical venous plasma LCPUFA concentrations can therefore be taken as an indicator for the prenatal availability of these fatty acids to the fetus. To investigate the relation between child development and the percentages of DHA and A A in umbilical venous plasma, we measured several aspects of cognitive and motor function of 306 children at 7 years of age and the visual function of 59 children at 8 years of age.

Many variables, other than the LCPUFA status at birth, exert an influence on child development. Childhood cognitive performance, for example, is known to be associated to social class $(5)$, maternal intelligence $(6,7)$, parenting skills $(5,7)$, maternal smoking (8) and drinking habits during pregnancy (9), breastfeeding dutation (10) and the child's sex (11), birth order (12) and birthweight (13). Since these variables can confound the relations between the developmental outcomes and the LCPUFA status at birth, especially because of the relatively long period between birth and follow up, they were included in our statistical analyses.

Measures of cognitive function in this study were the scores of the children on a standardized test of intelligence and achievement, and several school achievement scores. None of these cognilive outcomes showed a relation with LCPUFA percentages in umbilical plasma (Chapter 2). With respect to motor function it was the quality, not the quantity, of movement that was related the DHA status at birth (Chapter 4). So, not the ability of a child to perform al movement, but the way the child performs the movement relates to the prenatal DHA availability. Perhaps, this aspect of movement is more sensitive to small variations in CNS function than the quantitative aspects of movemetit.

Signilicant associations regarding the visual outcomes were found at three levels: litstly, there was a significant association of DHA with visual acuity, which not only involves retual and optic nerve function, but also cortical neuronal development (14). Secondly, a higher DHA status at birth was associated with faster processing of visual information via the optic nerve to the visual cortex (15). Another significant positive relation was observed between umbilical plasma DHA and retinal speed of information processing, which is known to be a consequence of photoreceptor 
maturation (16). Of course, the observational design of this study does not allow to interpret these findings in terms of causality. As far as we know, no other studies investigating the relation between prenatal LCPUFA availability (measured by proxy) and cognitive or motor performance in childhood have been published yer. Only one study related the visual outcome stereoacuity to prenatal LCPUFA availability (measured by maternal DHA intake during pregnancy) (17). The positive association found in that study between stereoacuity at 3.5 years of age and maternal DHA intake is in line with our results with regard to visual function.

Although statistically significant, the positive associations we found between umbilical plasma DHA percentages and developmental outcomes at 7 or 8 years are relatively small. For example, an increase in umbilical plasma DHA from 4.3 to $7.9 \%$ of total fatty acids is associated with an increase of 4 points in movement quality score (mean score $=52$ points, $\mathrm{SD}=10$ points). Therefore, the clinical relevance of the reported associations may be questioned. However, even a minor increase in the average score of a population removes some children from below any arbitrary cutoff. In consequence, the number of children referred to special care or education may decline when the dietary DHA intake during pregnancy is increased in the whole population. This would have benefits both on mational level (reduced health care expenses) and on individual level (reduced chance of the indiwidual child to be stigmatized by peers and others). Of course, further research has to be done before anything can be said about these aspects. There is another important comment to make about this interpretation of the results. The purpose of our study was to describe variations in CNS function in relation 10 LCPUFA availability, not to detect deviations from normal CNS function. Thus, our starting-point is normal, physiological, variation in CNS function.

The consequences of an increase in dietary DHA intake during pregnancy may in particular be important for children born prematurely, who also need special care more often than do term children. Because preterm intants partly miss the intrauterine fatty acid accretion, their DHA status at birth is lower than that of infants born at term (18). Therefore, small variations in DHA supply may then have a more pronounced influence on later CNS function in children born prematurely as compared with lem children.

Arachidonic acid status at birth was not significantly associated with the outcome parameters at $7-8$ years of age. However, some negalive associations were on the border of significance. For instance, umbilical plasma A percentage was negatively associated with the movement quality score on the Mastricht Motor Test $(p=0.052)$. Therefore, this fatty acid needs more attention in future studies.

\section{Postnatal LCPUFA availability}

\section{Infont nutrition}

Neonates depend on human milk or artificial formula for their essential latty acid supply. However, the fatty acid composilion of standard artificiat formulas differs from that of human milk $(19,20)$. Human milk generally contains arachidonic acid and docosahexaenoic acid, whereas standard artificial formulas do not contain these LCPUFA. This difference results in a lower brain DHA concentration in infants fed artificial formulas as compared with lhuman milk-fed infants (21-24), which may have functional consequenses later on. We compared the cognitive, motor and visual performance of children fed artificial formula with that of breastfed children, keeping in mind that the potential differences are not necessarily the consequense of 
differences in dietary fatly acid supply berween the two feeding groups. The observational design of our study does not pernit causal interpretation.

There was a significant difference in cognitive function, measured at 7 years of age with the Kaufman-Assessment Battery for Chidren, between the 161 formula-fed and the 1.44 breastfed children, in favor of the latter (Chapter 3). However, after adjustment for social class, maternal cognitive function, parental skills, maternal smoking and drinking habits during pregnancy, and for the child's sex, birth order and birilnwelght, this difference was no longer significant. This suggests that it is not the infant nutrition itself that is associated with later intellectual development. Thus, the differences in cognitive function between the two feeding groups may be explained by other, environmental, factors, for instance maternal intelligence, parenting style and/or health behavior (25-27). The tests for motor function, administered at 7 years of age, distinguished between quantity and quality of movements (Chapter 4). Both aspects of movement did not differ between the formula and the breastfed children. The relation between visual function and infant feeding habits (breastfeeding/formula-feeding) was investigated both in our follow-up study (Chapter 7) and in an infant study (Chapter 6). In both studies, no significant differences in visual outcomes were found between the formula and breastied children.

Several intervention studies have been conducted to investigate the influence of LCPUFA in infant nutrition on developmental outcomes. In some studies, supplementation of formulas with LCPUFA did not result in better cognitive or visual function in term infants as compared with a non-supplemented formula-group (28-35). However, other studies did find differences in later performance between term children who received standard artificial formulas and children who received LCPUFA-supplemented formulas $(36-42)$. Several explanations for these inconsistencies in the literature lnave been mentioned (Chapter 5), including variations. in initial fatty acid concentrations at birth. In the study described in Chapter 3 , we also investigated the hypothesis that the difference in cognitive function between artificial formulas and human milk is more pronounced in the group of children who had low LCPUFA values at birth as compared with the group of children with high LCPUFA values at birth. Although this appeared to be true, the interaction between infant feeding and umbilical plasma DHA or AA percentages was not statistically significant. Thus, the LCPUFA status at birth did not significantly influence the association between cognitive performance at 7 years of age and infant feeding habits in this observational study. However, it cannot be excluded that the initial DHA or AA status still plays a role in intervention studies. It is recommended to take the initial LCPUPA status into account in future studies.

Although the findings of the studies described in this thesis do not provide evidence lor an association between cognitive, motor or visual performance at 7 years of age and type of infant nutrition, our results do not detract from the proven values of human milk (43). The fact that the concentrations of DHA and other essential fatty acids are lower in plasma and red blood cells of formula-fed infants compared with those of breasted infants (Chapter 6) may lead to other, not yet discovered, physiological consequences.

\section{Childhood LCPUFA availability}

In longer-term development, L...CPUFA supply during childhood may also play a role, because dietary LCPUFA possibly are associated to the LCPUFA concentrations in CNS membrane phospholipids. Therefore, we also investigated the association 
between LCPUFA percentages in venous plasma sampled at 7 years of age as a measure of LCPUFA availability during childhood, and cognitive, motor and visual performance at 7 or 8 years (Chapters 2,4 and 7 , respectively). Results of these analyses show that none of the aspects of CNS function was related to the LCPUFA status at 7 years of age. The only significant positive correlation was between DHA and reading scores reported by the school. AA showed a negative association with arithmetics reported by the school, which was not found with the direct measurement of arithmetics with the Kaufman test (Chapter 2). Thus, prenatal LCPUFA availability seems to be more important for later CNS function than childhood dietary LCPUFA. The finding that LCPUFA in plasma at 7 years are not associated with developmental status at that age suggests that either later availability of these fatty acids is not important for CNS function or that the plasma values of these fatty acids do not represent the concentrations in the CNS. This and other methodological considerations are discussed in the next section.

\section{Methodological considerations}

Study design

The follow-up study, described in this thesis, can be classified as an observational retrospective cohort study. In this kind of studies, populations are defined on the basis of data sampled in the past and current outcomes are related to these 'historical' data (44). Our study related the current developmental outcomes to the umbilical venous plasma fatty acid values, sampled $7-8$ years before. In general, the internal validity of retrospective cohort studies is lower than that of prospective colnont studies (in which all data still need to be collected at the start of the study). Reasons for this are the often non-specific measurement of the historical data, the absence of a proper measurement of covariables, and difficalties in relating the current data to the data sampled in the past (44). The design of our study did not suffer from these weaknesses. The independent variable, LCPUFA status at birth, was measured directly in the umbilical venous plasma phospholipids, as part of an earlier study on maternal and neonatal LCPUFA status and pregnancy outcome (45); the values of most covariables were also collected at the time of birth as part of this earlier study, other cowariables were measured at follow-up. Since both historical data and current data were sampled within the same research line, coupling of these data did not give rise to difficulties. Therefore, the internal validity of our study is regarded companable to the internal validity of prospective cohort studies.

\section{Brochemical methods}

In all but one of the studies presented in this thesis, the LCPUFA avallability was studied as percentage of total fatty acids in plasma total phospholipids. In associating this information with the developmental outcomes, we made the assumption that plasma phospholipid LCPUFA percentage reflects the awailability of these LCPUFA to neural tissue. However, it is possible that the LCPUFA status, expressed in this way, is not a good indicator for the presence of these fatty acids in the central nervous ussue. Studies in piglets, for instance, have shown that plasma phospholipid levels of $A A$ and red blood cell DHA were lower in piglets fed formula without LCPUFA as compared with those fed natural milk, which contains $A A$ and DHA, even when brain AA and DHA concentrations were comparable (46).

Only one human study directly related blood LCPUFA values 10 brain values (24) and found a significant association between DHA percentage in red blood cell total 
lipids and cortex DHA. Because of the high, statistically significant, correlation we found between plasma phospholipids and red blood cell phospholipids in DHA and AA percentages $(r=0.8$ and 0.9 , respectively, $p<0.0001$ in both cases, unpublished data), the findings of Makrides et al can probably be extended to plasma LCPUFA percentages.

\section{Methods of outcome measurements}

High levels of DHA and AA are present in neural membranes throughout the CNS. Therefore, LCPUFA status potentially has an influence on several aspects of development, e.g. cognitive function, information processing, motor function, attention, motivation and arousal, behavior or sensory function $(47,48)$. The methods we chose rellect a variety of CNS functions. The Kaufman-Assessment Battery for Children (K-ABC (49)) assesses the intelligence and achievement of 2.5-to 12.5-yearold children (Chapters 2 and 3). Two other world-wide-known intelligence tests for children are the Wechsler Intelligence Scales for Children (Revised: WISC-R (50)) and the McCarthy Scales of Development (51). We chose to use the K-ABC for several reasons: the good theoretical background is one of them. Another reason is the distinction this test makes between achievement and problem solving skills. We expected the latter aspect to be less influenced by environmental influences than the scores on the WISC-R. Practical reasons also played a role in our decision: the K$A B C$ is easier to score and is more pleasant for 7 -year-old children than the WISC-R, which is suitable for children of 6 to 16 years old. Furthermore, administration of the K-ABC takes less time than administration of the WISC-R, which was an important prerequisite, because of the rather demanding test program. With respect to the McCarthy Scales of Development we anticipated a ceiling effect, because this test can be administcred until a maximum age of 8.5 years.

Motor function was tested both quantitatively and qualitatively, as mentioned before (Chapter 4). The results differed for both aspects of movement, which suggests movement quality to be a more sensitive indicator of brain maturation and integrity than movement quantity $(52,53)$. The Maastricht Motor Test is the only test that quantifies the qualitative aspects of movement in children.

Several measures of wisual function were used in our studies (Chapters 6 and 7 ), which were all considered to be a measure of CNS function, and not merely as visual measures. The a-wave latency measured with electroretinography is known to be the consequence of the maturation of photoreceptors (16). The latency of Visual Evoked Potentials is considered to be the most sensitive and reliable measure of optic nerve conduction velocity (15). Visual acuity not only involves retinal and optic nerve function, but also cortical neuronal development (14). Again, the purpose was to describe variations in the function of the visual system in relation to LCPUFA status, not to detect deviations from normal visual function.

The ages at which the tests were administered were 7 months for the Teller Acuity Card method, 7 years for the test for cognitive and motor performance, and 8 years for the other visual measurements. Teller acuity shows a plateau between 6 and $\$ 2$ months of age, after a period of rapid development from birth to 6 months of age (54). Chances to find significant results may be higher in the period between birth and 6 months of age. However, measuring visual acuity at 7 months is more likely to represent actual visual function levels. Interindividual differences in clevelopment speed may suggest differences in visual function at younger ages while the eventual level of visual performance does not have to differ between these individuals. 
With respect to other domains of development, differences between individuals are also common. Investigating these developmental domains at 7 or 8 years of age is a safe choice, especially because there are indications that the course of development might be discontinuous (52). Developmental outcomes at this age also correlate better to adult intelligence and performance (55). Furthermore, it was not possible to measure school achievement at an earlier (preschool) age.

Unfortunately, in 7 years, many children were lost to follow-up. From the 750 eligible children, only 306 participated in the follow-up at 7 years of age. Twenty two children $(2.9 \%)$ could not be traced, $3(0.4 \%)$ were deceased, and $34(4.5 \%)$ had emigrated. From the invited $691(92.1 \%)$ families 133 did not give any respons, even after several letters and repeated phone-calls; the parents of 231 children did not give consent, due to lack of time to participate in this study and the concern of the parents that this study would burden their child too much. So, informed consent was obtained from the parents of 327 children, of which 21 dropped out of the sudy by repeatedly not showing up at the appointment. There were no differences in clinical characteristics between the participants and non-participants, except for a small difference in umbilical venous plasma arachidonic acid percentages. The participants had an umbilical plasma percentage of $16.6 \%$ of the total amount of fatty acids. whereas this percentage was $16.9 \%$ in non-participants. This difference of less than 2 $\%$ of the given arachidonic acid values was considered clinically irrelevant.

\section{Conclusions and recommendations for future research}

From the studies described in this thesis, it can be concluded that the DHA status at birth shows a small, but statistically significant association with some developmental outcomes at 7-8 years of age in children born at term, whereas neither the LCPUFA status at 7 years of age nor the type of infant nutrition (breastfeeding versus formulafeeding) was significantly associated with child development. These findings suggest that prenatal LCPUFA availability may be mone important for later CNS function than childhood dietary LCPUFA.

Neonatal LCPUFA values can be influenced by maternal diet during pregnancy (45), so maternal LCPUFA intake can be expected to influence later functional development of the child. The influence of LCPUFA intake of molhers during pregnancy and lactation on child development should be investigated by means of intervention studies, in order to generate recommendations for the dictary LCPUFA intake in this period. These studies should not only address childhood performance, but also include clinical and functional consequences for the mother. Furthermore, safety aspects of supplementation should be taken into account.

Since there are indications that the influence of dietary LCPUFA on CNS function is transient, the influence of prenatal LCPUFA avalability on later development should be investigated with follow-up studies, measuring the children several times between birth and adulthood. Other areas of development, e.g. velocity of information processing or child behavior, also need to be studied in relation to prenatal LCPUFA availability. The associations we found between umbilical plasma DHA and some aspects of development, may also be related to other aspects of CNS function. Movement quality, for instance, may predict developmental problens like attention deficit hyperactivity disorder (ADHD) and learning problems $(53,56,57)$. Therefore, the positive association we found between DHA status at birth and this aspect of motor function is in line with the idea that LCPUFA status might also be associated 10 behaviour and learning disorders $(58,59)$. Studying more specific developmenta! 
domains may provide more information that could help target the underlyng mechanisms of action of LCPUFA in the CNS (47).

Although there was a reasonable variation in umbilical plasma LCPUFA percentages in our population, none of the children had extremely low LCPUFA values. The associations between prenatal LCPUFA availability and later development should also be investigated in other populations with a relative shortage of LCPUFA. Since considerable differences in maternal and neonatal fatty acid status exist between different populations (60), it would, theoretically, be interesting to compare the CNS function of children from these populations. In practice, the value of such a comparison would be limited, due to factors like potential confounders and problems with the standardization of the measurements, among others.

Finally, special attention should be paid to the consequences of LCPUFA supply to children born prematurely, since these children miss the last intrauterine accretion of fatty acids and are, therefore, born with a lower DHA status than term children (18). On the one hand, intervention studies in the general pregnant population, as recommended above, will give the opportunity to study the influence of maternal dietary DHA intake on later development both in term and in preterm born children. On the other hand, early identification of pregnancies "at risk for premature delivery" would be a more efficient way to investigate this relation in children born prematurely. However, this latler kind of studies may easily be biased (by selection), and would, therefore, give rise to difficulties in interpreting the results.

\section{Literature}

1. Sastry PS. Lipids of nervous tissue: composition and metabolism. Prog Lipid Res 1985;24:69 176.

2. Q'Brien JS, Fillerup DL, Mead JF. Quintification and fatly acid and faty aldehyde composition of ethanolamine, choline, and serine glycerophosphatides in human cerebral grey and white matter. IJipid Res 1964:5:329 -38.

3. Clandinin MT, Chappell JE, Leong $S$, Heim T, Swyer PR, Chance GW. Intrauterine fatty acid accretion rates in human brain: implications for fatty acid requirements. Early Hum Dev $1980 ; 4: 121-9$.

4. Clandinin MT, Chappell JE, Leong S, Heim T, Swyer PR, Chance GW. Extraterine fatty acid accretion in infant braim: implications for fatty acid requirements. Early Hum Dev 1980;4:1318.

5. Andersson HW, Sommerfell K. Sonnander K, Ahlsten G. Maternal child-rearing attitudes, $1 Q$ and socioeconomic status as related to cognirive abilitics of fre-year-old children. Psychol Rep $1996 ; 79: 3-14$

6. Bachurach VR, Bameister A. Effects of maternal intelligence, marital status, income, and home enviroment on cognitive development of low birthweight infants. J Pediatr Psychol 1998:23:197-205.

7. Jacobson SW. Assessment of long chain polyunsaturated fatty acid nutritional supplementation on infun meurobehaviont development and visual acuity. Lipids $1.999 \cdot 34: 151-60$.

8. MacArthur C. Knox EG, Simons KJ. Breastfeeding and intelligence. Lancet 1992;339:612-3.

9. Lamoque B. Kaminski M, Dehaene P, Subtil D. Delfosse MJ, Querteu D. Moderate prenatal alcohol exposure and psychomotor development at preschool age. Am I Public Health $1995 ; 85: 1654-61$.

10. Anderson JW, Johnstone BM, Remley DT. Breast-feeding and cognitive development: a metaanalysis. Am J Clin Nutr 1999:70:525-35. 
11. Andersson HW, Sonnander K. Sommerfelt K. Gender and its comtribution to the prediction of cognitive abilities at 5 years. Scand 1 Psychol 1998;39:267-74.

12. Rogan WJ. Gladen BC. Breast-feeding and cognitive development. Barly Hum Dev 1993:31:181-93.

13. Richards M. Hardy R, Kuh D. Wadsworth ME. Binh weigh and cognitive function in the British 1946 birth cohort: longitudinal population based study. BM. 2001,322:199-203.

14. Birch E. Visual acuity testing in infants and young children. Ophthalmol Ch $\mathrm{N}$ Am 1989:2:369-89.

15. Chiappa K. Evoked Potentials in Clinical Medicine. New York: Raven Press; 198.

16. Leaf A.A, Green CR, Esuck A, Costeloe KL. Prior PE. Maturation of electroretinograms and visual evoked potentials in preterm infants. Dev Med Child Neurol 1995:37:814-26.

17. Williams C, Birch EE, Emmett PMA. Northstone K. Stereoncuity at age 3.5 y in children bom full-term is associated with prenatal and postnatal dietary factors: a report from a populationbased cohort study. Am I Clin Nutr 2001;73:316-22.

18. Foreman van Drongelen MM, al MD, van Houwelingen AC. Blanco CE. Honstra $G$. Comparison between the essential fatty acid status of preterm and full term infans, measured in umbilical vessel walls. Exuly Hum Dew 1995;42:241-51.

19. Rice RD. Brastfeeding and intelligence. Lancet 1992;339:613-4.

20. Crawford MA. Costeloe K. Laurance B, Leaf A. Leighfield MJ. Breastfeeding and intelligence. Lamcer 1992;339:614.

21. Farquharson J. Cockbum F, Patrick WA, Jamieson EC, Logan RW. In fant cerebral contex phospholipid fatry-acid composition and diet. Lancer 1992;340:810-3.

22. Farquharson J. Infant cerebrall cortex and dietary fatty acids. Eur J Clin Nutr 1994;48:524-6.

23. Farquharson J, Jamieson EC. Abbasi KA, Patrick WJ, Logan RW, Cockburn F. Effect of diet on the faty acid composition of the major phospholitpids of infant cerebral corter. Arch Dis Child 1995;72:198-203.

24. Makrides M, Neumann MA, Byard RW, Simmer K. Gibson RA. Fatty acid composition of brain, retina, and erythrocytes in breast- and formula-fed infants. Am J Clin Nutr 1994;60:18994.

25. Pollock JI. Mother's choice to provide breast milk and developmental outcome. Arch Dis Child $1989 ; 64: 763-4$.

26. Morley R, Cole TJ, Powell R, Lucas A. Mother"s choice to provide breast milk and developnentat outcome. Arch Dis Child 1988:63:1382-5.

27. Lucas A, Cole TJ, Morley R. Lucas PJ. Davis JA, Barrord MF, Crowle P. Dossetor IF, Pearse R, Boon A. Factors associated with maternal choice to provide breast milk for low bithweight infants. Arch Dis Child 1988:63:48-52.

28. Carlson S. LCPUFA and functional development of preterm and term infants. In: Bindels JG, Goedhat AC, Visser HKA, editors. Recent developments in infant nutrition. Dordirech: Klower Academic Pubishers; 1996. p. $218-24$.

29. Agostoni C. Trojan S, Bellu R, Riva $\mathbb{E}$, Luotui D, Giovanni M. LCPUFA slatus and developmental quotiem in term infans fed different dictary sources of lipids in the frrst months of life. In: Bindels 1G, Goedhart AC, Visser HKA, editors. Recent developments in infant nutrition. Dordrecht: Kluwer Academic Pubfishers; 1996. 0. 212-7.

30. Agostoni C, Trojan S. Bellu R. Riva E. Bruzzese MG, Giovannini M. Developmental quotient at 24 months and fatty acid composition of diet in early infancy: a follow up study. Arch Dis Child $1997: 76: 421-4$

31. Scott DT, Janowsky JS, Carroll RE, Taylor JA, Auestad N, Monallo MB. Formula supplementation with long-chain polyunsaturated faty acids: are there developmental benefies? Pediatrics 1998;102:E59. 
32. Lucas A, Stafford M, Morley R, Abbont R. Stephenson T, MacFadyen U, Elias-Jones A, Clements $H$. Efficacy and safety of long-chain polyunsaturated fatry acid supplementation of infiant-formula milk: a randomised trial. Lancel 1999;354: 1948-54.

33. Makrides M, Neumann MA, simmer K, Cibson RA. A critical appraisal of the role of dietary long-chain polyunsaturated fatty acids on neural indices of term infants: a randomized. controlled trial. Pediatrics 2000;105:32-8.

34. Aucstad N, Montalto MB, Hall RT, Fitzgerald KM, Wheeler RE, Connor WE, Neuringer M. Connor SL, Taylor JA, Harmann EE. Wisual acuity, erythrocyte fatty acid composition, and growth in term infants fed formulas with long chain polyunsaturated fatty acids for one year. Pediatr Res 1997;41:1-10.

35. Innis SM. Akrabawi SS, Diersen Schade DA. Dobson MV, Guy DG. Visual acuity and blood lipids in lerm infants fed human milk or formulae. Lipids $1997 ; 32: 63-72$.

36. Agostoni C, Trojan S, Bellu R, Riva E Giovannini M. Neurodewelopmental quotient of healtyy term infants at 4 months and feeding practice: the role of long-chain polyunsaturated fatty acids. Pediallir Res 1995:38:262-6.

37. Willats P, Forsyth JS, DiModugno MK, Varma $S$, Colvin M. Effect of long-chain polyunsaturated fatty acids in infant formula on problem solving at 10 months of age. Lancet 1998:352:688-91.

38. Willats P, Forsyti JS, DiModugno MK, Varma S, Colvin M. Influence of long-chain polyunsamiated fally acids on infant cognitive function. Lipids 1998;33:973-80.

39. Birch EE Garfield S. Foffman DR, Uauy R, Birch DG. A randomized controlled trial of early dietary supply of long-chain polyunsaturated fatty acids and mental dewelopment in term infants. Dev Med Chilld Neurol 2000;42:174-81.

40. Birch EE, Hoffman DR, Uauy R, Birch DG, Prestidge $C$. Vistal acuity and the essentiality of docosalyexaenoic acid and arachidonic acid in the diet of term infants. Pediatr Res 1998;44:2019.

41. Carlson SE. Ford AJ. Werkman SH, Peeples. JM. Koo WW. Wisual acuity and fatty acid status of term infants fed human milk and formulas wih and without docosahexaenoate and arachidonate from egg yolk lecithin. Pediatr Res 1996;39:882-8.

42. Makrides M, Neumann M, Simmer K, Pater J, Gibson R. Are long-chain polyunsaturated fatty acids essential nutrients in infancy? Lancet 1995; 345:1463-8.

43. American Academy of Pedatrics Wgob. Breastfeeding and the use of human milk. Pediatrics 1997:100:1035-39.

44. Bouter L.M. Dongen MCMM. Epidemiologisch onderzoek: opzet en interpretatie (in Dutch). Houtcon: Boh Staflen Van Loghum; 1991.

45. A MDM, Houwelingen ACW, Kester ADM. Hasaart RHM, Jong EAPd, Hornstra G. Matemal assential fatty acid pattem during normal pregnancy and their relationship to neonatal essential fatly acid status. Br J Nutr 1995:74:55-68.

46. Innis SM. Plasma and red blood cell fatty acid values as indexes of essential fatty acids in the developing organs of infants fed with milk or formulas. I Pediatr 1992;120:578-86.

47. Cintson SE. Behavioral methods used in the study of long-chain polyunsaturated fatty acid nutrition in primate infants. Am J Clin Nutr 2000; 71:\$268-74.

48. Neuringe $M$. Reisbick $S$, Janowsky J. The role of $n-3$ fatty acids in visual and cognitive development: current evidence and methods of assessment. I Pediatr 1994;125:539-47.

49. Kaufman AS, Kaufman N.. Kaufman Assessment Battery for Children. Circle Pines, Mimesota: American Guidance Service; 1983.

50. Wechsler D. Manual for the Wechsler intelligence scale for children - Revised. New York: The Psychological Corponation; 1974. 
51. McCarthy D. Manual for the MacCarthy scales of chidren's abilites. New York: The Psychological Corporation; 1972.

52. Gabbard CP. Livelong motor development. Boston: McGraw-Hill Companies; 1996.

53. Touwen BCL. Examination of the child wixh minor neurological dy sfunction. London: Spastics International Medical Publications; 1979.

54. Teller D. Teller Acuiry Card Handbook. Onio: Vistech Consultants. Inc: 1990.

55. Bornstein $\mathrm{MH}$, Sigman MD. Coninuity in mental development from infancy. Child Dev 1986;57:251-74.

56. Soorani-Lunsing RJ, Hadders-Algra M, Olinga AA, Huisjes HJ. Touwen BC. Is minor neurological dysfunction at 12 years related to behaviour and cognition? Dev Med Child Neurol 1993;35:321-30.

57. Weisglas-Kupens N, Baerts W, Fetter WP. Hempel MS, Mulder PG. Touwen BC, Samer PJ. Minor neufological dysfunction and quality of movement in relation to neonataf cerebral damage and subsequent development. Dev Med Child Neurol 1994;36:727-35.

58. Stevens IJ, Zentall SS, Deck JL, Abate ML, Watkins BA. Lipp SR, Burgess. IR. Essential fatty acid metabolism in boys with attention-deficit hyperactivity disonder. An $\mathrm{J}$ Clin Nutr $1995 ; 62: 761-8$.

59. Burgess J, Stevens L. Zhan W, Peck L. Long-chain polyunsaturated fatty acids in children with attention-deficit hyperactivity disorder. Am J Clin Nutr 2000;71:\$327-30.

60. Oto SI, Vanhouwelingen AC, Antal M, Manninen A, Godfrey K. LopezJaramillo P. Hornstra G. Maternal and neonatal essential fatty acid status in phospholipids: an international comparative study. Eur J Clin Nutr 1997:51:232 42. 


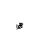




\section{Summary}

The central nervous system (CNS) is very rich in long-chain polyunsaturated fatty acids (LCPUFA), especially docosahexaenoic acid (DHA) and arachidonic acid (AA). The most rapid accretion of these fatty acids in the CNS takes place during the CNS growth spurth, in the last intrauterine trimester and in the first year of life. Therefore, an adequate supply of LCPUFA to the CNS during this period may be important for CNS growth and development. The fetus is supplied with these fatty acids by the mother via transport through the placenta. Neonates depend on breastfeeding or artificial formulas for their fatty acid supply. Breastmilk generally contains DHA and AA, whereas standard artificial formulas do not contain these LCPUFA.

The aim of the studies described in this thesis was to investigate the relation between pre- and postnatal LCPUFA availability and later cognitive, motor and visual function. To study this relation we invited 691 children, born at term, for a follow-up measurement at 7 years of age. The fatty acid profiles in umbilicat venous plasma phospholipids of all children were known from an earlier study on maternal and neonatal LCPUFA status and pregnancy outcome. These profiles were taken as an indicator for the prenatal fatty acid availability. From all invited families 306 aciually participated in this study; 231 did not give their consent, 133 did not respond at all, in spite of several letters and repeated phone-calls, and 21 dropped out of the study after giving consent. The results of this follow-up study were described in the Chapters 2,3 and 4. A subgroup of 59 children was followed until 8 years of age. At this age, their visual function was measured extensively. Chapter 7 reported on this study. Visual function was also the subject of another study, in which we measured the visual acuity of 74 children at 7 months of age (Chapter 6). The review of the literature on the relation between LCPUFA and visual function (Chapter 5) serves as introduction to the two chapters about visual function.

Cognitive performance has been shown to be influenced by postnatal LCPUFA supplementation, although not all studies confirm this. Studies in this field are limited to infancy. Since the absolute accretion rates of the n-3 fatty acids are even greater in the prenatal period compared with the postnatal period, it can be hypothesized that prenatal LCPUFA supply may also be important for later cognitive function. In the study described in Chapter 2, cognitive performance was assessed at 7 years of age in relation to the LCPUFA status at birth, as a part of the follow-up study, using the Kaufman-Assessment Battery for Children. In addition the school achievement scores were obtained. The analyses with these outcomes included the covariables social class, maternal intelligence and parenting skills, among others. Consistent with the literature, significant relations were found between cognitive outcome measures and maternal education, maternal intelligence and the child's birthweight. No significant associations with either DHA or AA at birth and the cognitive performance at 7 years of age were found. In long-term development, LCPUFA supply during later life can also play a role. Therefore, we also investigated the association between cognitive performance and LCPUFA status in venous plasma sampled at 7 years. However, the LCPUFA levels at 7 years were not clearly associated with the cognitive outcomes. The relations between the sehool achievement scores and the LCPUFA levels at birth or at 7 years of age were not consistent. Thus, our results do not provide evidence for 
a positive association between cognitive performance at 7 years and LCPUFA status at birth or at 7 years of age.

Children who received artificial formula-feeding as infants have been shown to have lower scores on tests for cognitive function than breasted children. The differences in fatty acid composition between standard artificial formula and human milk may contribute to these differences in cognitive function. This idea is supported by studies showing a lower brain DHA in infants fed artificial formulas as compared with human milk-fed infants. Chapter 3 reported on the relation between infant feeding habits and cognitive function at 7 years of age. In agreement with many other studies, we found a significant difference in cognitive function between formula and breastfed children, in favour of the breastfed children. However, after adjustment for social class, maternal intelligence, parenting skills and other covariables, this difference was no longer significant. In this study, we also ilvestigated the influence of the LCPUFA status at birth on the relationship between infant nutrition and cognitive development. At first sight, the difference in cognitive function between the formula group and the human milk group is larger in children who had low DHA values in umbilical plasma than in children with high DHA walues at birth. However, the interactions between infant feeding and umbilical plasma DHA or AA were not statistically significant, which implies that infant feeding effects were not significantly dilferent for children with either a low or a high LCPUFA status at birth.

Another interesting aspect of development, in relation to perinatal LCPUFA values, is motor function. Motor function involves several CNS domains and can be distinguished between movement quantily (the ability of the child to perform a movement) and quality of movement (how the movement is performed). Both aspects. were measured at 7 years of age in our follow-up study (Chapter 4), using the Movement-Assessment Battery for Children (movement quantity) and the Maastricht Motor Test (movement quantity and quality). These outcomes were studied in relation to the LCPUFA status at birth and the infant feeding habits. No differences in motor function were found between formula- and breastfed children. However, there was a positive relation between umbilical plasma DHA and the Maastricht Motor Test total score and movement quality score, corrected for gender, age at measurement, and cognitive performance. Movement quantity (on both tests) was not significantly associated to DHA and AA (both at birth and at 7 years of age). Regarding the positive association between umbilical plasma DHA and movement quality, matemal LCPUFA intake during pregnancy may infuence later movement quality of the child, because neonat LCPUFA values are known to be influenced by maternal diet during pregnancy.

A third aspect of child development, visual function, has been studied extensively in infants in relation to LCPUFA in infant mutrition. Chapter 5 gives an overview of these studies. DHA is the major fatty acid in the retinal phospholipids, and is, therefore, likely to play a functional role in the visual system. In premature infants dietary DHA has been shown to have a positive inflwence on visual development in almost all studies. The results of studies in term infants are not consistent. Chapter 5 provides possible explanations for this and includes recommendations for future studies.

In the study described in Chapter 6 the relation between visual acuity and dietary fatty acid composition, and the influence of potential confounders on this relation was investigated. Visual acuity of 48 breastfed and 26 formula-fed term infants was measured at 7 months of age using the Teller Acuity Cards. This study, like others. 
showed that the concentrations of DHA are lower in plasma and red blood cell phospholipids of formula-fed infants compared to that of breasted infants. However, no differences in visual acuity could be found between the two groups. Moreover, no significant relationship was found between the amounts of DHA in plasma and red blood cell phospholipids and the visual acuity. There was also no confounding influence of smoking habits and alcohol use during pregnancy, socioeconomic background and other potential confounders.

Since fine visual acuity cloes not reach adult values until at least 3 years of age, it is possible that dietary DHA has an influence on visual acuity function in later life. Therefore, we studied the relation between visual function at 8 years of age and the prenatal and postnatal DHA availability in a subgroup of the children who participated in the follow-up study at 7 years of age (Chapter 7). Visual function was assessed by ophthalmologic measurements (including visual acuity, stereopsis and contrast sensitivity), visual evoked potentials (VEP) and electroretinography (ERG). The DHA status at birth showed a positive association with visual acuity, with a measure for optic nerve conduction velocity (VEP) and with a measure for photoreceptor maturation (ERG) at 8 years of age, corrected for gestational age, age at meastrement, duration of breastfeeding and sex. The DHA status at 7 years of age was not significantly related to these visual outcomes; neither were infant feeding habis.

In conclusion, the studies described in this thesis demonstrate that the DHA status at birth shows a small, but statistically significant association with some developmental outcomes at 7-8 years of age in children born at term, whereas neither the LCPUFA status at 7 years of age nor the type of infant nutrition was significantly associated with child development. These findings suggest that prenatal L.CPUFA availability may be more important for later CNS function than childhood dictary LCPUFA. In Chapter 8 the implications of these findings are discussed. It is recommended that future research addresses the functional consequences of increasing dietary LCPUFA intake during pregnancy, with as purpose the generation of recommendations for the dietary LCPUFA intake in this period. 


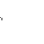




\section{Samenvatting}

Lange-keten meervoudig onverzadigde vetzuren (long-chain polyunsaturated falty acids, LCPUFA) komen in hoge concentraties voor in het centrale zenmwstelsel. Dit geldt met name voor de vetzuren docosahexaeenzuur (docosahexaenoic acid, DHA) en arachidonzuur (arachidonic acid, AA). Vooral tijdens de groeispurt van het centrale zenuwstelsel, in het laatste intra-uterine trimester en het eerste levensjaar, vindt cen snelle opstapeling van deze vetzuren plaats. Voor een optimale groei en ontwikkeling van het centrale zenuwstelsel is voldoende toevoer van LCPUFA naar het centrale zenuwstelsell waarschijnlijk van groot belang. De foetus wordt van deze vetzuren voorzien door de moeder, via transport door de placenta. Neonaten zijn voor hun vetzuurvoorziening afhankelijk van moedermelk of flesvoeding. In tegenstelling tot moedermelk bevat standaard flesvoeding geen DHA en AA.

Het doel van de in dit proefschrift beschreven studies was het verband te onderzoeken tussen de pre- en postnatale beschikbaarheid van LCPUFA en het latere cognitieve, motorische en visuele functioneren. Hiervoor werden 691 a term geboren kinderen uitgenodigd op 7-jarige leeftijd een aantal tests te ondergaan. Van al deze kinderen waren de vetzuurprofielen in de fosfolipiden van het veneus navelstrengplasma bekend, als resultaat van een eerdere studie naar de maternale en neonatale LCPUFA status en de zwangerschapsuitkomst. Deze vetzumrprofielen zijn gebruikt als een indicator voor de prenatale beschikbaarheid van vetzuren. Driehonderd zes van de uitgenodigde families namen deel aan het vervolgonderzoek op 7-jarige leeftijd; 231 families gaven geen toestemming voor deelname; 133 families gaven helemaal geen respons op onze brieven en telefoontjes en 21 kinderen vielen uit nadat de ouders al toestemming hadden gegeven. De resultaten van deze vervolgstudie zijn beschreven in de hoofdstukken 2,3 en 4 . Bij 59 van de deelnemende kinderen werd op 8-jarige leeftijd een uitgebreid onderzoek verricht naar het functioneren van het visuele systeem. Deze studie is beschreven in hoofdstuk 7 . In een andere studie hebben we de visus van 74 kinderen op een leeftijd wan 7 maanden bestudeerd (hoofdstuk 6). Het literatuuroverzicht over de relatie tussen LCPUFA en het visuele functioneren, beschreven in hoofdstuk 5 , is bedoeld als inleiding voor de twee hoofdstukken over de visuele functie.

Diverse cerder gepubliceerde onderzoeken lieten een positief verband zien tusser postnatale LCPUFA suppletie en cognitieve ontwikkeling bij kinderen tot 18 maanden. Er zijn echter ook studies die dit verband niet vonden. De opstapeling van $n-3$ vetzuren in het centraal zenuwstelsel verloopt in de prenatale periode met een nog hogere snelheid dan in de postnatale periode. De prenatale vetzuurvoorziening is daarom wellicht eveneens van belang voor het latere cognitieve functioneren. In de studie beschreven in hoofdstuk 2 is het cognitieve functioneren op 7 -jarige leeftijd onderzocht in relatie tot de vetzuurstatus bij de geboorte. Het cognitieve functioneren werd gemeten met de Kaufman-Assessment Battery for Children, als onderdeel van de vervolgstudie. Ook de schoolresultaten zijn opgevraagd. Bij de analyse van deze uitkomsten is rekening gehouden met mogelijk verstorende variabelen als sociaaleconomische status, intelligentie van de moeder en opvoedingsstij] van de ouders. Dit resulteerde in significante correlaties tussen de cognitieve uitkomstmaten van het kind en de opleiding en intelligentie van de moeder en het geboortegewicht van het kind, zoals ook eerder onderzoek liet zien. Er werd geen significant verband gevonden 
tussen de DHA of AA status bij de geboorte en de cognitieve uitkomsten op 7 jaar. Bij de ontwikkeling op de lange termijn speelt de LCPUFA voorziening in het latere leven mogelijk een rol. Daarom onderzochten we ook het verband tussen de cognitieve prestaties en de LCPUFA status in veneus plasma op 7-jarige leeftijd. Tussen deze variabelen vonden we echter geen duidelijk verband. De relatie tussen de schoolresultaten en de LCPUFA waarden bij de geboorte of op 7 jaar waren niet consistent. Kortom, onze resultaten leverden geen bewijs op voor een positief verband tussen het cognitieve functioneren op 7-jarige leeftijd en de LCPUFA status bij de geboorte of op 7-jarige leeftijd.

Het is bekend dat kinderen die standaard flesvoeding kregen als baby lager scoren op intelligentietests dan kinderen die borstvoeding kregen. Het verschil in vetzuursamenstelling tussen beide typen babywoeding draagt mogelijk bij aan deze intelligentieverschillen. De DHA waarde in de hersenen is lager bij fllesgevoede kinderen dan bij kinderen die moedermelk kregen. Ook dit wijst op een rol van bepaalde vetzuren in de babywoeding in de cognitieve ontwikkeling. In hoofdstuk 3 is de relatic tussen het type babyvoeding en het cognitieve functioneren op 7 -jarige leeftijd behandeld. In deze studie werd een significant verschil in cognitief functioneren gevonden tussen fles- en borstgevoede kinderen, in het voordeel van de borstgevoede kinderen, zoals ook beschreven in de literatuur. Echter, na correctie voor sociaal-economische status, intelligentie van de moeder, opvoedingsstijl en andere mogelijk verstorende variabelen, verdween dit verschil. In deze studie werd ook de invloed van de LCPUFA status bij de geboorte op het verband tussen babyvoeding en intelligentie onderzocht. Op het eerste gezicht leek het verschil in cognitief functioneren tussen de flesvoeding-en de moedermelkgroep groter te zijn bij kinderen die bij de geboorte een lage DHA status hadden in vergelijking met kinderen met een hogere: DHA status. De interactie tussen babyvoeding en DHA of AA in navelstrengplasma was echter niet statistisch significant. Dit betekent dat het effect van babyvoeding op de intelligentie niet significant verschilde tussen kinderen die een hoge of lage LCPUFA status bij de geboorte hadden.

Een ander interessant aspect van de ontwikkeling in relatie tot de perinatale LCPUFA waarden is het motorisch functioneren, omdat hierbij diverse gebieden van het centrale zenuwstelsel zijn betrokken. Bij het meten van de motoriek bij kinderen kan onderscheid worden gemaakt tussen het kwantitatieve motorische functioneren (kan een kind een bepaaldle beweging uitvoeren ?) en het kwalitatieve motorische functioneren (hoe voert een kind een bepaalde beweging uit ?). In het vervolgvetzuuronderzoek zijn beide aspecten van motorisch functioneren op 7-jarige leeftijd genneten met behulp van de Movement-Assessment Battery for Children (kwantitatief molorisch functioneren) en de Maastrichtse Motoriek Test (zowel kwantitatief als kwalitatief motorisch functioneren). In hoofdstuk 4 zijn deze uitkomsten in verband gebracht met de LCPUFA status bij de geboorte en met het type babyvoeding. Er werden geen verschillen in motorisch functioneren gevonden tussen kinderen die flesvoeding kregen en kinderen die moedermelk kregen. Wel werd een positief verband gevonden tussen de score op de Maastrichtse Motoriek Test, de score voor kwalitatief motorisch functioneren en de DHA waarden in het navelstrengplasma, rekening houdende met geslacht, leeftijd en intelligentie. Het kwantitatieve motorische functioneren (gemeten met beide tests) was niet gerelateerd aan de LCPUFA waarden bij de geboorte en op 7 jaar. De neonatale LCPUFA waarden. kumnen beinvloed worden door de maternale voeding gedurende de zwangerschap. 
Hierdoor is de moederlijke inname van LCPUFA mogelijk van invloed op de latere kwaliteit van bewegen van het kind.

Er is al veel onderzoek gedaan naar de relatie tussen LCPUFA in babyvoeding en een derde aspect van ontwikkeling bij kinderen, namelijk de visuele ontwikkeling. Hoofstuk 5 geeft een overzicht van deze studies. DHA is het belangrijkste vetzuur in de fosfolipiden van de retina en speelt daarom waarschijnlijk een belangrijke functionele rol in het visuele systeem. Bij premature kinderen werd in vrijwel alle studies een positief verband tussen DHA in de babyvoeding en de visuele ontwikkeling gevonden. De resultaten van studies bij a term geboren kinderen zijn minder consistent. In hoofdstuk 5 wordt gezocht naar verklaringen voor deze inconsistentie en worden aanbevelingen gedaan voor toekomstig onderzoek.

In hoofdstuk 6 is de relatie tussen de visus en de vetzuren in de voeding onderzocht bij baby"s. Ook is de invloed van mogelijk verstorende variabelen op deze relatie bekeken. Op een leeftijd van 7 maanden werd de visus van 48 borstgevoede en 26 flesgevoede a term geboren kinderen gemeten door middel van de Teller Acuity Card procedure. In deze studie werden, evenals in andere studies, lagere DHA concentraties in plasma en rode bloedcellen gevonden bij flesgevoede kinderen vergeleken met borstgevoede kinderen. Er was echter geen verschil in visus tussen beide groepen. Ook was er geen significant verband tussen de hoeveetheid DHA in plasma en rode bloedcellen en de visus. Roken, alcoholgebruik tijdens de zwangerschap, sociaal-economische status, en de andere gemeten variabelen bleken geen confounders te zijn in dit verband.

Omdat de ontwikkeling van het visuele systeem niet compleet is tot tenminste 3jarige leeftijd, kan het visuele functioneren in het latere leven mogelijk wel beïnvloed worden door DHA in de voeding. Daarom werd in hoofdstuk 7 het verband bestudeerd tussen het functioneren van het visuele systeem op 8-jarige leeftijd en de prenatale en postnatale beschikbaarheid van DHA bij een deel van de kinderen die op 7-jarige leeftijd deelnamen aan het vervolg-vetzuuronderzoek. Om het visuele functioneren te meten werden oogheelkundige metingen (waaronder visus, stereopsis en contrastgevoeligheid), Visual Evoked Potentials (VEP) en electroretinografie (ERG) verricht. De DHA status bij de geboorte vertoonde een positief verband met visus, met een maat voor de geleidingssnelheid van de oogzenuw (VEP) en met een maat voor de fotoreceptor rijping (ERG) op 8-jarige leeftijd, gecorrigeerd voor zwangerschapsduur, leeftijd, geslacht en lactatieperiode. De DHA status op 7-jarige leeftijd en het type babyvoeding waren niet significant gerelatcerd aan de visuele uitkomsten.

Uit de studies beschreven in dit proefschrift kunnen we concluderen dat er een klein maar statistisch significant verband bestaat tussen verschillende ontwikkelingsmaten op 7-8 jarige leeftijd en de DHA status bij de geboorte bij a term geboren kinderen. De LCPUFA status op 7 jarige leeftijd en het type babyvoeding waren niet geassocieerd met de ontwikkeling bij kinderen. Deze resultaten suggereren dat de prenatale beschikbaarheid van LCPUFA wellicht belangrijker is voor de latere ontwikkeling van het central zenuwstelsel dan de beschikbaarheid van LCPUFA na de geboorte. In hoofstuk $\mathbf{8}$ is de betekenis van deze bevindingen besproken. De functionele consequenties van het verhogen van de maternale LCPUFA inname tijdens de zwangerschap zullen in toekomstige studies moeten worden onderzocht, met als doel te komen tot aanbevelingen met betrekking tot de inname van dezc vetzuren tijdens deze periode. 
- 


\section{Dankwoord}

De bevalling is achter de rug: mijn proefschrift is geboren!

Veel mensen hebben mij, in de leuke en leerzame tijd die hieraan voorafging, geholpen een zelfstandig onderzoeker te worden. Bij deze bedank ik iedereen die in de afgelopen jaren een bijdrage heeft geleverd aan mijn wetenschappelijke opleiding. Een aantal mensen wil ik met name noemen.

Allereerst Gerard Hornstra, mijn eerste promotor. Heel hartelijk bedankt, Gerard, voor het vertrouwen in mij en mijn werk, de prettige samenwerking en begeleiding, en de kritische beoordeling van alles wat ik produceerde. Ook mijn tweede promotor, Carlos Blanco, bedankt voor de plezierige samenwerking en de belangstelling voor mijn werk.

De onderzoeken, beschreven in dit proefschrift, waren niet mogelijk geweest zonder de medewerking van de honderden proefpersoontjes en hun ouders. Heel hartelijk bedankt allemaal, dat jullie aan dit onderzoek mee wilden doen. Ik hoop dat jullie het net zo leuk hebben gevonden als ik!

Ook mijn collega-promovendus en kamergenoot Patrick Rump wil ik bedanken. Ondanks onze sterk verschillende promotie-onderwerpen, hebben wij heel veel samen gedaan. Het was een hele klus om het 'vervolg-vetzuur-onderzoek' in goede banen te leiden. Wij hebben het toch maar mooi gefikst!

Dank ook aan Monique $\mathrm{Al}$ (en alle verloskundigen die hun medewerking aan haar onderzoek verleenden): zonder jouw onderzoek was het mijne er ook niet geweest !

Het was een hele klus om alle kinderen, geboren tussen 1990 en 1994 in dit onderzoek, weer op te sporen voor het vervolg-vetzuur-onderzoek. Gelukkig kregen we daarbij hulp van Marco van Sint Fiet, Mehnaz Bergers en vooral van Peggy Peeters. Hartelijk dank hiervoor.

Eenmaal hier ontvingen we de kinderen op de polikliniek Kindergeneeskunde. Bij deze bedank ik alle medewerkers van de poli voor hun medewerking aan ons onderzoek. Op de poli ondergingen de kinderen al hun eerste onderzoek: het neurologisch onderzoek. Hierbij bedank ik professor Hans Vles voor het onderzoeken van meer dan 300 kinderen, een geweldige klus!

Daarna volgde het meest vervelende onderdeel wan het hele onderzoek: do bloedprik! Patrick, bedankt voor het verzorgen van de vaak lastige venapunctie bij het merendeel van 'onze' kinderen. De monsters werden na afname meteen verwerkt door onze vakkundige analisten. Jo ${ }^{\dagger}$, Frank, René, Dennis, Maurice, Sjoerd en Hasibe, hartelijk bedankt daarvoor. De vetzuurbepalingen in de monsters zijn gedaan bij Numico B.V. in Wageningen, met dank aan Jeroen van den Berg.

De tests die ik in de volgende 3,5 uur bij de kinderen afnam on de cognitieve en motorische ontwikkeling te meten, waren zorgvuldig gekozen. Alle mensen die mij hierin hebben geadviseerd en getraind: hartelijk bedankt.

Met name Alex Ghys, heel hartelijk bedankt voor de tijd die je altijd had om mijn vele vragen over de cognitieve ontwikkeling te beantwoorden, voor de goede training in de Kaufman-Assessment Battery for Children, voor de prettige samenwerking, en de gezellige discussies die we samen hadden (in de trein naar Nijmegen, bijwoorbeeld). Ik vind het heel moedig van je dat je je, als klinisch psycholoog, op het vlak van het biologische 'vetzuuronderzoek' hebt begeven! 
Nogmaals, professor Hans Vles, hartelijk dank voor alle adviezen rondom de metingen van de motorische ontwikkeling, en alle achtergronden daarbij. Jullie test om de kwaliteit van bewegen te meten, de Maastrichtse Motoriek Test, kwam precies op tijd voor mijn onderzoek. Bij deze bedank ik ook Marielle Kroes en Yvonne Vissers voor het mij aanleren van deze test en de nuttige besprekingen die wij samen hadden hierover.

Bij een onderzoek naar ontwikkeling bij kinderen speelt de opvoeding naturulijk ook cen belangrijke rol. Voor het meten van verschillende opvoedingsvariabelen kregen wij hulp van de vakgroep Algemene Pedagogiek van de Katholieke Universiteit Nijmegen. Met name professor Jan Gerris, Judith Dubas, Ignace Vemaes, Nicole van As en Ilse Tamrouti wil ik hierbij bedanken voor het samenstellen van de meetinstrumenten en voor het analyseren van de gegevens.

Een aantal kinderen onderging niet alleen cognitieve en motorische tests, maar ook een uitgebreid onderzoek van het visuele systeem. Dit deel van het onderzoek werd zeer succesvol opgezet door Margaret Tychon, die niet alleen de logistiek van het onderzoek goed regelde, maar ook de kinderen wist te motiveren de soms vervelende metingen te ondergaan. Margaret, bedankt woor de fijne samenwerking en al het werk dat je in deze studie hebt gestoken! Deze studie werd later voortgezet door Miriam de Werd, die, net alls Margaret, ook op zeer kindvriendelijke wijze de data binnen wist te halen. Miriam, hartelijk bedankt, niet alleen woor je werkzaamheden voor deze studie, maar ook voor de zeer voortvarende manier waarop je te werk ging tijdens mijn zwangerschapsverlof, waardoor ik nog voor mijn bevalling nieuwe 'klusjes' voor je moest bedenken!

De metingen van het visuele systeem werden uitgevoerd aan de afdelingen Klinische neurofysiologie en Oogheelkunde van het academisch ziekenhuis Maastricht.

Van de afdeling $K$ linische neurofysiologie bedank ik met name professor Spaans en Jos Reulen, voor de mogelijkheid die jullie ons gaven ons onderzoek op jullie afdeling uit te voeren. Verder waren ook jullie opmerkingen en adviezen tijdens onze besprekingen heel nuttig. Paul Bergs en Linda Jennekens, hartelijk dank voor het uitvoeren van alle electroneurofysiologische metingen bij $59 \mathrm{kinderen}$, die dit niet alltijd even leuk vonden. Een hele prestatie!

Van de afdeling Oogheelkunde wil ik met name Marcel ten Tusscher bedanken voor zijn nedewerking en advies. Ook de orthoptisten Ellen van Riel en Diny van Drunen, bedankt voor jullie enthousiaste medewerking aan ons onderzoek.

Rian van Houwelingen bedank ik voot de begeleiding en samenwerking bij het onderzoek naar de visuele ontwikkeling van kinderen tot 7 maanden. Fijn dat je me wegwijs hebt gemaakt in de vetzurenwereld. Dit onderzoek was nog maar het begin.....

Nadat alle data binnen waren, kon de statistische verwerking beginnen. Een hele klus. Gelukkig had ik de steun en wijze woorden van onze statisticus Anold Kester. Arnold, hartelijk bedankt voor alle goede adviezen en hulp bij de vaak lastige statistische procedures die mijn data moesten ondergaan. Ik ben veel wijzer geworden.

Helas hing de voortgang van mijn analyses en schrijfwerk niet alleen af van mijn kennis. De techniek liet me ook vaak in de steek, maar gelukkig waren daar Loek en Paul, die al mijn computer problemen weer snel oplosten. Bedankt ! Stelling 10 draag ik bij deze op aan jullie!

Toen was het boek af, en moest het beoordeeld worden. Hartelijk dank aan de beoordelingscommissie, die deze taak op zich heeft genomen. 
I would like to thank Prof. Dr. Ir. R. Mensink, Prof, Dr. F. Hendrikse, Prof. Dr. I. Troost, Dr. P. Willatts and Dr. H. Woltil for their time and effort in the critical evaluation of this thesis. Dr. P. Willatts, thank you also very much for your hospitatity during my visit to Dundee, which was a very instructive and nice time for me.

Verder wil ik al mijn kamergenoten door de jaren heen bedanken voor de gezelligheid en de leuke discussies: Marianne, Suzie, Hasibe, Anita, Liesbeth en Patrick, bedankt. Ook alle andere collega's van Humane Brologie en Kindergeneeskunde, bedankt! Vooral Renate, de laatst overgebleven 'perinat-AIO", heel hartelijk bedankt voor je steun in de laatste fase van de productic van dit proefschrift, maar ook woor de gezelligheid tijdens en na het werk. Verder datk ik ook de student-assistenten Hester en Diane voor het werk dat ze voor mij gedaran hebben.

Suzie en Hasibe, ik vind het fijn dat jullie letterlijk en figurbijk acher me staun tijdens de 'nageboorte": de verdediging van dit proefschrift. Hartelijk bedankt voor de begelleiding die jullie me hebben gegeven vanaf mijn allereerste stappen in de vetzurenwereld tot nu, maar ook voor de steun en gezelligheid (onder andere tijotom onze lunchpauze wandelingen) en wetenschappelijke discussies. Suzie, ook veel dark voor het kritisch lezen van al mijn stukken, ook al zit je al een tijd op een heel andere plek.

Grote dank gaat ook uit naar mijn ouders. Henk en Greet, hartelijk bedankt voor allo mogelijkheden die jullie mij hebben geboden om zover te komen on voor julfic interesse in mijn onderzoek. Sven, bedankt voor het werpen van je creatieve blik op de omslag van dit proefschrit.

Harold, bedankt voor alle steun en hulp in de afgelopen jaren. Fijn dat je er altijd voor me bent. Roel, lieverd, ik ben blij dat je er bent (al makte jouw nachelike onrust de laatste loodjes van dit onderzoek er niet makkelijker op). Maar gelukkig: het is af ! Mamadag zall nu weer echt mamadag worden, en niet meer "mana-moetwerken-dag". (Bij deze bedank ik Maria - en ook Jef - voor allo oppasuren en extra oppasuren. Gelukkig heeft Roel het bij jullie altijd prima naar zijn zin). Tot slot mijn familie, vrienden, kennissen en niet te vergeten mijn collega"s van de Vroedvrouwenschool: hartelijk dank voor jullie belangstelling en stem bij het afronden van 'mijn boek'!

Het is tijd om de navelstreng door te knippen: mijn wetenschappelijke opleiding is voltooid. 


\section{Curriculum Vitae}

Esther Corina Bakker was born in Hoom on the 19th of July 1973. After completing her secondary education (Athaeneum) at the Rijksscholengemeenschap Enkhuizen in 1991, she started her study Health Sciences at Limburg University in Maastricht (now called Universiteit Maastricht), with majors in Biological. Health Sciences and Health Education. During her study she carried out several studies in the field of nutrition and child development at the department of Human Biology (Universiteit Maastricht) and at the Institute for research, development and knowledge-transfer in the field of rehabilitation and handicap. Hoensbroek. For one of these studies she received an award of the NVVL (Dutch Association for Nutritional Science and Food Technology). In August 1996 she graduated as a Health Scientist (cum laude). Between September 1996 and June 1997 she joined the Department of Human Biology of the Universiteit Maastricht as research-assistant. Between June 1997 and August 2001 she carried out the study described in this thesis at the department of Pediatrics of the University Hospital Maastricht and the Department of Human Biology of the Universiteit Maastricht. In September 2001 she started to work at the 'Vroedvrouwenschool' (school for midwifery) in Kerkrade. In May 2000 she received a son, Roel.

Esther Corina Bakker werd geboren in Hoorn op 19 juli 1973. Nadat ze in 1991 haar Atheneum diploma behaalde aan de Rijksscholengemeenschap Enkhuizen begon ze met haar studie Gezondheidswetenschappen aan de Rijksuniversiteit Limburg (nu Universiteit Maastricht), met als afstudeerrichtingen Biologische Gezondheidkunde en Gezondheidsvoorlichting en Opvoeding. Gedurende haar studie heeft ze gewerkt atan verschillende onderzoeken op het gebied van voeding en ontwikkeling bij kinderen bij de vakgroep Humane Biologie (Universiteit Maastricht) en bij het Instituut voor onderzoek, ontwikkeling en kennisoverdracht op het gebied van revalidatie en handicap in Hoensbroek. Voor een van deze studies ontving ze de scriptieprijs van de Nederlandse Vereniging voor Voedingsleer en Levensmiddelentechnologie (NVVL). In augustus 1996 studeerde zij af als Gezondheidswetenschapper (cum laude). Tussen september 1996 en juni 1997 was zij als onderzoeksassistent verbonden aan de vakgroep Humane Biologie van de Universiteit Maastricht. Tussen juni 1997 en augustus 2001 werkte zij aan het onderzoek zoals beschreven in dil proefschrift bij de afdeling Kindergeneeskunde van het academisch ziekenhuis Maastricht en do capaciteitsgroep Humane Biologie van de Universiteit Maastricht. Sinds 1 september 2001 is zij als docent verbonden aan de Vroedvrouwenschool in Kerkrade. In mei 2000 kreeg zij cen zoon, Roel. 


\section{Publications}

1. Bakker EC. Hulpverlening aan kinderen met taalontwikkelingsproblemen en hun ouders. BOSK Magazine 1996;4:17-8.

2. Bakker $\mathrm{EC}$, Houwelingen $\mathrm{AC}$, Homstra $\mathrm{G}$. Voeding en gezichtsscherpte bij jonge kinderen: Een onderzoek naar het effect van essentiele vetzuren. Voeding 1997,58:1415.

3. Bakker EC, van Houwelingen $\mathrm{AC}$, Hornstra $\mathrm{G}$. Early nutrition, essential fatty acid status and visual acuity of tem infants at 7 months of age. European Joumal: of Clinical Nulrition 1999:53:872-9.

4. Bakker EC, Ghys AJA, Kester ADM, Vles JSH, Dubas JS, Blanco CE, Hornstra G. Long-chain polyunsaturated fatty acids at birth and cognitive function at 7 years of age. Submitted for publication.

5. Bakker EC, Ghys AJA, Gerris JRM, Blanco CE, Hornstra G. Infant breast or formula feeding and cognitive function at 7 years of age: the influence of docosahexaenoic acid status at birth. Submitted for publication.

6. Bakker EC, Vles JSH, Kester A, Kroes M, Blanco CE, Hornsta G. Long-cinain polyunsaturated fatty acids at birth and motor function at 7 years of age. Submitted for publication.

7. Balker EC, Tychon M, Reulen IPH, Spaans F, Tusscher M ten, Vles JSH, Blanco CE, Hornstra $\mathrm{G}$. Long-chain polyunsaturated fatty acid status at term birth and visual function at 8 years of age. Subnitted for publication.

8. Balkom L.M van, Bakker EC. Taalzorg. Logopedie en Fonatrie 1998; 10:168-174.

9. Ghys $A$, Bakker $\mathrm{E}$, Hornstra $\mathrm{G}$, Hout $\mathrm{M}$ van den. Essential fatty acid status at binth and cognitive development at 4 years of age. Submitied for publication.

10. Ghys A, Bakker E, Rump P, Hornstra G, Hout M van den. Socio-economic status and long-chain polyunsaturated fatty acids. Subminted for publication.

1. Kroes M, Vissers $\mathrm{Y}$, Sleijpen F, Feron F, Kessels F, Bakker E, Kalff A, Hendriksen J, Steyaert J, Zeben $T$ van, Jolles J, Troost $J$, Vles J. Reliability and validity of a qualitative and quantitative motor test for 5 -to 6 year-old children. Submitted for publication.

\section{Abstracts}

1. Bakker EC, Houwelingen AC van, Hornstra G. Essentièle vetzuren en visual acuity bij a term geboren kinderen wan 7 manden oud. $21 \mathrm{e}$ WEON congres, Vereniging voor Epidemiologie (Utrecht, 6-7 juni 1996), middenkatem Tijdschr Soc Gezondheidsz $1996 ; 74(4): 41 \cdots 2$.

2. Bakker EC, Howwelingen ACv, Hornstra G. Essential fatty acids and visual acuity in infants. Congres of the European Society of Pediatric Research (Lyon, France, 1-5 September, 1996).

3. Bakker $\mathrm{EC}$, Houwelingen $\mathrm{AC}$, Hornstra $\mathrm{G}$. Essential fatty acids and visual acuity in tem infants of 7 months. "Fats of life" (Barcelona, Spain, 4-6 November 1996).

4. Bakker $\mathrm{EC}$, Houwelingen $\mathrm{AC}$, Hormstra $\mathrm{G}$. Effect of matemal linoleic acid consumption during pregnancy on neonatal n-3 status. ISSFAL Congres (Lyon, France, 1-5 June, 1998).

5. Bakker EC, Reulen J, Spaans F, Blanco CE, Homstra $G$. The relationship between the essential fatty acid status at birth and neurophysiological function of the visual system at 8 years of age. Conference on PUFA in matemal and child health (Kansas City, MO, USA, 10-13 September, 2000). 